\title{
Interventions for drug-using offenders in the courts, secure establishments and the community. (Review)
}

\author{
Perry A, Coulton S, Glanville J, Godfrey C, Lunn J, McDougall C, Neale Z
}
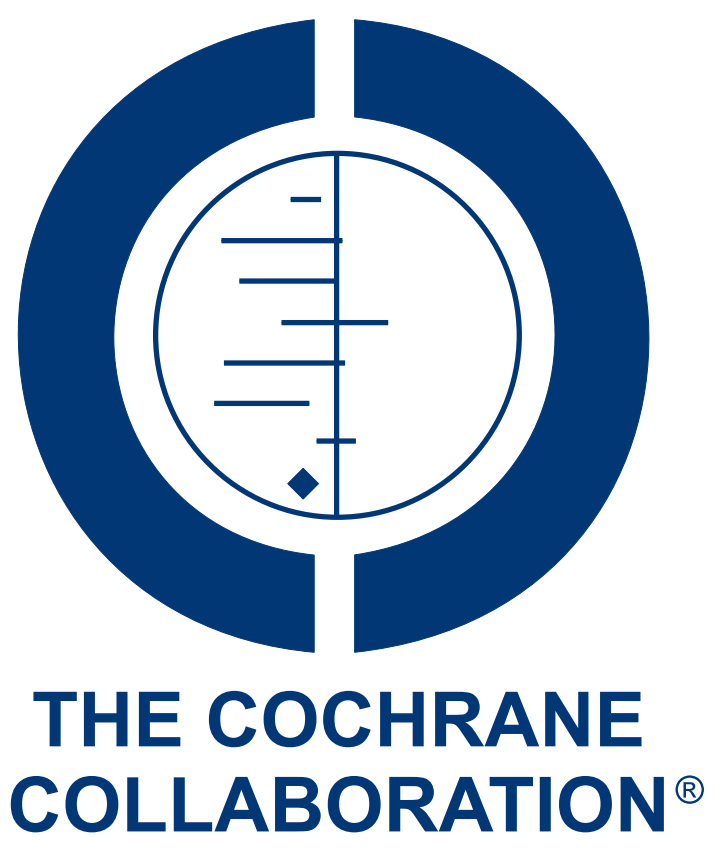

This is a reprint of a Cochrane review, prepared and maintained by The Cochrane Collaboration and published in The Cochrane Library 2006, Issue 3

http://www.thecochranelibrary.com

\section{WILEY}

Interventions for drug-using offenders in the courts, secure establishments and the community. (Review)

Copyright $\odot 2008$ The Cochrane Collaboration. Published by John Wiley \& Sons, Ltd. 
TABLE OF CONTENTS

HEADER

ABSTRACT

PLAIN LANGUAGE SUMMARY . . . . . . . . . . . . . . . . . . . . . . . . . . . . . . . . . . . . 2

BACKGROUND . . . . . . . . . . . . . . . . . . . . . . . . . . . . . . . . . . . . . .

OBJECTIVES . . . . . . . . . . . . . . . . . . . . . . . . . . . . . . . . . . . . . . . . . . . . . . .

METHODS . . . . . . . . . . . . . . . . . . . . . . . . . . . . . . . . . . . . . . . .

RESULTS . . . . . . . . . . . . . . . . . . . . . . . . . . . . . . . . . . . . . . .

DISCUSSION . . . . . . . . . . . . . . . . . . . . . . . . . . . . . . . . . . . . . . 12

AUTHORS' CONCLUSIONS . . . . . . . . . . . . . . . . . . . . . . . . . . . . . . . . . . . 12

ACKNOWLEDGEMENTS . . . . . . . . . . . . . . . . . . . . . . . . . . . . . . . . . 12

REFERENCES . . . . . . . . . . . . . . . . . . . . . . . . . . . . . . . . . . . . . . 13

CHARACTERISTICS OF STUDIES . . . . . . . . . . . . . . . . . . . . . . . . . . . . . . . . . . . . . .

DATA AND ANALYSES . . . . . . . . . . . . . . . . . . . . . . . . . . . . . . . . . . . . . . . . . . . . . . . .

Analysis 1.1. Comparison 1 RCT Courts (Britt studies $3 \& 4$ ): pre-trial release \& drugs testing \& sanctions vs. routine pretrial release., Outcome 1 Arrest at 90 days.. . . . . . . . . . . . . . . . . . . . . . . . . . . . . . . 36

Analysis 2.1. Comparison 2 RCT Secure Establishments (Sacks \& Wexler): TC \& aftercare vs. mental health program/waiting-list control., Outcome 1 Incarceration at 1 year.. . . . . . . . . . . . . . . . . . . 36

Analysis 2.2. Comparison 2 RCT Secure Establishments (Sacks \& Wexler): TC \& aftercare vs. mental health program/waiting-list control., Outcome 2 Incarceration at I year: sensitivity analysis.. . . . . . . . . . . . . 37

Analysis 3.1. Comparison 3 RCT Community (Petersilia studies 1-4): intensive supervision vs. routine parole/probation., Outcome 1 Recidivism at 1 year..

Analysis 3.2. Comparison 3 RCT Community (Petersilia studies 1-4): intensive supervision vs. routine parole/probation., Outcome 2 Arrest at 1 year..

Analysis 3.3. Comparison 3 RCT Community (Petersilia studies 1-4): intensive supervision vs. routine parole/probation., Outcome 3 Drug arrest at 1 year..

Analysis 3.4. Comparison 3 RCT Community (Petersilia studies 1-4): intensive supervision vs. routine parole/probation., Outcome 4 Conviction at 1 year..

Analysis 3.5. Comparison 3 RCT Community (Petersilia studies 1-4): intensive supervision vs. routine parole/probation., Outcome 5 Incarceration at 1 year..

Analysis 4.1. Comparison 4 RCT Community (Petersilia studies 5-7): int. supervision \& increased surveillance vs. int. supervision., Outcome 1 Recidivism at 1 year..

Analysis 4.2. Comparison 4 RCT Community (Petersilia studies 5-7): int. supervision \& increased surveillance vs. int. supervision., Outcome 2 Arrest at 1 year..

Analysis 4.3. Comparison 4 RCT Community (Petersilia studies 5-7): int. supervision \& increased surveillance vs. int. supervision., Outcome 3 Drug arrest at 1 year..

Analysis 4.4. Comparison 4 RCT Community (Petersilia studies 5-7): int. supervision \& increased surveillance vs. int. supervision., Outcome 4 Conviction at 1 year..

Analysis 4.5. Comparison 4 RCT Community (Petersilia studies 5-7): int. supervision \& increased surveillance vs. int. supervision., Outcome 5 Incarceration at 1 year.. . . . . . . . . . . . . . . . . . . . . . . 47

ADDITIONAL TABLES . . . . . . . . . . . . . . . . . . . . . . . . . . . . . . . . . . 47

WHAT'S NEW . . . . . . . . . . . . . . . . . . . . . . . . . . . . . . . . . . . . . . $\quad . \quad 73$

HISTORY . . . . . . . . . . . . . . . . . . . . . . . . . . . . . . . . . . . . . . . . . .

CONTRIBUTIONS OF AUTHORS . . . . . . . . . . . . . . . . . . . . . . . . . . . . . . . . . 74

DECLARATIONS OF INTEREST . . . . . . . . . . . . . . . . . . . . . . . . . . . . . . . . . 74

SOURCES OF SUPPORT . . . . . . . . . . . . . . . . . . . . . . . . . . . . . . . . . . 74

INDEX TERMS . . . . . . . . . . . . . . . . . . . . . . . . . . . . . . . . . . . . . 74

Interventions for drug-using offenders in the courts, secure establishments and the community. (Review)

Copyright @ 2008 The Cochrane Collaboration. Published by John Wiley \& Sons, Ltd. 


\title{
[Intervention Review] \\ Interventions for drug-using offenders in the courts, secure establishments and the community.
}

\author{
Amanda Perry ${ }^{1}$, Simon Coulton ${ }^{2}$, Julie Glanville ${ }^{3}$, Christine Godfrey ${ }^{4}$, Judith Lunn ${ }^{5}$, Cynthia McDougall ${ }^{6}$, Zoe Neale ${ }^{7}$ \\ ${ }^{1}$ Centre for Criminal Justice Economics and Psychology, University of York, York, UK. ${ }^{2}$ RCT Unit, University of York, Heslington, UK. \\ ${ }^{3}$ York, UK. ${ }^{4}$ Department of Health Sciences and Clinical Evaluation, University of York, University of York, UK. ${ }^{5}$ Centre for Criminal \\ Justice Economics and Psychology, Wenthworth College, Heslington, UK. ${ }^{6}$ Centre for Criminal Justice Economics and Psychology, \\ Wentworth College, Heslington, UK. ${ }^{7}$ Centre for Criminal Justice economics and Psychology, Wentworth College, Heslington, UK \\ Contact address: Amanda Perry, Centre for Criminal Justice Economics and Psychology, University of York, Heslington, York, \\ YO105DD, UK. A.Perry@psych.york.ac.uk.
}

Editorial group: Cochrane Drugs and Alcohol Group.

Publication status and date: Edited (no change to conclusions), published in Issue 3, 2008.

Review content assessed as up-to-date: 18 May 2006.

Citation: Perry A, Coulton S, Glanville J, Godfrey C, Lunn J, McDougall C, Neale Z. Interventions for drug-using offenders in the courts, secure establishments and the community.. Cochrane Database of Systematic Reviews 2006, Issue 3. Art. No.: CD005193. DOI: 10.1002/14651858.CD005193.pub2.

Copyright (C) 2008 The Cochrane Collaboration. Published by John Wiley \& Sons, Ltd.

\begin{abstract}
A B S T R A C T
Background

Drug strategies internationally recognize link between drug use and crime. This review consider interventions for drug-using offenders under the care of the criminal justice system.
\end{abstract}

Objectives

To assess the effectiveness of interventions for drug-using offenders in reducing criminal activity and drug use in the courts, secure establishments and community-based settings.

\section{Search methods}

Twenty two electronic databases were searched (1980 to 2004). Internet sites and experts in the field were contacted for further information.

\section{Selection criteria}

Randomised Controlled Trials designed to reduce, eliminate or prevent relapse in drug using offenders

\section{Data collection and analysis}

Two authors independently assessed trials for inclusion. Data were extracted by one author and double checked.

\section{Main results}

Twenty four studies, 8936 participants, met the inclusion criteria. Results show that comparing a court-based community pre-trial release with drugs testing and sanctions versus routine pre-trial, for arrest at 90 days results favoured the comparison group OR 1.33 (95\% CI 1.04 to 1.70). Comparing therapeutic community with aftercare with a mental health programme with a waiting list control, considering incarceration at 12 months OR 0.37 (95\% CI 0.16 to 0.87 ), results in favour of the treatment Comparing intensive supervision with routine parole/probation, for recidivism OR 1.98 (95\% CI 1.01 to 3.87) results in favour of comparison group, no

Interventions for drug-using offenders in the courts, secure establishments and the community. (Review)

Copyright @ 2008 The Cochrane Collaboration. Published by John Wiley \& Sons, Ltd. 
statistically significant difference between the groups for arrest OR 1.49 (95\% CI 0.88 to 2.51), drug arrest OR 1.10 (95\% CI 0.50 to 2.39), conviction OR 0.93 (95\% CI 0.55 to 1.58 ) and incarceration at one year OR 0.88 (95\% CI 0.50, 1.54). Comparing intensive supervision and increased surveillance with intensive supervision alone, no statistically significant difference between the groups for recidivism OR 2.09 (95\% CI, 0.86 to 5.07), arrest OR 1.22 (95\% CI 0.51 to 2.88]), drug arrest, OR 1.29 (95\% CI 0.35 to 4.85), conviction OR0.1.14 (95\% CI, 0.22, to 5.91) and incarceration OR 1.30 (95\% CI 0.39, to 4.30]) at one year.

\section{Authors' conclusions}

Limited conclusions can be drawn about the effectiveness of drug treatment programmes for drug-using offenders in the courts or the community. This is partly due to the broad range of studies and the heterogeneity of the different outcome measures presented. Therapeutic communities with aftercare show promising results for the reduction of drug use and criminal activity in drug using offenders. Standardisation of outcome measures and costing methodology would help improve the quality of research conducted in the area.

\section{PLAIN LANGUAGE SUMMARY}

\section{Therapeutic communities with aftercare in secure settings may reduced drug misuse and criminal activity.}

A number of policy directives are aimed at enabling people with drug problems to live healthy, crime free lives. Drug-using offenders naturally represent a socially excluded group who may experience problems in relation to their drug use. A number of studies and previous systematic reviews have considered the effectiveness of drug treatment interventions for drug misusers in the general population, mixed populations of offenders and non-offenders, drug treatment in a specific setting or country with limited outcome measures. This review focuses on drug treatment for offenders across a number of different settings. A number of studies have been conducted displaying a wide range of outcome measures with varying methodological quality. Little information is provided on the costs and costeffectiveness of such interventions. Promising results are shown for therapeutic communities with aftercare.

\section{B A C K G R O U N D}

National drug strategies in countries worldwide recognize the link between drug use and crime, and consequently acknowledge the role of the criminal justice system in implementing policies. All of the European Union members' national strategies that are outlined in the European Monitoring Centre for Drugs and Drug Addiction (EMCDDA 2002) review consider treatment interventions in the criminal justice system. Similarly the Australian National Drug Strategy (Australian Gov 2004) aims to 'improve access to treatment programmes and services (including diversion programmes) in the criminal justice system' (Australian Gov 2004, p.8). To demonstrate how national strategies influence criminal justice system approaches, a more detailed description is presented, using current policy initiatives developed in England and Wales.

One of the four overarching aims of the UK National Drug Strategy (Home Office 1999) is to enable people with drug problems to live healthy, crime-free lives by increasing the participation of problem drug misusers (including offenders), in drug treatment programmes. A further strategy target is to reduce levels of repeat offending amongst drug-misusing offenders by $25 \%$ by 2005 and
$50 \%$ by 2008. In England Drug Action Teams (DAT) work towards these targets, identifying people with drug misuse problems in the criminal justice system and providing them with a mechanism for treatment via such schemes as Arrest Referral and Drug Treatment and Testing Orders (DTTO).

More recently, the Updated National Drug Strategy of September 2004 (see www.drugs.gov.uk/ReportsandPublications/NationalStrategy/1038840683) introduced the Drug Interventions Programme. Formerly known as the Criminal Justice Interventions Programme (CJIP) the strategy aims to take advantage of opportunities within the criminal justice system by tracking drug-misusing offenders, many of whom are difficult to access by other approaches and, by doing so, moving them away from drug use and crime.

This beginning-to-end support system supports the new Criminal Justice Act (Nat Probation 2004), which focuses on a unified offender management process, joining both Prison and Probation Services together through the National Offender Management Service (NOMS). Similar alliances have also been developed between the National Health Service (NHS) and the HM Prison 
Service with the introduction in England and Wales of the Future Organisation of Prison Healthcare (NHS/HMP 1999) and the Research and Development Strategy for Public Health for England and Wales (DOH 2001). These policies acknowledge the need to target specifically vulnerable and socially excluded groups, such as drug-misusing offenders. It is further suggested that such inequalities in healthcare should be reduced by the identification of best practice and proven effectiveness, however there is little research to-date that has reported on systematic evaluations of drug treatment programs for offenders in the UK and internationally.

The following section provides a brief overview of the current research describing: 1) the health and social inequalities between prisoners and the general population, 2) the use of treatment programmes for substance misuse and 3) current studies which have assessed drug treatment interventions for offenders.

Regardless of whether offenders are in prison or not, they naturally represent a socially excluded group One of the many differences identified between offenders and the general population is in relation to drug use and subsequent health problems. Studies that have looked at the prevalence of drug dependence in UK prisons have reported between 10\% (Gunn 1991) and 39\% (Brooke 1996); in the general population it is known to be much lower. This work is supported by a further study (Mason 1997) which evaluated a consecutive sample of 548 remand prisoners who were comprehensively screened for substance misuse; 382 (70\%) gave a history of illicit drug use at some point in their lives, with 33\% reaching the current misuse or dependency criteria. Similar trends have been reported in many countries, and in the US it is recognised that many offenders are in need of treatment to tackle their drug use (Lo 2000). Whilst these health problems are well documented there has been little emphasis to date on the proven systematic effectiveness of current treatment programmes specifically for offenders (McMurran 2000; Shaw 2000).

There are wide ranges of different treatments for substance misuse. These include: detoxification, maintenance prescription, antagonist prescription, therapeutic communities, motivational enhancement therapy, counselling and psychotherapy, cognitive-behavioural therapies, family relationship therapies, community reinforcement and combinations of the above. Many of these programmes have been traditionally used with drug-misusers in the community and have been adopted for use in the criminal justice system.

Some treatment programmes, such as cognitive-behavioural approaches, including self-monitoring, goal setting, self-control training, interpersonal skills training, relapse prevention, group work and lifestyle modification have shown signs of success with offenders (Baldwin 1991; Day 1993; Little 1991; Peters 1992; Platt 1980; Shewan 1996). Furthermore, evidence suggests that the effectiveness of drug treatment is directly related to the length of time an individual remains in treatment, and whether the of- fender enters voluntarily or under some form of coercion (Anglin 1990; Anglin 1992; Falkin 1992).

Despite these findings two reports (McMurran 2000; Shaw 2000) suggested that the treatment of drug withdrawal and other treatment interventions for offenders are inadequate for this specific population and we still require information to assess:

(1) What works best (i.e. treatment type, intensity and duration)?

(2) With whom, and with what types of substance?

(3) With what client characteristics (e.g., age, gender, ethnicity)?

(4) Under what conditions (i.e. prisons, special hospitals, probation in the community, arrest referral schemes, diversion from court)?

More recently international concerns have focused on the cost and cost-effectiveness of such interventions, and whether they are effective in reducing both criminal activity and drug-use. Some evidence can be drawn from systematic reviews completed in the area. These have concentrated on: (1) specific drug treatments for the general population, (2) drug treatments more generally for a mixed population (i.e., contains offenders and non-offenders), (3) drug treatments for offenders in a specific setting (4) drug treatments for offenders, but limited to a specific country (5) outcome measures.

Specific drug treatments for the general population and drug treatments for generally mixed populations have concentrated on: naltrexone maintenance treatment for opioid dependence, the efficacy of methadone maintenance, and drug abuse treatment of comparison group studies (Marsch 1998; Minozzi 2006; Prendergast 2002). These reviews do not however, focus specifically on offenders under the care of the criminal justice system.

Systematic reviews that have been completed on offender populations or in correctional settings have been limited to focusing on either one setting area such as community-based programs, corrections-based and out-patient treatment (Chanhatasilpa 2000; Mitchell 2000; Pearson 1999; Taxman 2002), or have focused on literature from only one country (e.g., Germany or the USA) (Chanhatasilpa 2000; Egg 2000). These reviews help to fulfil some of the gaps highlighted by the literature, but do not attempt to compare different interventions in different treatment settings.

Outcome measures in the systematic reviews focus on either recidivism in correctional or community settings (Chanhatasilpa 2000; Egg 2000; Pearson 1999) or specific drug and property related criminal behaviour for methadone maintenance treatment (Marsch 1998). A recent systematic review commissioned by the Home Office for England and Wales focused on the effectiveness of criminal justice and treatment programmes in reducing drug related crime, but did not specifically focus on offenders (Holloway 2005). Additionally, none of the above reviews consider the im- 
pact of the intervention on both criminal activity and drug misuse in a number of different settings or interventions.

The current review will fulfil this gap, focusing on the international literature, it will provide a unique comprehensive overview of the research literature relating to the effectiveness of interventions for drug-misusing offenders. In order to address this broad topic a series of questions will consider the effectiveness of different interventions in different settings (e.g. the courts, secure establishments and the community), in relation to both criminal activity and drug misuse. The review will additionally report descriptively on the costs of such treatment programs. The cost and cost-effectiveness data has not been presented in previous systematic reviews in this area (e.g. Holloway 2005).

\section{O B J E C T IVES}

To assess the effectiveness of interventions for drug-misusing offenders in reducing criminal activity and drug misuse across a range of criminal justice settings. The review addressed the following questions:

\section{Court-based}

(1) Do court-based interventions for drug-misusing offenders reduce criminal activity?

(2) Do court-based interventions for drug-misusing offenders reduce drug use?

\section{Secure establishment-based}

(1) Do secure establishment-based interventions for drug-misusing offenders reduce criminal activity?

(2) Do secure establishment-based interventions for drug-misusing offenders reduce drug use?

\section{Community-based}

(1) Do community-based interventions for drug-misusing offenders reduce criminal activity?

(2) Do community-based interventions for drug-misusing offenders reduce drug use?

The review additionally considered the effectiveness of different types of interventions in relation to drug use and re-offending behaviour.

\section{METHODS}

\section{Criteria for considering studies for this review}

\section{Types of studies}

The current review forms part of a larger Department of Health for England and Wales-funded project (Perry submitted submitted), which also includes studies that have a comparison group, but are not randomly assigned (i.e., experimental studies without randomisation and controlled observational studies). For the purposes of this review however, only randomised controlled trials (RCTs) are reported.

\section{Types of participants}

Drug-misusing offenders were included in the review regardless of gender, age, ethnicity, or psychiatric illness. Offenders were defined as individuals who have been referred by the criminal justice system at baseline to the study. Offenders were either in police custody, being processed by the courts system, residing in secure establishments (e.g., special hospitals, prisons), or based in the community (i.e., under the care of the probation service).

\section{Types of interventions}

The review included any evaluated intervention; a component of which is designed to reduce, eliminate or prevent relapse to drug use. Types of interventions were further classified into the categories presented below and analysed separately. The comparison group of drug-misusing offenders was not restricted to a no treatment control; studies that contained comparisons with another intervention or a minimal treatment group (i.e. any reduced component of the intervention, such as therapeutic community with intensive aftercare compared to therapeutic community without intensive aftercare) were included and were similarly classified as for the experimental interventions.

\section{Experimental interventions:}

(1) Pharmacological (e.g., methadone, naltrexone)

(2) Sentencing options (e.g., drug court, mental health court, diversion)

(3) Monitoring (e.g., drug testing, surveillance, intensive supervision)

(4) Punitive (e.g., sanctions)

(5) Aftercare

(6) Case management

(7) Shock incarceration/boot camp

(8) Therapeutic communities

(9) Counselling

(10) Work release/vocational

(11) Cognitive skills (e.g., 12-step, relapse prevention, multi-systemic therapy)

(12) Substance abuse education

Comparison interventions:

(1) Treatment as usual

(2) Minimal treatment

(3) Waiting-list control

Interventions for drug-using offenders in the courts, secure establishments and the community. (Review)

Copyright $\odot 2008$ The Cochrane Collaboration. Published by John Wiley \& Sons, Ltd. 
(4) No treatment

\section{Types of outcome measures}

Primary outcomes:

(1) Drug use as measured by:

- Self-report drug use (unspecified drug, not including alcohol)

- Self-report drug use (specific drug)

- Addiction Severity Index (ASI drug use)

- Drug testing by urine analysis

- Drug testing by hair analysis

- Saliva analysis

- Any other additional tools (e.g., MAP or CISS)

(2) Criminal activity as measured by:

- Arrest for any offence (self-report/official records)

- Arrest for a drug offence (self-report/official records)

- Arrest for a technical violation (self-report/official records)

- Conviction for any offence (self-report/official records)

- Conviction for a drug offence (self-report/official records)

- Incarceration for any offence (self-report/official records)

- Incarceration for a drug offence (self-report/official records)

- Recidivism (self-report/official records)

- Criminal activity (self-report/official records)

Secondary outcomes:

(3) Health status (e.g., mentally disordered offenders)

(4) Information on concurrent psychiatric illness were recorded. Where appropriate, these groups of offenders were considered separately within a meta-analysis.

(5) Cost and cost effectiveness

Resource and cost information were recorded from the papers where available. A descriptive narrative was used to describe these findings. Where a paper reported on the cost-effectiveness, a full critical appraisal based on the Drummond 1997, checklist was undertaken for those studies with sufficient information presented.

\section{Search methods for identification of studies}

\section{Electronic searches:}

We searched

(1) MEDLINE (1966-October 2004)

(2) EMBASE (1980-October 2004)

(3) PsycINFO (1978-January 2004)

(4) Pascal (1973-November 2004)

(5) SciSearch (Science Citation Index) (1974-November 2004)

(6) Social SciSearch (Social Science Citation Index) (1972November 2004)

(7) ASSIA (1987-November 2004)

(8) Wilson Applied Science and Technology Abstracts (1983-October 2004)

(9) Inside Conferences (1993-November 2004)
(10) Dissertation Abstracts (1961-October 2004)

(11) NTIS (1964-November 2004)

(12) Sociological Abstracts (1963-September 2004)

(13) HMIC (To September 2004)

(14) PAIS (1972-October 2004)

SIGLE (1980-June 2004)

(15) Criminal Justice Abstracts (1968-December 2003)

(16) National Research Register (March 2004)

(17) Current Controlled Trials (January 2004)

(18) Drugscope (February 2004)

(19) SPECTR (March 2004)

The search strategy was restricted to studies that were published or unpublished from 1980 onwards. By using this date the review encompasses a large body of research, allowing comparisons to be drawn concerning trends in quality assessment across time. A scoping review indicated that research prior to 1980 would bare little relevance on current treatment options.

Search strategies were developed for each database in order to exploit the search engine most effectively and to make use of any controlled vocabulary. The search strategies were not designed to restrict the results to RCTs as the current review forms part of a larger Department of Health-funded project, which also includes studies that have a comparison group, but are not randomly assigned (i.e., experimental studies without randomisation and controlled observational studies). All searches included any language. See ' Additional Table 1; Table 2; Table 3; Table 4; Table 5; Table 6; Table 7; Table 8; Table 9; Table 10; Table 11; Table 12; Table 13 ' for each search strategy.

A range of relevant Internet sites including those of the Home office, National Institute of Drug Abuse (NIDA) and European association of libraries and information services on alcohol and other drugs (ELISAD). Directory web sites, including OMNI (http:// www.omni.ac.uk) were searched for further relevant web sites.

\section{Reference Checking}

Attempts to identify further studies were made by examining the reference lists of all retrieved articles. Searches of the catalogues of relevant organisations and research founders were also undertaken. 3. Personnel communication

Experts were contacted and asked of their knowledge of other studies, published or unpublished, relevant to the review article.

\section{Data collection and analysis}

\section{Study Selection}

Two independent authors inspected the search hits by reading the titles and abstracts. Each potentially relevant study located in the search was obtained as a full article and independently assessed for inclusion by two authors. In the case of discordance, a third independent author arbitrated. Where it was not possible to evaluate the study because of language problems or missing information the studies were classified as 'translation/information required to determine decision' until a translation or further details was pro- 
vided. The pre-screening criteria are divided into eight key questions.

\section{Pre-screening criteria}

- (1) Is the document written in 1980 or later? [If "no," exclude document]

- (2) Is the document an empirical study? [If "no" exclude document]

- (3) Does the study evaluate an intervention, a component of which is designed to reduce, eliminate, or prevent relapse with drug-using offenders?

(E.g. drug-using is implied if the program is targeted at reducing drug use in a group of individuals, and/or can be ascertained from the background characteristics of the group)

(E.g., offenders residing in special hospitals, prisons, the community (i.e., under the care of the probation service) or offenders who are diverted from court or placed on arrest referral schemes for treatment).

[If "no" exclude document]

Note: the entire sample need not be drug-using.

- (4) Are the participants referred by the criminal justice system at baseline?

Note: the entire sample needs to be offenders.

[If "no" exclude document]

- (5) Does the study report pre and post-program measures of drug use?

Note: pre and post measures must be the same before and after, e.g. use vs. abstinence. Where measures are not the same, these papers should be excluded.

[If "no" to question $5 \& 6$ then exclude document]

OR (Note: studies do not need to include both drug and crime outcomes.)

- (6) Does the study report pre and post-program measures of criminal behaviour?

Note: pre and post measures must be the same, but setting (e.g., prison) could be used to infer incarceration (pre) vs. re-incarceration (post). Where measures are not the same, these papers should be excluded.

[If "no" to both $5 \& 6$ then exclude document]

- (7) Does the study include a comparison group?

(E.g. this could include a control or minimal treatment group or another intervention group.)

[If "no" exclude document]

- (8) Do the outcome measures refer to the same length of follow-up for two groups?

(E.g. a paper would be excluded that reported outcome measures for the intervention at one month and the control group at six months.)

[If "no" exclude document]

Assessment of methodological quality
Two independent reviewers assessed each study for methodological quality using the Centre for Reviews and Dissemination Guidelines (CRD 2001), using ratings of 'adequate', 'partial', 'reported' 'inadequate' and 'unknown'. Allocation concealment was also assessed using the Cochrane ratings of A, B, C and D (Higgins 2005). The quality evaluation was not used as a criterion for exclusion and inclusion, but the limits were described and are discussed in the relevant sections of the review. The quality assessment considered the following items:

\section{Assessment of baseline characteristics.}

This question will assess whether the groups were similar at baseline with respect to criminal and drug history characteristics.

We used the following classifications:

(A) Yes: reviewer consults list of baseline characteristics, author comments and any statistical tests and decides that the characteristics are similar.

(B) No: reviewer consults list of baseline characteristics, author comments and any statistical tests and decides that the characteristics are not similar.

(C) Unknown: insufficient information is provided to assess the similarity of baseline characteristics.

\section{Blinding methodology.}

This question will assess whether the outcome assessors were adequately blinded to treatment allocation.

We used the following classifications:

(A) Adequate: independent person or panel or (self) assessments in watertight blind conditions.

(B) Inadequate: clinician is assessor in trial on drugs with clear side effects or a different influence on outcomes.

(C) Unknown: no statements on procedures and not deducible.

Loss to follow-up .

This question will assess whether loss to follow-up was adequately reported.

We used the following classifications:

(A) Adequate: number randomised must be stated. Number(s) lost to follow-up (dropped out) stated or deducible (from tables) for each group and reasons summarised for each group.

(B) Partial: numbers, but not the reasons (or vice versa).

(C) Inadequate: numbers randomised not stated or not specified for each group.

(D) Unknown: no details provided in text.

\section{Allocation concealment}

We used the following classifications:

(A) Low risk of bias: adequate allocation concealment, i.e. central randomisation (e.g. allocation by a central office unaware of subject characteristics), pre-numbered or coded identical bottles or containers which are administered serially to participants, drug prepared by the pharmacy, serially numbered, opaque, sealed envelopes, on-site computer system combined with allocations kept in a locked unreadable; computer file that can be accessed only after the characteristics of an enrolled participant have been entered or other description that contained elements convincing of 
concealment.

(B) Moderate risk of bias: unclear allocation concealment, in which the authors either did not report an allocation concealment approach at all or report an approach that did not fall in the category A or C.

(C) High risk of bias: inadequate allocation concealment, such as alternation or reference to case numbers, dates of birth, day of the week. Any procedure that is entirely transparent before allocation, such as an open list of random numbers or other description that contained elements convincing of not concealment.

(D) No allocation concealment used: when reviewers have not used this method of rating study quality, i.e. for studies which are not randomised or quasi randomised.

\section{Data extraction}

The first autho extracted data by and confirmed by the second reviewer. Data extraction tables were used to present a narrative description of the papers included in the review. Those papers excluded from the second stage of pre-screening are presented in exclusion tables, alongside the reasons for exclusion. Papers are presented according to setting and further divided into broad themes of populations, intervention and outcome measures. This helped to categorise similar studies together.

\section{Data synthesis}

A series of meta-analyses and a narrative review were performed where appropriate to address each of the key questions outlined in the objectives for each of the settings, intervention categories and nominated outcomes. The narrative tables included a presentation of the study details (e.g., author, year of publication, and country of study origin), study methods (e.g., random assignment), participants (e.g., number in sample, age, gender, ethnicity, age, mental health status) interventions (e.g., description, duration, intensity and setting), outcomes (e.g., description, follow-up period and reporting mechanism), resource and cost information and resource savings (e.g., number of staff, intervention delivery, estimated costs and estimated savings) and notes (e.g., methodological and quality assessment information).

\section{Statistical analysis}

The Revman software package was used to perform a series of meta-analyses for continuous and dichotomous outcome measures. Where appropriate, sensitivity analyses was conducted. Tests for homogeneity were conducted to assess the appropriateness of the meta-analysis. Statistical advice was provided by a statistician at the University of York. Where appropriate presentation of this information was generated via forest plots, and Odds Ratios (ORs).

\section{RES U L T S}

\section{Description of studies}

See: Characteristics of included studies; Characteristics of excluded studies.

The search strategies revealed a total of 8,217 titles and abstracts of potential relevance. Screening reduced this to 90 studies eligible for further evaluation. The 90 studies resulted in 36 randomised controlled trials (RCTs). Of these 36 trials, 12 were excluded from the review, leaving a total of 24 RCTs.

\section{Excluded studies}

The 12 excluded trials had three main reasons for exclusion. Firstly, the lack of an appropriate comparison group (Stevens 1998S). Secondly, the outcome measures were not appropriately measured at pre- and post-test (Anglin 1999; Dembo 2000; Dugan 1998; Grohman 2002; Harrell 2001; Henggeler 1991; Henggeler 2002; Messina 2000; Nemes 1998; Nemes 1999). Thirdly, studies were excluded where follow-up periods were not equivalent (Dembo 2000; Di Nitto 2002).

\section{Included studies}

The included studies display data from 19 publications describing 24 RCTs. Of these 24 RCTs, seven were conducted in a court setting, these were divided into monitoring interventions (4 studies) and sentencing interventions ( 3 studies). 4 were conducted in a secure establishment setting, these included interventions focusing on therapeutic communities (3 studies) and pharmacological interventions ( 1 study). The remaining and 13 were conducted in the community. These were divided into monitoring interventions (9 studies), pharmacological interventions (1 study), aftercare (1 study) and cognitive skills training (2 studies).

\section{Court setting: Monitoring interventions}

Four of the seven court-based studies focused on monitoring interventions. All of these studies originated from one publication, which used four separate samples to assess the effectiveness of community-based pre-trial release with drug testing and sanctions in comparison to routine pre-trial release (Britt $1992 \mathrm{a}$; Britt $1992 \mathrm{~b}$; Britt 1992 c; Britt 1992 d). Across these studies, drug-misusing offenders were randomly assigned to an active monitoring intervention or treatment as usual. The duration of the intervention was not reported. The sample size across the 4 studies totaled 2,007 although it is not possible to determine the number assigned in studies 3 and 4 (Britt 1992 c; Britt 1992 d). Details about the participants' gender, psychiatric diagnosis and drug and or alcohol use were not reported. All four studies measured arrest, using data from official records at three-month and seven to nine-month follow-up periods.

\section{Court setting: Sentencing interventions}

The three remaining court-based studies examined sentencing interventions. Two studies assessed the effectiveness of drug courts compared to routine probation and/or parole; the later of these studies examined the same sample of participants across multiple follow-up periods (Deschenes 1994; Gottfredson 2002). The other study assessed the effectiveness of a mental health drug court with ACT (assertive community treatment) case management in 
comparison to treatment as usual (Cosden 2003). Across these studies, drug-misusing offenders were randomly assigned to an active sentencing intervention, treatment as usual or routine parole or probation. The duration of the interventions varied from 6 to 24 months. The sample size across the four studies varied from 235 to 639 participants. Over half of all participants in all of the studies were male, and in one study all participants were mentally disordered (Cosden 2003). Drug use at baseline was reported in all participants in two of the studies (Deschenes 1994; Gottfredson 2002). Only one study measured drug use (Cosden 2003), using self-report data from the Addiction Severity Index (ASI) at 12month follow-up. Using data from official records the other two studies reported on arrest, drug arrest, drug charge and conviction at between 6 and 24 months (Deschenes 1994; Gottfredson 2002).

\section{Secure establishment: Therapeutic community interventions}

Five publications evaluating three RCTs were found to examine secure establishment-based therapeutic community interventions. Three publications produced one study using the same sample of participants across multiple follow-up periods assessing the effectiveness of a prison-based AMITY therapeutic community followed by community-based residential aftercare, which was compared to a waiting list control (Wexler 1999). Of the remaining two studies, one study assessed the effectiveness of a CREST work release transitional therapeutic community in comparison to routine work release (Nielsen 1996). The full data set is reported here although it was found that the effects of treatment are no longer observed when considering the female participants only. The final study assessed the effectiveness of a Personal Reflections therapeutic community followed by community-based aftercare, which was compared to a prison-based mental health program (Sacks 2004). Across these studies, drug-misusing offenders were randomly assigned to an intervention of a therapeutic community (sometimes followed by aftercare) or to a waiting list control; a prison-based mental health program or routine work release. The duration of the interventions ranged from 6 to 24 months. The sample size across the three studies ranged from 236 to 715 . Two studies contained only male participants, whereas the Nielsen 1996 study contained both male and female participants. Two studies contained solely mentally disordered participants (Sacks 2004; Wexler 1999). Drug use history was reported in the Nielsen 1996 and Wexler 1999 studies, and both drug and alcohol use was reported in the Sacks 2004 study. The three studies measured drug use, recidivism criminal activity and incarceration. Drug use was reported using self-report data between 6 and 18-month follow-up periods. Recidivism, criminal activity and incarceration reported using data from official records between 6 and 60 months.

\section{Secure establishment: Pharmacological interventions}

One study assessed the effectiveness of a pharmacological intervention, randomly assigning drug-using offenders to prison-based methadone maintenance treatment or a waiting list control (Dolan 2003). The average duration of the intervention was 144 days (range 72-530). The sample size of participants was 382; all were male with no psychiatric history being reported. All participants had a drug use history. The study measured drug use using data from hair analysis at two, three and four-month follow-ups. Only participants that had been in continuous custody between assignment and follow-up were included.

\section{Community: Monitoring interventions}

Monitoring interventions were evaluated in eight studies, seven of which were extracted from one publication, using separate samples to assess the effectiveness of intensive supervision and surveillance in comparison to routine parole (Petersilia 1992 a; Petersilia 1992 b; Petersilia 1992 c; Petersilia 1992 d) and to assess the effectiveness of intensive supervision and surveillance in comparison to intensive supervision alone (Petersilia 1992 e; Petersilia 1992 f; Petersilia 1992 g). The remaining study evaluated the effectiveness of parole with varying frequencies of drug testing in comparison to routine parole (Haapanen 2002). Across these studies, drugusing offenders were randomly assigned to different monitoring conditions. The duration of the intervention ranged between 6 and 24 months. The sample size across the studies ranged from 50 to 1958 . Across all samples participants included both male and female offenders, with no history of psychiatric disorder reported. The majority of participants had a drug offending history, but the drug testing evaluation also contained offenders who were not drug-using (Haapanen 2002). Alcohol use was not reported. The seven Petersilia studies (Petersilia 1992 a; Petersilia 1992 b; Petersilia 1992 c; Petersilia 1992 d; Petersilia 1992 e; Petersilia 1992 f; Petersilia 1992 g) measured recidivism, arrest, drug arrest, conviction and incarceration using data from official records at one-year follow-up. The Haapanen 2002 study reported arrest at 24 and 42-month follow-up periods.

\section{Community: Pharmacological interventions}

One study assessed the effectiveness of a naltrexone program and routine parole in comparison to routine parole (Cornish 1997), randomly assigning drug-using offenders to a pharmacological intervention or no treatment. The duration of the intervention was six months. The sample size was 51 and included both male and female participants, with no psychiatric history reported. All participants had a drug history, but alcohol use was not reported. The study measured incarceration using official data from at six months.

\section{Community: Aftercare interventions}

One study assessed an aftercare intervention by randomly assigning drug-using offenders to a community-based opportunity to succeed aftercare program or to routine parole or probation (Rossman 1999). The duration of the intervention was between one and two years. The sample contained 398 participants, comprised of both male and female offenders, with psychiatric diagnosis, drug and alcohol use not reported. The study measured any marijuana use, intense marijuana use, any hard drug use, intense hard drug use and drug dealing, using self-report data at between 
3-month and 12-month follow-up periods.

\section{Community: Case management interventions}

One study assessed the effectiveness of a community-based case management intervention. In this study, drug-using offenders were randomly assigned to ACT (assertive community treatment) case management or to routine parole (Martin 1993). The duration of the intervention was six months. The sample size was 188 and included only the subset of participants for which the necessary follow-up period had elapsed. Both male and female offenders were included; psychiatric diagnosis and alcohol history were not reported. Drug history and offending history was apparent in all participants. The study measured incarceration, using data from official records at six-month follow-up and drug use, using data from self-report at six-month follow up.

\section{Community: Cognitive skills training interventions}

Two studies examined cognitive skills training. The effectiveness of multi-systemic therapy delivered in the home and community was compared to community services as usual (Henggeler 1999; Schoenwald 1996) and a social support program was compared to drug testing and routine parole, and also to routine parole (Hanlon 1999). The duration of the interventions ranged from 5 months to 12 months. The sample size across the two studies ranged from 118 to 536; both studies included male and female offenders. The Henggeler 1999 study focused on juvenile offenders only; the majority of these participants also had a psychiatric diagnosis. Drug use was reported in the Hanlon et al. (1999) study, and both drug and alcohol history were reported in the Henggeler 1999 study. The Henggeler 1999 study measured drug use and delinquency, using data from self-report at post treatment and six months follow-up. The Hanlon 1999 study reported arrest and incarceration, using data from official records at one-year followup.

\section{Risk of bias in included studies}

Randomization: All the studies were described as randomised, but only 4 of the 24 RCT studies reported adequate methods of randomisation (Cosden 2003; Deschenes 1994; Dolan 2003; Haapanen 2002). The most common reason for the studies not being rated as adequate was either unclear reporting of the randomisation methodology or unacceptable methods of randomisation such as alternation. In some studies the randomisation methodology may have been acceptable, but the authors did not describe the methodology. Consequently, such studies received a poor rating by the reviewers.

Characteristics at baseline: Of the 24 studies, 7 reported that participants' drug history was similar across the groups at baseline (Deschenes 1994; Dolan 2003; Haapanen 2002; Petersilia 1992 a; Petersilia 1992 c; Petersilia 1992 g; Wexler 1999). A greater number of the studies $(n=18)$ reported similar criminal history characteristics at baseline (Britt 1992 a; Britt 1992 b; Britt 1992 c; Britt 1992 d; Cosden 2003; Deschenes 1994; Dolan 2003;
Gottfredson 2002; Haapanen 2002; Henggeler 1999; Petersilia 1992 a; Petersilia 1992 b; Petersilia 1992 c; Petersilia 1992 e; Petersilia 1992 f; Petersilia 1992 g; Sacks 2004; Wexler 1999)

Allocation concealment: Across the 24 studies only 4 were allocated an A for adequate allocation concealment (Cosden 2003; Deschenes 1994; Dolan 2003; Haapanen 2002). The majority of the studies $(\mathrm{n}=14)$ were categorised as moderate risk of bias and were rated as B (Cornish 1997; Gottfredson 2002; Henggeler 1999; Martin 1993; Nielsen 1996; Petersilia 1992 a; Petersilia 1992 b; Petersilia 1992 c; Petersilia 1992 d; Petersilia 1992 e; Petersilia 1992 f; Petersilia 1992 g; Sacks 2004; Wexler 1999). The description of the random allocation concealment for the five remaining studies was unclear, representing a high risk of bias and rated as C (Britt 1992 a; Britt 1992 b; Britt 1992 c; Britt 1992 d; Hanlon 1999).

Follow-up: Only seven studies reported loss to follow-up with the reasons adequately described (Deschenes 1994; Dolan 2003; Haapanen 2002; Henggeler 1999; Rossman 1999; Rossman 1999; Wexler 1999).

\section{Effects of interventions}

Of the 24 RCT studies 15 were included in a series of meta-analyses. Tests for heterogeneity at the 0.01 level revealed that across all of the meta-analyses the studies were found to be homogeneous. Odds Ratios (OR) were used to investigate the results of combining dichotomous outcome measures. A random effects model was used to account for the fact that the participants did not come from a single underlying population.

\section{- COURT-BASED INTERVENTIONS}

\section{Monitoring interventions}

Four studies were found to evaluate court-based monitoring interventions. All four studies originated from one publication, which used four separate samples to assess the effectiveness of pre-trial release with drug testing and sanctions in comparison to routine pre-trial release (Britt 1992 a; Britt 1992 b; Britt 1992 c; Britt 1992 d).

\section{(1) Drug use}

The studies did not report on drug use.

(2) Criminal activity

All four studies measured arrest, using data from official records at three and seven to nine-month follow-up periods. A meta-analysis combining studies 3 and 4 (Britt 1992 c; Britt 1992 d) showed a significant $\mathrm{OR}$ for arrest at 90 days favouring the comparison group OR 1.33 (95\% CI, 1.04 to 1.70), see comparison 01, outcome 01 .

\section{Sentencing interventions}

Three studies were found to evaluate court-based sentencing interventions. Two studies assessed the effectiveness of drug courts compared to routine probation and/or parole; the later of these 
studies examined the same sample of participants across multiple follow-up periods (Deschenes 1994; Gottfredson 2002). The other study assessed the effectiveness of a sentencing intervention (mental health drug court) combined with ACT (assertive community treatment) case management, in comparison to treatment as usual (Cosden 2003). None of these studies were homogenous enough to combine in a meta-analyses and the results from each singular study are presented below.

\section{(1) Drug use}

One study measured drug use (Cosden 2003), using self-report data from the Addiction Severity Index (ASI) at 12-month followup to evaluate a mental health drug court combined with ACT case management. The OR was not found to be statistically significant OR 0.00 (95\% CI -0.03 to 0.03 ).

\section{(2) Criminal activity}

Deschenes 1994 reported arrest for any offence at 6-month followup OR 1.12 (95\% CI, 0.70 to 1.79) and 12-month follow-up OR 0.94 (95\% CI, 0.65 to 1.37) using data from official records, and arrest for a drug offence at 12-month follow-up OR $1.02(95 \%$ CI, 0.65 to 1.61 ) using data from official records. None of these results were statistically significant.

Using data from official records Gottfredson 2002G reported on arrest, conviction and drug charge at 12 and 24-month follow-up. A significant OR was found favouring the Baltimore drug court programme when arrest was used as an outcome measure at both 12 months OR 0.53 (95\% CI ,0.31 to 0.91 ) and 24 months OR 0.45 (95\% CI, 0.24 to 0.84 ).

At 12 months there was no significant effect regarding criminal activity as measured by drug charge OR 0.65 (95\% CI, 0.37 to 1.13]), however there was at 24 months OR 0.57 (95\% CI, 0.34 to 0.97]). The ORs were not found to be significant when conviction was used at either 12 months OR 0.82 (95\% CI 0.47 to 1.42$])$ or 24 months OR 0.85 (95\% CI, 0.50, 1.42).

\section{- SECURE ESTABLISHMENT-BASED}

\section{INTERVENTIONS}

\section{Therapeutic community interventions}

Five publications evaluating three RCTs were found to examine secure establishment-based therapeutic community interventions. Three publications produced one study using the same sample of participants across multiple follow-up periods assessing the effectiveness of a prison-based AMITY therapeutic community followed by community-based residential aftercare, which was compared to a no-treatment control (Wexler 1999). Of the remaining two studies, one study assessed the effectiveness of a CREST work release transitional therapeutic community in comparison to routine work release (Nielsen 1996). The full data set is reported here although it was found that the effects of treatment are no longer observed when considering the female participants only. The final study assessed the effectiveness of a Personal Reflections therapeutic community followed by community-based aftercare, which was compared to a prison-based mental health program (Sacks 2004).

\section{(1) Drug use}

In evaluating the CREST work release therapeutic community Nielsen 1996 reported drug use as measured by self-report at 6month OR 0.12 (95\% CI 0.08, 0.18) and 18-month follow-up OR 0.28 (95\% CI 0.17 to 0.47$]$ ). The ORs were both found to be statistically significant favouring the CREST work release therapeutic community over routine work release.

\section{(2) Criminal activity}

All of the studies showed significant ORs with the criminal activity outcome measures favouring the intervention groups. Nielsen et al. (1996) reported criminal activity as measured by recidivism for any offence, which referred to an offender being arrested and charged. These outcomes were collected through self-report and referred to 6-month OR 0.32 (95\% CI 0.20 to 0.50 ] and 18month follow-up periods OR 0.36 (95\% CI 0.23 to 0.58 ).

One meta-analyses was possible combining the Sacks 2004 and Wexler 1999 studies focusing on the effectiveness of a therapeutic community and aftercare in comparison to a mental health programme and waiting list control. Incarceration at 12 months OR 0.37 , (95\%CI, 0.16 to 0.87 ), see comparison 02 , outcome 01 and following sensitivity analyses OR 0.66 (95\% CI, 0.38 to 1.15 ), are showed in comparison 02 , outcome 02 .

\section{Pharmacological interventions}

One study assessed the effectiveness of a pharmacological intervention, randomly assigning drug-using offenders to prison-based methadone maintenance treatment or a waiting list control (Dolan 2003).

\section{(1) Drug use}

Dolan 2003 reported drug use as measured by drug testing (hair analysis; official records) at 2 months OR 0.67 (95\% CI 0.36 to 1.25), 3 months OR 0.46 (95\% CI 0.25 to 0.82 ) and 4 months OR 0.66 (95\% CI 0.37 to 1.21) follow-up. The OR was found to be significant at three months only, favouring the intervention group.

\section{(2) Criminal activity}

Criminal activity was not reported on.

\section{- COMMUNITY-BASED INTERVENTIONS}

\section{Monitoring interventions}

Monitoring interventions were evaluated in eight studies, seven of which were extracted from one publication, using separate samples to assess the effectiveness of intensive supervision and surveillance in comparison to routine parole (Petersilia 1992 a; Petersilia 1992 b; Petersilia 1992 c; Petersilia 1992 d) and to assess the effectiveness of intensive supervision and surveillance in comparison to intensive supervision alone (Petersilia 1992 e; Petersilia 1992 f; Petersilia $1992 \mathrm{~g}$ ). The remaining study evaluated the effectiveness of parole with varying frequencies of drug testing in comparison to routine parole (Haapanen 2002).

\section{(1) Drug use}

Drug use was not reported on.

(2) Criminal activity

Petersilia 1992 a; Petersilia 1992 b; Petersilia 1992 c; Petersilia 
$1992 \mathrm{~d}$ were combined in a series of meta-analyses focusing on the effectiveness of intensive supervision vs routine parole/probation. A series of different outcome measures were used:

- Recidivism at one year OR 1.98 (95\% CI 1.01 to 3.87) see comparison 03, outcome 01

- Arrest at one year OR 1.49 (95\% CI 0.88 to 2.51 ) see comparison 03 , outcome 02 ,

- Drug arrest at one year OR 1.10 (95\% CI 0.50, to 2.39) see comparison 03, outcome 03,

- Conviction at one year OR 0.93 (95\% CI 0.55 to 1.58 ) see comparison 03, outcome 04,

- Incarceration at one year OR 0.88 (95\% CI 0.50 to 1.54$)$ see comparison 03, outcome 05,

Petersilia 1992 e; Petersilia 1992 f; Petersilia 1992 g were combined a series of meta-analyses focusing on the effectiveness of intensive supervision and increased surveillance vs. intensive supervision. A series of different outcome measures were used:

- Recidivism at one year OR 2.09 (95\% CI 0.86 to 5.07) see comparison 04 , outcome 01

- Arrest at one year OR 1.22 (95\% CI 0.51 to 2.88$)$ see comparison 04 , outcome 02

- Drug arrest at one year OR 1.29 (95\% CI 0.35 to 4.85$)$ see comparison 04 , outcome 03

- Conviction at one year OR 1.14 (95\% CI 0.22 to 5.91) see comparison 04 , outcome 04

- Incarceration at one year OR 1.30 (95\% CI 0.39, to 4.30]) see comparison 04 , outcome 05

The Haapanen 2002 study reported arrest at 24 and 42-month follow-up periods. Comparing the four groups receiving drug testing to the routine parole group revealed no significant effect sizes at 24 months OR 0.93 (95\% CI 0.71 to 1.22$)$, OR $1.05(95 \%$ CI 0.79 to 1.38$)$, OR 1.16 (95\% CI 0.88 to 1,52$)$, OR $1.11(95 \%$ CI 0.77 to 1.59 ), OR 1.02 (95\% CI 0.75 to 1.38$]$ ), OR 1.06 (95\% CI 0.78 to 1.45 ) and OR 1.24 (95\% CI 0.8 to 1.89 ]). At 42 months the only significant OR was found to favour the routine parole group $\mathrm{OR}=1.46$ (95\% CI 1.05 to 2.02 ).

\section{Pharmacological interventions}

One study assessed the effectiveness of a naltrexone program and routine parole in comparison to routine parole (Cornish 1997), randomly assigning drug-using offenders to a pharmacological intervention or no treatment.

\section{(1) Drug use}

Drug use was not reported

\section{(2) Criminal activity}

The Cornish 1997 study reported on incarceration using official data from at six months. A significant OR 0.25 (95\% CI 0.07 to 0.86 ) was found for incarceration, favouring the intervention group.

\section{Aftercare interventions}

One study assessed an aftercare intervention by randomly assigning drug-using offenders to a community-based opportunity to succeed aftercare program or to routine parole or probation (Rossman 1999).

\section{(1) Drug use}

The Rossman 1999 study measured any marijuana use, intense marijuana use, any hard drug use, intense hard drug use and drug dealing, using self-report data at between 3-month and 12-month follow-up periods. The results were inconclusive with a significant ORS found favouring the intervention group using intense marijuana use as the outcome, OR 0.49 (95\% CI 0.25 to 0.96]), yet favouring the comparison group when drug dealing was used as the outcome OR 2.31 (95\% CI 1.40 to 3.79)

\section{(2) Criminal activity}

Criminal activity was not reported on.

\section{Case management interventions}

One study assessed the effectiveness of a community-based case management intervention. In this study, drug-using offenders were randomly assigned to ACT (assertive community treatment) case management or to routine parole (Martin 1993).

(1) Drug use

The Martin and Scarpitti (1993) study self-report drug use at six-months follow-up did not show any significant $\mathrm{OR}(\mathrm{OR}=$ $1.44[95 \% \mathrm{CI}=0.66,3.12])$.

(2) Criminal activity

Measuring incarceration at six-months follow-up the Martin and Scarpitti (1993) study showed no significant OR (OR= 0.84[95\% CI $0.41,1.73])$.

\section{Cognitive skills training interventions}

Two studies examined cognitive skills training. The effectiveness of multi-systemic therapy delivered in the home and community was compared to community services as usual (Henggeler 1999) and a social support program was compared to drug testing and routine parole, and also to routine parole (Hanlon 1999).

\section{(1) Drug use}

The Henggeler 1999 study measured drug use using self-report data at post treatment OR 1.28 (95\% CI 0.54 to 3.05), and at six months OR 1.35 (95\% CI 0.56 to 3.23), neither were found to be statistically significant.

\section{(2) Criminal activity}

The Henggeler 1999 study measured delinquency using self-report data at post treatment OR 1.00 (95\% CI 12.77 to 14.77), and at six months OR 2.00 (95\% CI 11.96 to 15.96]), neither were found to be statistically significant.

The Hanlon 1999 study reported arrest using official records at one year I vs I1 OR 0.66 (95\% CI 0.41 to 1.05]), I vs. C OR 0.74 (95\% CI 0.48 to 1.13 ), and I1 vs. C OR 1.13 (95\% CI 0.67 to $1.91)$, and incarceration at one year I vs. I1 OR 0.90 (95\% CI 0.54 to 1.51 ), I vs. C OR 0.74 (95\% CI 0.47 to 1.16$)$ and I1 vs. C OR 0.82 (95\% CI 0.46 to 1.44 ), none of the results were found to be statistically significant.

\section{Cost and cost effectiveness}

No explicit cost data was available for the court-based interventions. One study contained some information about the cost of 
providing a therapeutic community intervention (Sacks 2004). For this intervention the additional marginal costs on top ot the specific incarceration costs were USD \$7.37 per day. Cost information was reported in seven of the community studies (Henggeler 1999; Petersilia 1992 a; Petersilia 1992 b; Petersilia 1992 c; Petersilia 1992 d; Rossman 1999). Petesillia suggests that there is an additional cost of USD $\$ 3000$ per annum (1992 prices) for intensive probation supervision. On cost comparison, the costs per day are lower or comparable to the additional costs per day of the therapeutic community in prison. Without any allowance for administration costs, Rossman et al. (1999) suggests that the service provision cost for the opportunity to succeed scheme is about USD $\$ 1810$ for the one to two year programme. This study does provide an estimate of the benefits of the programme in financial terms, and were found to be similar (USD $\$ 105,339$ ) to the service provision costs (USD \$108,632). These figures were based on cost per programme.

One study provided enough data for a detailed critique of cost effectiveness using the Drummond Scale. Schoenwald 1996 is an economic paper linked to the Henggeler 1999 evaluation of the community-based multi-systemic therapy. The paper compared services accessed by young offenders to the costs of specific programme costs. Individual outcomes for the programme were included in the economic analysis and the results of an additional USD $\$ 877$ cost per young person for the therapy was estimated.

\section{DISCUSSION}

This systematic review provides evidence from 24 RCTs, 15 of these were included in a series of sub-set meta analyses. Little conclusive evidence can be drawn from the studies conducted in the courts or community settings. The inference of these interventions is weakened by the limited methodological quality of some of the RCTs, including loss to follow-up and potential baseline differences between the groups. Therapeutic community interventions, followed by aftercare, may be promising for drug-using offenders. This work is also supported by quasi-experimental designs (e.g., Inciardi 1997), but such studies are susceptible to a greater amount of bias.

The outcome measures used in the current studies are broad ranging and reflect the multidisciplinary nature of working across agencies with drug-using offenders. The appropriate use of such measures is important when trying to assess the effectiveness of such treatment programmes. Other outcome measures that might reflect success in treatment could perhaps include, employment.

Cost information within the studies is sparse, with only one study providing the opportunity for a full economic evaluation (Schoenwald 1996). This lack of information allows for little comparison of cost effectiveness between different types of drug treatment programmes. Furthermore, very few studies include females, juveniles and young offenders with the majority reporting on male adults. Development of studies focusing on these particularly vulnerable groups may help the development of specifically tailor made interventions for such participants. In line with such comments is the importance of selecting participants appropriately for specifically targeted programmes. For example, incorrect selection of participants for programmes could give misleading negative results.

\section{A U THORS, CONCLUSIONS}

\section{Implications for practice}

Very limited conclusions can be drawn about the overall effectiveness of drug treatment programmes for offenders under the care of the criminal justice system. Promising results are highlight the use of therapeutic communities with aftercare facilities. The success of such programmes in secure settings maybe attributed to the large numbers of participants completing the programme. Maintainence and retention of such individuals in the courts or the community is very difficult due to the often chaotic lifestyle led by individuals attending such programmes. Such problems affect the continuity of treatment programmes. Standardisation of outcome measures for drug-using offenders should be used in a range of different interventions and settings.

\section{Implications for research}

There is some evidence to suggest that therapeutic communities with aftercare have some success in reducing drug use and criminal activity in drug-using offenders. There has however been little research evaluating and developing interventions with females, juveniles and young offenders. There is therefore perhaps a need to develop interventions that are tailor made to the needs of these subgroups of populations. Very limited information is provided on the costs and resources involved in the delivery of such interventions, particularly with regards to the UK literature. Attempts to address this gap could follow costing methodology developed in the USA (Yates, 1999). A broad range of outcome measures have been presented in this review reflecting the multidisciplinary nature of working with clients across a number of different agencies and criminal justice settings. Future work should consider the most appropriate use of outcomes and produce some standardisation from which comparison can be made across the literature. Additionally, it is important to stress the need to conduct high quality RCTs in drug misuse treatment in general. This will help policy makers to make informed choices about the relative effectiveness of treatment for specific groups of individuals.

\section{ACKNOWLEDGEMENTS}


We would like to acknowledge the help of the Centre for Reviews and Dissemination, the Health Sciences Department, the RCT trials Unit at the University of York and Steve Hamer from COM-

PASS, a voluntary drug agency in York, UK.

\section{RE F E R E N C E S}

\section{References to studies included in this review}

\section{Britt 1992 a \{published data only\}}

* Britt IC, Gottfredson MR, Goldkamp JS. Drug testing and pretrial misconduct: An experiment on the specific deterrent effects of drug monitoring defendants on pretrial release. Journal of Research in Crime and Delinquency 1992; 29(1):62-78.

\section{Britt 1992 b \{published data only\}}

* Britt IC, Gottfredson MR, Goldkamp JS. Drug testing and pretrial misconduct: An experiment on the specific deterrent effects of drug monitoring defendants on pretrial release.. Journal of Research in Crime and Delinquency 1992; 29(1):62-78. 1992;29(1):62-78.

Britt 1992 c \{published data only\}

* Britt IC, Gottfredson MR, Goldkamp JS. Drug testing and pretrial misconduct: An experiment on the specific deterrent effects of drug monitoring defendants on pretrial release.. Journal of Research in Crime and Delinquency 1992; 29(1):62-78.

Britt 1992 d \{published data only\}

* Britt IC, Gottfredson MR, Goldkamp JS. Drug testing and pretrial misconduct: An experiment on the specific deterrent effects of drug monitoring defendants on pretrial release. Journal of Research in Crime and Delinquency 1992; 29(1):62-78.

Cornish 1997 \{published data only\}

* Cornish JW, Metzger D, Woody GE, Wilson D, McLellan A.T, Vandergrift B, et al.Naltrexone pharmacotherapy for opioid dependent federal probationers. Journal of Substance Abuse Treatment 1997;14(6):529-34.

Cosden 2003 \{published data only\}

* Cosden M, Ellens JK, Schnell JL, Yamini-Diouf Y, Wolfe MM. Evaluation of a mental health treatment court with assertive community treatment. Behavioral Sciences \& the Law 2003;21(4):415-27.

Deschenes 1994 \{published data only\} * Deschenes EP, Greenwood PW. Maricopa-County Drug Court - an innovative program for 1st-time drug offenders on probation. Justice System Journal 1994;17(1):99-115.

Dolan 2003 \{published data only\}

* Dolan K A, Shearer J, MacDonald M, Mattick RP, Hall W, Wodak AD. A randomised controlled trial of methadone maintenance treatment versus wait list control in an Australian prison system. Drug and Alcohol Dependence 2003;72(1):59-65.
Gottfredson 2002 \{published data only\}

* Gottfredson DC, Exum ML. The Baltimore City drug treatment court: One-year results from a randomized study. Journal of Research in Crime and Delinquency 2002;39(3): 337-56.

Gottfredson DC, Najaka SS, Kearley B. Effectiveness of drug treatment courts: evidence from a randomized trial. Criminology and Public Policy 2003;2(2):171-96.

Haapanen 2002 \{published data only\}

* Haapanen R, Britton L. Drug testing for youthful offenders on parole: An experimental evaluation. Criminology and Public Policy 2002;1(2):217-44.

Hanlon 1999 \{published data only\} * Hanlon TE, Bateman RW, O'Grady KE. The relative effects of three approaches to the parole supervision of narcotic addicts and cocaine abusers. Prison Journal 1999; 79(2):163-81.

\section{Henggeler 1999 \{published data only\}}

* Henggeler SW, Pickrel SG, Brondino MJ. Multisystemic treatment of substance-abusing and dependent delinquents: outcomes, treatment fidelity, and transportability. Mental Health Services Research 1999;1(3):171-84.

\section{Martin 1993 \{published data only\}}

* Martin SS, Scarpitti SR. An intensive case management approach for paroled IV drug users. Journal of Drug Issues 1993;23(1):43-59.

Nielsen 1996 \{published data only\}

Farrell A. Women, crime and drugs: Testing the effect of therapeutic communities. Women and Criminal Justice 2000;11(1):21-48.

* Nielsen AL, Scarpitti FR, Inciardi J A. Integrating the therapeutic community and work release for drug-involved offenders The CREST Program. Journal of Substance Abuse Treatment 1996;13(4):349-58.

Petersilia 1992 a \{published data only\}

* Petersilia J, Turner S, Deschenes EP. Intensive supervision programs for drug offenders. In: JM Byrne, AJ Lurigio editor(s). Smart sentencing: The emergence of intermediate sanctions. Thousand Oaks, CA: Sage Publications Inc, 1992:18-37.

Petersilia 1992 b \{published data only\} * Petersilia J, Turner S, Deschenes EP. Intensive supervision programs for drug offenders. In: JM Byrne, AJ Lurigio editor(s). Smart sentencing: The emergence of intermediate sanctions. Thousand Oaks, CA: Sage Publications Inc, 1992:18-37. 
Petersilia 1992 c \{published data only\}

* Petersilia J, Turner S, Deschenes EP. Intensive supervision programs for drug offenders. In: JM Byrne, AJ Lurigio editor(s). Smart sentencing: The emergence of intermediate sanctions. Thousand Oaks, CA: Sage Publications Inc, 1992:18-37.

Petersilia 1992 d \{published data only\}

* Petersilia J, Turner S, Deschenes EP. Intensive supervision programs for drug offenders. In: JM Byrne, AJ Lurigio editor(s). Smart sentencing: The emergence of intermediate sanctions. Thousand Oaks, CA: Sage Publications Inc, 1992:18-37.

Petersilia 1992 e \{published data only\}

* Petersilia J, Turner S, Deschenes EP. Intensive supervision programs for drug offenders. In: JM Byrne, AJ Lurigio editor(s). Smart sentencing: The emergence of intermediate sanctions. Thousand Oaks, CA: Sage Publications Inc, 1992:18-37.

Petersilia 1992 f \{published data only\}

* Petersilia J, Turner S, Deschenes EP. Intensive supervision programs for drug offenders. In: JM Byrne, AJ Lurigio editor(s). Smart sentencing: The emergence of intermediate sanctions. Thousand Oaks, CA: Sage Publications Inc, 1992:18-37.

Petersilia 1992 g \{published data only\}

* Petersilia J, Turner S, Deschenes EP. Intensive supervision programs for drug offenders. In: JM Byrne, AJ Lurigio editor(s). Smart sentencing: The emergence of intermediate sanctions. Thousand Oaks, CA: Sage Publications Inc, 1992:18-37.

Rossman 1999 \{published data only\}

* Rossman S, Sridharan S, Gouvis C, Buck J, Morley E. Impact of the Opportunity to Succeed (OPTS) aftercare program for substance-abusing felons: Comprehensive final report. Washington D.C.: Urban Institute, 1999.

Sacks 2004 \{published data only\}

* Sacks S, Sacks JY, McKendrick K, Banks S, Stommel J. Modified TC for MICA inmates in correctional settings: crime outcomes. Behavioural Sciences and the Law 2004;22 (4):477-501.

Wexler 1999 \{published data only\}

Prendergast ML, Hall EA, Wexler HK, Melnick G, Cao Y. Amity Prison-Based Therapeutic Community: 5-year outcomes. Prison Journal 2004;84(1):36-60.

* Wexler HK, DeLeon G, Thomas G, Kressel D, Peters $\mathrm{J}$. The Amity prison TC evaluation - reincarceration outcomes. Criminal Justice and Behavior 1999;26(2): $147-67$.

Wexler HK, Melnick G, Lowe L, Peters J. Three-year reincarceration outcomes for Amity in-prison therapeutic community and aftercare in California. Prison Journal 1999; 79(3):321-36

\section{References to studies excluded from this review}

Anglin 1999 \{published data only\}

Anglin MD, Longshore D, Turner S. Treatment alternatives to street crime - An evaluation of five programs. Criminal Justice and Behavior 1999;26(2):168-95.

Dembo 2000 \{published data only\}

Dembo R, Ramirez GG, Rollie M, Schmeidler J, Livingston S, Hartsfield A. Youth recidivism twelve months after a family empowerment intervention: Final report. Journal of Offender Rehabilitation 2000;31(3/4):29-65.

Di Nitto 2002 \{published data only\} Di Nitto DM, Webb DK, Rubin A. The effectiveness of an integrated treatment approach for clients with dual diagnoses. Research on Social Work Practice 2002;12(5): 621-41.

Dugan 1998 \{published data only\} Dugan JR, Everett RS. An experimental test of chemical dependency therapy for jail inmates. International Journal of Offender Therapy \& Comparative Criminology 1998;42(4): 360-8.

Grohman 2002 \{published data only\} Grohman K, Fals-Stewart W, Bates ME. Cognitive rehabilitation for neuropsychologically impaired substanceabusing patients: posttreatment outcomes [web page]. Available: http://addictionandfamily.org [2004, 29 Oct] 2002.

Harrell 2001 \{published data only\}

Harrell A, Roman J. Reducing drug use and crime among offenders: the impact of graduated sanctions. Journal of Drug Issues 2001;31(1):207-32.

Henggeler 1991 \{published data only\} Henggeler SW, Borduin CM, Melton GB, Mann BJ. Effects of multisystemic therapy on drug use and abuse in serious juvenile offenders: A progress report from two outcome studies. Family Dynamics of Addiction Quarterly 1991;1(3): $40-51$.

Henggeler 2002 \{published data only\} Henggeler SW, Clingempeel WG, Brondino MJ, Pickrel SG. Four-year follow-up of multisystemic therapy with substance-abusing and substance-dependent juvenile offenders. Journal of the American Academy of Child \& Adolescent Psychiatry 41;7:868-74.

Messina 2000 \{published data only\} Messina N, Wish E, Nemes S. Predictors of treatment outcomes in men and women admitted to a therapeutic community. American Journal of Drug \& Alcohol Abuse 2000;26(2):207-27.

Nemes 1998 \{published data only\} Nemes S, Wish E, Messina N. The District of Columbia Treatment Initiative (DCI) final report. College Park, MD: University of Maryland, National Evaluation Data and Technical Assistance Center (NEDTAC), 1998.

Nemes 1999 \{published data only\} Nemes S, Wish ED, Messina N. Comparing the impact of standard and abbreviated treatment in a therapeutic community Findings from the District of Columbia 
treatment initiative experiment. Journal of Substance Abuse Treatment 1999;17(4):339-47.

\section{Stevens 1998 \{published data only\}}

Stevens SJ, Patton T. Residential treatment for drug addicted women and their children: Effective treatment strategies. Drugs \& Society 1998;13(1-2):235-49.

\section{Additional references}

\section{Anglin 1990}

Anglin MD, Hser YI. Treatment of drug abuse. In: M. Tonry, J.Q. Wilson editor(s). Drugs and Crime. Chicago, IL: University of Chicago Press, 1990.

\section{Anglin 1992}

Anglin MD, Maughn TH. Overturning myths about coerced drug treatment. California Psychologist 1992;14: $20-2$.

\section{Australian Gov 2004}

Australian Government. The National Drug Strategy. Australia’s Integrated Framework 2004-2009. http:// www.nationaldrugstrategy.gov.au/. Australian Government: Department of Health and Ageing, 2004.

\section{Baldwin 1991}

Baldwin S, Heather N, Lawson A, Robertson I, Mooney J, Braggins F. Comparison of effectiveness: Behavioural and talk-based courses for court-referred young offenders. Behavioural Psychotherapy 1991;19:157-92.

\section{Brooke 1996}

Brooke D, Taylor C, Gunn J, Maden A. Point Prevalence of Mental Disorder in Unconvicted Male Prisoners in England and Wales. British Medical Journal 1996;313:1524-7.

\section{Chanhatasilpa 2000}

Chanhatasilpa C, Mackenzie DL, Hickman LJ. The effectiveness of community-based programs for chemically dependent offenders: A review and assessment of the research. Journal of Substance Abuse Treatment 2000;19: 383-93.

\section{CRD 2001}

Centre for Reviews and Dissemination. CRD Report Number 4 (2nd edition). Undertaking systematic reviews of research effectiveness: CRD's guidance for carrying out or commissioning reviews. 2001.

\section{Day 1993}

Day A, Maddicks R, McMahom D. Brief Psychotherapy in two-plus-one sessions with a young offender population. Behavioural and Cognitive Psychotherapy 1993;21:357-69.

\section{DOH 2001}

Department of Health. A Research and Development Strategy for Public Health. London: Department of Health, 2001.

\section{Drummond 1997}

Drummond M, O’Brien B, Stoddart G, Torrance G. Methods for the economic evaluation of health care programmes. 2nd Edition. Oxford University Press, 1997.

\section{Egg 2000}

Egg R, Pearson FS, Cleland CM, Lipton DS. Evaluations of correctional treatment programs in Germany: A review and meta-analysis. Substance Use and Misuse 2000;35(12-14):

1967-2009.

\section{EMCDDA 2002}

European Monitoring Centre for Drugs and Drug Addiction. Strategies and coordination in the field of drugs in the European Union. A descriptive review. http:// www.emcdda.org/. European Monitoring Centre for Drugs and Drug Addiction, 2002.

\section{Falkin 1992}

Falkin GP, Wexler HK, Lipton DS. Drug treatment in state prisons. In: D.R. Gerstein, H.J. Harwood editor(s). Treating drug problems. Volume II. New York, NY: Narcotic and Drug Research, Inc, 1992:89-132.

\section{Gunn 1991}

Gunn J, Maden A, Swinton M. Treatment Needs of Prisoners with Psychiatric Disorders. British Medical Journal 1991;303:338-41.

\section{Higgins 2005}

Higgins JPT, Green S, editors. Cochrane Handbook for Systematic Reviews of Interventions 4.2.5 [updated May 2005]. The Cochrane Library, Issue 3. Chichester, UK:: John Wiley \& Sons, Ltd.Cochrane Collaboration, 2005.

\section{Holloway 2005}

Holloway K, Bennett T, Farrington D. The effectiveness of criminal justice and treatment programmes in reducing drug-related crime: a systematic review. Home Office Online Report 26/05 http://www.homeoffice.gov.uk/rds crime: a systematic review Home Office Online Report 26/ 052005.

\section{Home Office 1999}

Home Office. Tackling drugs to build a better Britain. London: Home Office, 1999.

\section{Inciardi 1997}

Inciardi JA, Martin SS, Butzin CA, Hooper RM, Harrison LD. An effective model of prison-based treatment for druginvolved offenders. Journal of Drug Issues 1997;27(2): 261-78.

Little 1991

Little GL, Robinson KD, Burnette KD. Treating drug offenders with Moral Reconation Therapy: a three-year recidivism report. Psychological Reports 1991;69:1151-4.

Lo 2000

Lo CC, Stephens RC. Drugs and prisoners: Treatment needs on entering prison. American Journal of Drug and Alcohol Abuse 2000;26:229-45.

\section{Marsch 1998}

Marsch LA. The efficacy of methadone maintenance interventions in reducing illicit opiate use, HIV risk behaviours and criminality: A meta-analysis. Addiction 1998;93(4):515-32.

\section{Mason 1997}

Mason D, Birmingham L, Grubin D. Substance use in remand prisoners: a consecutive case study. British Medical Journal 1997;315:18-21. 


\section{McMurran 2000}

McMurran M. Expert Paper: Dual Diagnosis of Mental Disorder and Substance Misuse. NHS National Programme on Forensic Mental Health Research and Development, 2000.

\section{Minozzi 2006}

Minozzi S, Amato L, Vecchi S, Davoli M, Kirchmayer $\mathrm{U}$, Verster A. Oral naltrexone maintenance treatment for opioid dependence. Cochrane Database of Systematic Reviews 2006, Issue 3. [DOI: 10.1002/14651858]

\section{Mitchell 2000}

Mitchell O, Mackenzie DL, Wilson DB. Systematic Review Title: Prison-based drug treatment programs. http://www.aic.gov.au/campbellcj/reviews/titles.html. University of Maryland, USA: The International Campbell Collaboration, 2000.

\section{Nat Probation 2004}

National Probation Service Briefing. Criminal Justice Act 2003. Sentence implementation programme- briefing update October 2004. http:/ /www.probation.homeoffice.gov.uk/files/pdf/NPD_ Briefing_18.pdf. National Probation Directorate Communications, 2004; Vol. October, issue 18.

\section{NHS/HMP 1999}

NHS Executive/HM Prison Service. The Future Organisation of Prison Health Care. London: Department of Health, 1999.

\section{Pearson 1999}

Pearson FS, Lipton DS. A meta-analytic review of the effectiveness of corrections-based treatments for drug abuse. The Prison Journal 1999;79(4):384-410.

\section{Perry submitted}

Perry A, Neale Z, Godfrey C, McDougall C, Lunn J, Glanville J, et al.The effectiveness of interventions for drugusing offenders in the courts, secure establishments and the community. London: Department of Health Report (submitted).

\section{Peters 1992}

Peters DH, May R. Drug treatment services in jails. In: C.J. Leukefeld, F.M. Tims editor(s). Drug abuse treatment in prisons and jails. Rockville, MD: NIDA (Research Monograph 118), 1992.

\section{Platt 1980}

Platt JJ, Perry GM, Metzeger DS. The evaluation of the heroin addiction treatment program within correctional environment. In: R.R. Ross, P. Gendreau editor(s). Effective Correctional Treatment. Toronto: Butterworth, 1980.

\section{Prendergast 2002}

Prendergast ML, Podus D, Chang E, Urada D. The effectiveness of drug abuse treatment: A meta-analysis of comparison group studies. Drug and Alcohol Dependence 2002;67:53-72.

\section{Schoenwald 1996}

Schoenwald SK, Ward DM, Henggeler SW, Pickrel SG, Patel H. Multisystemic therapy treatment of substance abusing or dependent adolescent offenders: Costs of reducing incarceration, inpatient, and residential placement. Journal of Child and Family Studies 1996;5(4):431-44.

\section{Shaw 2000}

Shaw J. An Expert Paper: Prison Health Care London. NHS National Programme on Forensic Mental Health Research and Development, 2000.

\section{Shewan 1996}

Shewan D, MacPherson A, Reid MM, Davies JB. The impact of the Edinburgh Prison (Scotland) Drug Reduction Programme. Legal and Criminological Psychology 1996;1: 83-94.

\section{Taxman 2002}

Taxman F. Systematic review title: Outpatient treatment for drug-involved offenders. http://www.aic.gov.au/campbellcj/ reviews/titles.html. University of Maryland, USA: The International Campbell Collaboration, 2002.

* Indicates the major publication for the study 


\section{CHARACTERISTICS OF STUDIES}

\section{Characteristics of included studies [ordered by study ID]}

\section{Britt 1992 a}

\begin{tabular}{|c|c|c|}
\hline Methods & \multicolumn{2}{|l|}{$\begin{array}{l}\text { Allocation: random assignment } \\
\text { Randomisation method: inadequate } \\
\text { Similar on drug use: yes } \\
\text { Similar on criminal activity: yes } \\
\text { Blinding methodology: unknown } \\
\text { Loss to follow-up: partial }\end{array}$} \\
\hline Participants & \multicolumn{2}{|l|}{$\begin{array}{l}619 \text { adults } \\
\text { Age not reported } \\
\text { Gender not reported } \\
\text { Ethnicity not reported } \\
\text { Drug use not reported } \\
\text { Alcohol use not reported } \\
\text { Psychiatric history not reported } \\
\text { Eligibility criteria: released pre-trial defendants }\end{array}$} \\
\hline Interventions & \multicolumn{2}{|c|}{$\begin{array}{l}\text { Court-based monitoring intervention vs. treatment as usual. } \\
\text { (I) pre-trial release } \& \text { drugs testing } \& \text { sanctions ( } \mathrm{n} \text { assigned not reported) vs. (C) routine pre-trial release } \\
\text { (n assigned not reported). Intensity and duration not reported for either group }\end{array}$} \\
\hline Outcomes & \multicolumn{2}{|c|}{ Arrest for any offence (official records) during the last 7-9 months at 7-9 months follow-up } \\
\hline \multicolumn{3}{|l|}{ Notes } \\
\hline \multicolumn{3}{|l|}{ Risk of bias } \\
\hline Item & Authors' judgement & Description \\
\hline Allocation concealment? & No & $\mathrm{C}$ - Inadequate \\
\hline
\end{tabular}

Britt 1992 b

\begin{tabular}{|c|c|}
\hline Methods & $\begin{array}{l}\text { Allocation: random assignment } \\
\text { Randomisation method: inadequate } \\
\text { Similar on drug use: yes } \\
\text { Similar on criminal activity: yes } \\
\text { Blinding methodology: unknown } \\
\text { Loss to follow-up: partial }\end{array}$ \\
\hline Participants & $\begin{array}{l}264 \text { adults } \\
\text { Age not reported } \\
\text { Gender not reported } \\
\text { Ethnicity not reported }\end{array}$ \\
\hline
\end{tabular}


Britt 1992 b (Continued)

Drug use not reported

Alcohol use not reported

Psychiatric history not reported

Eligibility criteria: released pre-trial defendants

\begin{tabular}{|c|c|c|}
\hline Interventions & \multicolumn{2}{|c|}{$\begin{array}{l}\text { Court-based monitoring intervention vs. treatment as usual. } \\
\text { (I) pre-trial release } \& \text { drugs testing } \& \text { sanctions ( } \mathrm{n} \text { assigned not reported) vs. (C) routine pre-trial release } \\
\text { (n assigned not reported). Intensity and duration not reported for either group }\end{array}$} \\
\hline Outcomes & \multicolumn{2}{|c|}{ Arrest for any offence (official records) during the last 7-9 months at 7-9 months follow-up } \\
\hline \multicolumn{3}{|l|}{ Notes } \\
\hline \multicolumn{3}{|l|}{ Risk of bias } \\
\hline Item & Authors' judgement & Description \\
\hline Allocation concealment? & No & $\mathrm{C}$ - Inadequate \\
\hline
\end{tabular}

Britt 1992 c

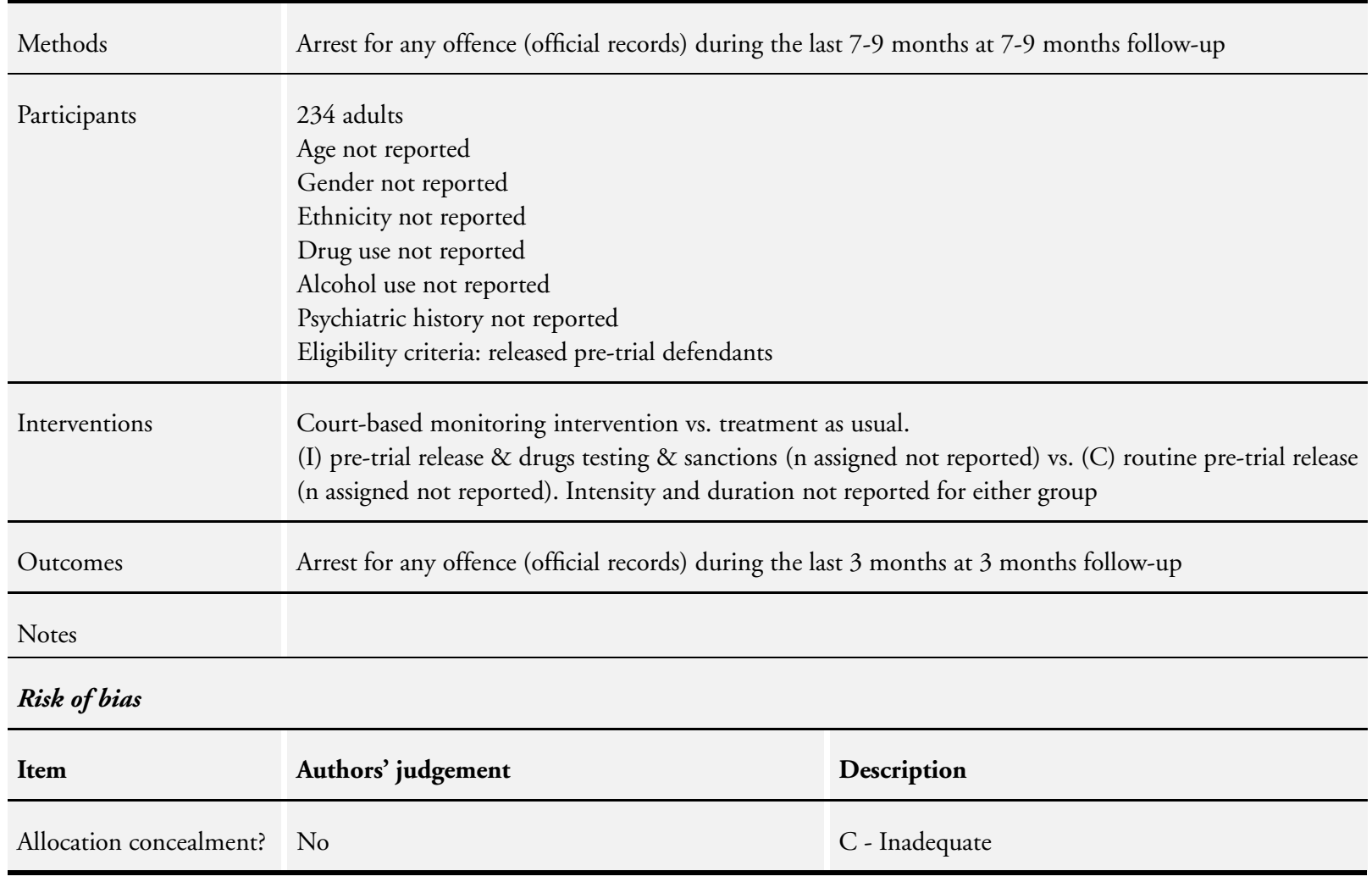


Britt 1992 d

\begin{tabular}{|c|c|c|}
\hline Methods & \multicolumn{2}{|l|}{$\begin{array}{l}\text { Allocation: random assignment } \\
\text { Randomisation method: inadequate } \\
\text { Similar on drug use: no } \\
\text { Similar on criminal activity: yes } \\
\text { Blinding methodology: unknown } \\
\text { Loss to follow-up: inadequate }\end{array}$} \\
\hline Participants & \multicolumn{2}{|l|}{$\begin{array}{l}890 \text { adults } \\
\text { Age not reported } \\
\text { Gender not reported } \\
\text { Ethnicity not reported } \\
\text { Drug use not reported } \\
\text { Alcohol use not reported } \\
\text { Psychiatric history not reported } \\
\text { Eligibility criteria: released pre-trial defendants }\end{array}$} \\
\hline Interventions & \multicolumn{2}{|c|}{$\begin{array}{l}\text { Court-based monitoring intervention vs. treatment as usual. } \\
\text { (I) pre-trial release \& drugs testing \& sanctions (n assigned not reported) vs. (C) routine pre-trial release } \\
\text { (n assigned not reported). Intensity and duration not reported for either group }\end{array}$} \\
\hline Outcomes & \multicolumn{2}{|c|}{ Arrest for any offence (official records) during the last 3 months at 3 months follow-up } \\
\hline Notes & & \\
\hline \multicolumn{3}{|l|}{ Risk of bias } \\
\hline Item & Authors' judgement & Description \\
\hline Allocation concealment? & No & $\mathrm{C}$ - Inadequate \\
\hline
\end{tabular}

\section{Cornish 1997}

Methods

Allocation:

random assignment

Randomisation method: unclear

Similar on drug use: yes

Similar on criminal activity: unknown

Blinding methodology: unknown

Loss to follow-up: inadequate

\begin{tabular}{ll}
\hline Participants & 51 adults \\
\hline Interventions & Community-based naltrexone program \& routine parole/probation vs. routie parole/probation \\
\hline Outcomes & Incarceration for technical violation (official records) during the last 6 months at 6 months follow-up \\
\hline
\end{tabular}

Notes

Interventions for drug-using offenders in the courts, secure establishments and the community. (Review) 


\section{Cornish 1997 (Continued)}

\section{Risk of bias}

\begin{tabular}{|c|c|c|}
\hline Item & Authors' judgement & Description \\
\hline Allocation concealment? & Unclear & B - Unclear \\
\hline
\end{tabular}

Cosden 2003

Methods

Allocation: random assignment

Randomisation method: adequate

Similar on drug use: unknown

Similar on criminal activity: yes

Blinding methodology: unknown

Loss to follow-up: partial

235 adults
Age not reported
$50.2 \%$ male
70.6\% European American
Drug use not reported
Alcohol use not reported
100\% psychiatric history
Eligibility criteria: adults charged with a felony or misdemeanour who were booked into county jail, had at
least one prior booking and were diagnosed with a serious and pervasive mental illness and were residents
of the county involved. Pre-plea participants were required to have no previous offenses involving violence;
post-adjudication participants with prior violence were eligible if they were considered to no longer pose
a threat
a threat

Interventions Court-based sentencing and case management intervention vs. treatment as usual.

(I) mental health treatment court (MHTC) \& assertive community treatment (ACT) case management $(\mathrm{n}=137)$ vs. (C) treatment as usual $(\mathrm{n}=98)$. The (I) group received weekly or bi-weekly court supervision and frequent contact with case managers, duration 18 months, followed by treatment as usual if required. The $(\mathrm{C})$ group received traditional court proceedings and county mental health services as usual for at least 18 months which was less intensive than (I)

Outcomes

Drug use (Addiction Severity Index, self-report) during the last 1 month at 12 months follow-up

Notes

Risk of bias

\begin{tabular}{lll}
\hline Item & Author' judgement & Description \\
\hline Allocation concealment? & Unclear & B - Unclear \\
\hline
\end{tabular}




\begin{tabular}{|c|c|}
\hline Methods & $\begin{array}{l}\text { Allocation: random assignment } \\
\text { Randomisation method: adequate } \\
\text { Similar on drug use: yes } \\
\text { Similar on criminal activity: yes } \\
\text { Blinding methodology: unknown } \\
\text { Loss to follow-up: adequate }\end{array}$ \\
\hline Participants & $\begin{array}{l}639 \text { adults } \\
\text { Mean age } 29.8 \text { (s.d. not reported) } \\
77.9 \% \text { male } \\
54.0 \% \text { white } \\
100 \% \text { drug-using } \\
\text { Alcohol use not reported } \\
\text { Psychiatric history not reported } \\
\text { Eligibility criteria: offenders sentenced to probation for a felony drug offence of drug use or possession and } \\
\text { those with similar needs for treatment. Offenders were ineligible if they required inpatient counselling, } \\
\text { the community punishment program, specialized caseload supervision or a different type of probation }\end{array}$ \\
\hline Interventions & $\begin{array}{l}\text { Court-based sentencing intervention vs. treatment as usual. } \\
\text { (I) post adjudication drug court ( } \mathrm{n}=177) \text { vs. (C) routine probation with varying frequencies of urine } \\
\text { testing }(\mathrm{n}=462) \text {. The (I) group received drug education classes, process groups, case management and } \\
\text { aftercare. The intervention consisted of three phases of treatment that last } 2 \text { months each, followed by up } \\
\text { to } 9 \text { months of aftercare. The first phase involved weekly classes, weekly process groups, weekly twelve-step } \\
\text { meetings, weekly meetings with probation officers and random urine testing. The second phase involved } \\
\text { weekly process groups, weekly twelve-step meetings, other terms of probation and random urine tests. } \\
\text { The third phase involved weekly process groups and at least weekly twelve-step meetings. The aftercare } \\
\text { involved weekly process groups. The drug court lasted between } 6 \text { and } 12 \text { months with monthly progress } \\
\text { reports with rewards and sanctions. The (C) group received routine probation with varying frequencies of } \\
\text { urine testing (none, random once per month, or scheduled for twice a week) and visits from the probation } \\
\text { officer as determined by the risk/need assessment; duration not reported }\end{array}$ \\
\hline
\end{tabular}

Outcomes

Arrest for any offence (official records) during the last 6 months at 6 months follow-up Arrest for any offence (official records) during the last 12 months at 12 months follow-up Arrest for a drug offence (official records) during the last 12 months at 12 months follow-up

Notes

Risk of bias

\begin{tabular}{|c|c|c|}
\hline Item & Authors' judgement & Description \\
\hline Allocation concealment? & Unclear & B - Unclear \\
\hline
\end{tabular}




\begin{tabular}{|l|l} 
Methods & Allocation: random assignment \\
Randomisation method: adequate \\
Similar on drug use: yes \\
Similar on criminal activity: yes \\
Blinding methodology: adequate \\
Loss to follow-up: adequate
\end{tabular}

Participants adults \& young offenders
Mean age 27 (s.d. 6)
$100 \%$ male
Ethnicity not reported
$100 \%$ drug-using
Alcohol use not reported
Psychiatric history not reported
Eligibility criteria: prisoners with a heroin problem, as confirmed by a detailed interview, who have at
least 4 months remaining on their prison sentence at time of interview

\begin{tabular}{l} 
Secure establishment-based pharmacological intervention vs. waiting-list control. \\
$\begin{array}{l}\text { (I) methadone maintenance }(\mathrm{n}=191) \text { vs. waiting-list control }(\mathrm{n}=191) \text {. (I) participants were given } 30 \mathrm{mg} \\
\text { of methadone each day, increasing by } 5 \mathrm{mg} \text { every } 3 \text { days until } 60 \mathrm{mg} \text { was achieved; duration in treatment } \\
\text { varied. Duration of waiting-list was } 4 \text { months }\end{array}$ \\
\hline
\end{tabular}

Outcomes

Drug testing (hair analysis; official records) during the last 2 months at 2 months follow-up Drug testing (hair analysis; official records) during the last 3 months at 3 months follow-up

Drug testing (hair analysis; official records) during the last 4 months at 4 months follow-up

Notes

Risk of bias

\begin{tabular}{lll}
\hline Item & Author' judgement & Description \\
\hline Allocation concealment? & Yes & A - Adequate \\
\hline
\end{tabular}

Gottfredson 2002

\begin{tabular}{l|l}
\hline Methods & $\begin{array}{l}\text { Allocation: random assignment } \\
\text { Randomisation method: unclear } \\
\text { Similar on drug use: unknown } \\
\text { Similar on criminal activity: yes } \\
\text { Blinding methodology: unknown } \\
\text { Loss to follow-up: partial }\end{array}$ \\
\hline Participants & $\begin{array}{l}235 \text { adults } \\
\text { Mean age 34.9 (s.d. 7.6) }\end{array}$ \\
\hline $\begin{array}{l}74.1 \% \text { male } \\
89.4 \% \text { African American } \\
100 \% \text { drug-using }\end{array}$ \\
\hline $\begin{array}{l}\text { Interventions for drug-using offenders in the courts, secure establishments and the community. (Review) } \\
\text { Copyright } \odot 2008 \text { The Cochrane Collaboration. Published by John Wiley \& Sons, Ltd. }\end{array}$
\end{tabular}


Gottfredson 2002 (Continued)

Alcohol use not reported

Psychiatric history not reported

Eligibility criteria: non-violent drug-involved adult offenders

Interventions Court-based sentencing intervention vs. treatment as usual.

(I) drug court ( $\mathrm{n}=139)$ vs. (C) routine parole/probation ( $\mathrm{n}=96)$. Drug court involved intensive supervision including 3 contacts per week with the probation officer, 2 home visits per month, montlhy verification of employment status, bi-weekly urine testing, weekly court hearings. Drug court also involved treatment for example outpatient, methadone maintenance, inpatient or transitional housing; intensity varied according to modality. Treatment was also available to the $(\mathrm{C})$ group. Duration of drug court up to 24 months; duration and intensity of routine parole/probation not reported

Outcomes $\quad$ Arrest for any offence (official records) during the last 12 months at 12 months follow-up Conviction for any offence (official records) during the last 12 months at 12 months follow-up Drug charge (official records) during the last 12 months at 12 months follow-up

Arrest for any offence (official records) during the last 24 months at 24 months follow-up

Conviction for any offence (official records) during the last 24 months at 24 months follow-up

Drug charge (official records) during the last 24 months at 24 months follow-up

Notes Data also from: Gottfredson 2003

\section{Risk of bias}

\begin{tabular}{l|ll}
\hline Item & Authors' judgement & Description \\
\hline Allocation concealment? & Unclear & B - Unclear \\
\hline
\end{tabular}

Haapanen 2002

\begin{tabular}{l|l}
\hline Methods & $\begin{array}{l}\text { Allocation: random assignment } \\
\text { Randomisation method: Adequate } \\
\text { Similar on drug use: yes } \\
\text { Similar on criminal activity: yes } \\
\text { Blinding methodology: unknown } \\
\text { Loss to follow-up: adequate }\end{array}$ \\
\hline Participants & 1958 adults, young offenders \& juveniles \\
\hline Interventions & $\begin{array}{l}\text { Community-based routine parole \& drugs testing (once/twice) vs. routine parole \& drugs testing } \\
\text { (monthly) vs. routine parole \& drugs testing (fortnightly) vs. routine parole \& drugs testing (weekly) vs. } \\
\text { routine parole }\end{array}$ \\
\hline Outcomes & $\begin{array}{l}\text { Arrest for any offence (official records) during the last } 24 \text { months at } 24 \text { months follow-up } \\
\text { Arrest for any offence (official records) during the last } 42 \text { months at } 42 \text { months follow-up }\end{array}$ \\
\hline Notes & I1, I2, I3, I4, C/I5? \\
\hline
\end{tabular}

\section{Risk of bias}

Interventions for drug-using offenders in the courts, secure establishments and the community. (Review) 
Haapanen 2002 (Continued)

\begin{tabular}{l|ll}
\hline Item & Authors' judgement & Description \\
\hline Allocation concealment? & Yes & A - Adequate \\
\hline
\end{tabular}

Hanlon 1999

\begin{tabular}{|c|c|c|}
\hline Methods & \multicolumn{2}{|l|}{$\begin{array}{l}\text { Allocation: random assignment } \\
\text { Randomisation method: inadequate } \\
\text { Similar on drug use: unknown } \\
\text { Similar on criminal activity: unknown } \\
\text { Blinding methodology: unknown } \\
\text { Loss to follow-up: partial }\end{array}$} \\
\hline Participants & \multicolumn{2}{|l|}{536 adults } \\
\hline Interventions & \multicolumn{2}{|c|}{$\begin{array}{l}\text { Community-based social support program vs. weekly drugs testing } \& \text { routine parole } \\
\text { Community-based social support program vs. routine parole } \\
\text { Community-based weekly drugs testing } \& \text { routine parole vs. routine parole }\end{array}$} \\
\hline Outcomes & \multicolumn{2}{|c|}{$\begin{array}{l}\text { Arrest (official records) during the last } 12 \text { months at } 12 \text { months follow-up } \\
\text { Incarceration (official records) during the last } 12 \text { months at } 12 \text { months follow-up }\end{array}$} \\
\hline Notes & \multicolumn{2}{|l|}{$\begin{array}{l}\text { I vs } \mathrm{I} 1 \\
\text { I vs } \mathrm{C} \\
\text { I1 vs } \mathrm{C}\end{array}$} \\
\hline \multicolumn{3}{|l|}{ Risk of bias } \\
\hline Item & Authors' judgement & Description \\
\hline Allocation concealment? & No & $\mathrm{C}$ - Inadequate \\
\hline
\end{tabular}

\section{Henggeler 1999}

\begin{tabular}{ll}
\hline Methods & Allocation: random assignment \\
& Randomisation method: unclear \\
& Similar on drug use: no \\
& Similar on criminal activity: yes \\
& Blinding methodology: unknown \\
& Loss to follow-up: adequate \\
\hline Participants & 118 juveniles \\
\hline
\end{tabular}

Interventions

Community-based multi-systemic therapy vs. community services as usual 


\section{Henggeler 1999 (Continued)}

\begin{tabular}{ll} 
Outcomes & Drug use (not alcohol or marijuana; self-report) at post treatment follow-up \\
& Drug use (not alcohol or marijuana; self-report) at 6 months post treatment follow-up \\
& Delinquency Scale (self-report) at post treatment follow-up \\
& Delinquency Scale (self-report) at 6 months post treatment follow-up \\
\hline Notes &
\end{tabular}

Risk of bias

\begin{tabular}{lll}
\hline Item & Authors' judgement & Description \\
\hline Allocation concealment? & Unclear & B - Unclear \\
\hline
\end{tabular}

Martin 1993

Methods

Allocation: random assignment

Randomisation method: unclear

Similar on drug use: unknown

Similar on criminal activity: no

Blinding methodology: unknown

Loss to follow-up: partial

Participants 365 adults

Interventions Communit-based ACT case management vs. routine parole

Outcomes $\quad$ Incarceration (official records) during the last 6 months at 6 months follow-up

Drug use (self-report) during the last 6 months at 6 months follow-up

Notes

\section{Risk of bias}

\begin{tabular}{|c|c|c|}
\hline Item & Authors' judgement & Description \\
\hline Allocation concealment? & Unclear & B - Unclear \\
\hline
\end{tabular}


Nielsen 1996

\begin{tabular}{|l|l|} 
Methods & Allocation: random assignment \\
Randomisation method: unclear \\
\hline Similar on drug use: no \\
\hline Similar on criminal activity: no \\
\hline Blinding methodology: unknown \\
Loss to follow-up: partial
\end{tabular}

Participants adults \& young offenders
Age not reported
$79.1 \%$ male
$28.9 \%$ white
$100 \%$ drug-using
Alcohol use not reported
Psychiatric history not reported
Eligibility criteria: offenders with a history of drug use who were eligible for work release or parole and
about to be released from prison

Interventions

Secure establishment-based therapeutic community vs. treatment as usual.

(I) CREST work-release therapeutic community ( $n=248$ ) vs. (C) routine work-release ( $n=441)$. (I) comprised 1 month of orientation followed by 2 months of primary treatment followed by 3 months of work release. The (I) was intensive given the nature of the intervention. Duration of (C) also 6 months, intensity not reported

\begin{tabular}{|c|c|}
\hline Outcomes & $\begin{array}{l}\text { Drug use (self-report) during the last } 6 \text { months at } 6 \text { months follow-up } \\
\text { Drug use (self-report) during the last } 18 \text { months at } 18 \text { months follow-up } \\
\text { Recidivism (arrested and charged) for any offence (self-report) during the last } 6 \text { months at } 6 \text { months } \\
\text { follow-up } \\
\text { Recidivism (arrested and charged) for any offence (self-report) during the last } 18 \text { months at } 18 \text { months } \\
\text { follow-up }\end{array}$ \\
\hline Notes & Farrell (2000) analysed a sub-set of this work, examining female offenders \\
\hline
\end{tabular}

Risk of bias

\begin{tabular}{|c|c|c|}
\hline Item & Authors' judgement & Description \\
\hline Allocation concealment? & Unclear & B - Unclear \\
\hline
\end{tabular}

\section{Petersilia 1992 a}

Methods

Allocation: random assignment

Randomisation method: unclear

Similar on drug use: yes

Similar on criminal activity: yes

Blinding methodology: unknown

Loss to follow-up: unknown

\begin{tabular}{l|l} 
Participants & 173 adults
\end{tabular}


Petersilia 1992 a (Continued)

\begin{tabular}{|c|c|c|}
\hline Interventions & \multicolumn{2}{|c|}{ Community-based intensive supervision vs. routine parole/probation } \\
\hline Outcomes & \multicolumn{2}{|c|}{$\begin{array}{l}\text { Recidivism for any offence (official records) during the last } 12 \text { months at } 12 \text { months follow-up } \\
\text { Arrest for any offence (official records) during the last } 12 \text { months at } 12 \text { months follow-up } \\
\text { Arrest for a drug offence (official records) during the last } 12 \text { months at } 12 \text { months follow-up } \\
\text { Conviction (official records) during the last } 12 \text { months at } 12 \text { months follow-up } \\
\text { Incarceration for a new offence (official records) during the last } 12 \text { months at } 12 \text { months follow-up }\end{array}$} \\
\hline \multicolumn{3}{|l|}{ Notes } \\
\hline \multicolumn{3}{|l|}{ Risk of bias } \\
\hline Item & Authors' judgement & Description \\
\hline Allocation concealment? & Unclear & B - Unclear \\
\hline
\end{tabular}

Petersilia 1992 b

\begin{tabular}{|c|c|c|}
\hline Methods & \multicolumn{2}{|l|}{$\begin{array}{l}\text { Allocation: random assignment } \\
\text { Randomisation method: unclear } \\
\text { Similar on drug use: No } \\
\text { Similar on criminal activity: yes } \\
\text { Blinding methodology: unknown } \\
\text { Loss to follow-up: unknown }\end{array}$} \\
\hline Participants & \multicolumn{2}{|l|}{115 adults } \\
\hline Interventions & \multicolumn{2}{|c|}{ Community-based intensive supervision vs. routine parole/probation } \\
\hline Outcomes & \multicolumn{2}{|c|}{$\begin{array}{l}\text { Recidivism for any offence (official records) during the last } 12 \text { months at } 12 \text { months follow-up } \\
\text { Arrest for any offence (official records) during the last } 12 \text { months at } 12 \text { months follow-up } \\
\text { Arrest for a drug offence (official records) during the last } 12 \text { months at } 12 \text { months follow-up } \\
\text { Conviction (official records) during the last } 12 \text { months at } 12 \text { months follow-up } \\
\text { Incarceration for a new offence (official records) during the last } 12 \text { months at } 12 \text { months follow-up }\end{array}$} \\
\hline \multicolumn{3}{|l|}{ Notes } \\
\hline \multicolumn{3}{|l|}{ Risk of bias } \\
\hline Item & Authors' judgement & Description \\
\hline Allocation concealment? & Unclear & B - Unclear \\
\hline
\end{tabular}


Petersilia 1992 c

\begin{tabular}{|c|c|c|}
\hline Methods & \multicolumn{2}{|l|}{$\begin{array}{l}\text { Allocation: random assignment } \\
\text { Randomisation method: unclear } \\
\text { Similar on drug use: yes } \\
\text { Similar on criminal activity: yes } \\
\text { Blinding methodology: unknown } \\
\text { Loss to follow-up: unknown }\end{array}$} \\
\hline Participants & \multicolumn{2}{|l|}{58 adults } \\
\hline Interventions & \multicolumn{2}{|c|}{ Community-based intensive supervision vs. routine parole/probation } \\
\hline Outcomes & \multicolumn{2}{|c|}{$\begin{array}{l}\text { Recidivism for any offence (official records) during the last } 12 \text { months at } 12 \text { months follow-up } \\
\text { Arrest for any offence (official records) during the last } 12 \text { months at } 12 \text { months follow-up } \\
\text { Arrest for a drug offence (official records) during the last } 12 \text { months at } 12 \text { months follow-up } \\
\text { Conviction (official records) during the last } 12 \text { months at } 12 \text { months follow-up } \\
\text { Incarceration for a new offence (official records) during the last } 12 \text { months at } 12 \text { months follow-up }\end{array}$} \\
\hline \multicolumn{3}{|l|}{ Notes } \\
\hline \multicolumn{3}{|l|}{ Risk of bias } \\
\hline Item & Authors' judgement & Description \\
\hline Allocation concealment? & Unclear & B - Unclear \\
\hline
\end{tabular}

Petersilia 1992 d

\begin{tabular}{|c|c|}
\hline Methods & $\begin{array}{l}\text { Allocation: random assignment } \\
\text { Randomisation method: unclear } \\
\text { Similar on drug use: yes } \\
\text { Similar on criminal activity: No } \\
\text { Blinding methodology: unknown } \\
\text { Loss to follow-up: unknown }\end{array}$ \\
\hline Participants & 53 adults \\
\hline Interventions & Community-based intensive supervision vs. routine parole/probation \\
\hline Outcomes & $\begin{array}{l}\text { Recidivism for any offence (official records) during the last } 12 \text { months at } 12 \text { months follow-up } \\
\text { Arrest for any offence (official records) during the last } 12 \text { months at } 12 \text { months follow-up } \\
\text { Arrest for a drug offence (official records) during the last } 12 \text { months at } 12 \text { months follow-up } \\
\text { Conviction (official records) during the last } 12 \text { months at } 12 \text { months follow-up } \\
\text { Incarceration for a new offence (official records) during the last } 12 \text { months at } 12 \text { months follow-up }\end{array}$ \\
\hline Notes & \\
\hline
\end{tabular}

\section{Risk of bias}


Petersilia 1992 d (Continued)

\begin{tabular}{|c|c|c|}
\hline Item & Authors' judgement & Description \\
\hline Allocation concealment? & Unclear & B - Unclear \\
\hline
\end{tabular}

Petersilia 1992 e

Methods

Allocation: random assignment

Randomisation method: unclear

Similar on drug use: yes

Similar on criminal activity: No

Blinding methodology: unknown

Loss to follow-up: unknown

\begin{tabular}{|c|c|c|}
\hline Participants & \multicolumn{2}{|l|}{50 adults } \\
\hline Interventions & \multicolumn{2}{|c|}{ Community-based intensive supervision $\&$ increased surveillance vs. intensive supervision } \\
\hline Outcomes & \multicolumn{2}{|c|}{$\begin{array}{l}\text { Recidivism for any offence (official records) during the last } 12 \text { months at } 12 \text { months follow-up } \\
\text { Arrest for any offence (official records) during the last } 12 \text { months at } 12 \text { months follow-up } \\
\text { Arrest for a drug offence (official records) during the last } 12 \text { months at } 12 \text { months follow-up } \\
\text { Conviction (official records) during the last } 12 \text { months at } 12 \text { months follow-up } \\
\text { Incarceration for a new offence (official records) during the last } 12 \text { months at } 12 \text { months follow-up }\end{array}$} \\
\hline \multicolumn{3}{|l|}{ Notes } \\
\hline \multicolumn{3}{|l|}{ Risk of bias } \\
\hline Item & Authors' judgement & Description \\
\hline Allocation concealment? & Unclear & B - Unclear \\
\hline
\end{tabular}

Petersilia $1992 \mathrm{f}$

\begin{tabular}{l|l}
\hline Methods & $\begin{array}{l}\text { Allocation: random assignment } \\
\text { Randomisation method: unclear } \\
\text { Similar on drug use: yes } \\
\text { Similar on criminal activity: No } \\
\text { Blinding methodology: unknown } \\
\text { Loss to follow-up: unknown }\end{array}$ \\
\hline Participants & 50 adults \\
\hline Interventions & Community-based intensive supervision \& increased surveillance vs. intensive supervision \\
\hline Outcomes & $\begin{array}{l}\text { Recidivism for any offence (official records) during the last } 12 \text { months at } 12 \text { months follow-up } \\
\text { Arrest for any offence (official records) during the last } 12 \text { months at } 12 \text { months follow-up } \\
\text { Arrest for a drug offence (official records) during the last } 12 \text { months at } 12 \text { months follow-up }\end{array}$ \\
\hline $\begin{array}{l}\text { Interventions for drug-using offenders in the courts, secure establishments and the community. (Review) } \\
\text { Copyright } \odot 2008 \text { The Cochrane Collaboration. Published by John Wiley \& Sons, Ltd. }\end{array}$
\end{tabular}

Copyright $\Subset 2008$ The Cochrane Collaboration. Published by John Wiley \& Sons, Ltd. 
Petersilia 1992 f (Continued)

Conviction (official records) during the last 12 months at 12 months follow-up

Incarceration for a new offence (official records) during the last 12 months at 12 months follow-up

Notes

Risk of bias

\begin{tabular}{lll}
\hline Item & Authors' judgement & Description \\
\hline Allocation concealment? & Unclear & B - Unclear \\
\hline
\end{tabular}

Petersilia $1992 \mathrm{~g}$

\begin{tabular}{|c|c|c|}
\hline Methods & \multicolumn{2}{|l|}{$\begin{array}{l}\text { Allocation: random assignment } \\
\text { Randomisation method: unclear } \\
\text { Similar on drug use: yes } \\
\text { Similar on criminal activity: No } \\
\text { Blinding methodology: unknown } \\
\text { Loss to follow-up: unknown }\end{array}$} \\
\hline Participants & \multicolumn{2}{|l|}{50 adults } \\
\hline Interventions & \multicolumn{2}{|c|}{ Community-based intensive supervision $\&$ increased surveillance vs. intensive supervision } \\
\hline Outcomes & \multicolumn{2}{|c|}{$\begin{array}{l}\text { Recidivism for any offence (official records) during the last } 12 \text { months at } 12 \text { months follow-up } \\
\text { Arrest for any offence (official records) during the last } 12 \text { months at } 12 \text { months follow-up } \\
\text { Arrest for a drug offence (official records) during the last } 12 \text { months at } 12 \text { months follow-up } \\
\text { Conviction (official records) during the last } 12 \text { months at } 12 \text { months follow-up } \\
\text { Incarceration for a new offence (official records) during the last } 12 \text { months at } 12 \text { months follow-up }\end{array}$} \\
\hline \multicolumn{3}{|l|}{ Notes } \\
\hline \multicolumn{3}{|l|}{ Risk of bias } \\
\hline Item & Authors' judgement & Description \\
\hline Allocation concealment? & Unclear & B - Unclear \\
\hline
\end{tabular}

Rossman 1999

\begin{tabular}{ll}
\hline Methods & Allocation: random assignment \\
& Randomisation method: unclear. Similar on drug use: No \\
& Similar on criminal activity: No \\
& Blinding methodology: unknown \\
& Loss to follow-up: adequate \\
\hline Participants & 398 adults
\end{tabular}

Interventions for drug-using offenders in the courts, secure establishments and the community. (Review) 
Rossman 1999 (Continued)

\begin{tabular}{|c|c|c|}
\hline Interventions & \multicolumn{2}{|c|}{ Community-based Opportunity to Succeed aftercare vs. routine parole/probation } \\
\hline Outcomes & \multicolumn{2}{|c|}{$\begin{array}{l}\text { Marijuana use (self-report) during the last } 12 \text { months at } 12 \text { months follow-up } \\
\text { Marijuana use (self-report) during the last } 3 \text { months at } 12 \text { months follow-up } \\
\text { Intense marijuana use (self-report) during the last } 12 \text { months at } 12 \text { months follow-up } \\
\text { Hard drug use (self-report) during the last } 12 \text { months at } 12 \text { months follow-up } \\
\text { Hard drug use (self-report) during the last } 3 \text { months at } 12 \text { months follow-up } \\
\text { Intense hard drug use (self-report) during the last } 12 \text { months at } 12 \text { months follow-up } \\
\text { Drug dealing (self-report) during the last } 12 \text { months at } 12 \text { months follow-up }\end{array}$} \\
\hline \multicolumn{3}{|l|}{ Notes } \\
\hline \multicolumn{3}{|l|}{ Risk of bias } \\
\hline Item & Authors' judgement & Description \\
\hline Allocation concealment? & Unclear & B - Unclear \\
\hline
\end{tabular}

Sacks 2004

\begin{tabular}{|c|c|}
\hline Methods & $\begin{array}{l}\text { Allocation: random assignment } \\
\text { Randomisation method: unclear } \\
\text { Similar on drug use: no } \\
\text { Similar on criminal activity: yes } \\
\text { Blinding methodology: unknown } \\
\text { Loss to follow-up: adequate }\end{array}$ \\
\hline Participants & $\begin{array}{l}236 \text { adults } \\
\text { Mean age } 34.3 \text { (s.d. } 8.8) \\
100 \% \text { male } \\
49 \% \text { white } \\
100 \% \text { drug-using } \\
32 \% \text { alcohol-using } \\
100 \% \text { psychiatric history } \\
\text { Eligibility criteria: prisoners who have both a serious mental disorder and a substance use disorder }\end{array}$ \\
\hline Interventions & $\begin{array}{l}\text { Secure establishment-based therapeutic community vs. treatment as usual. } \\
\text { (I) Personal Reflections therapeutic community \& voluntary residential aftercare ( } \mathrm{n}=142 \text { ) vs. (C) mental } \\
\text { health program ( } \mathrm{n}=94) \text {. } \\
\text { (I) therapeutic community included psycho-educational classes, cognitive behavioural methods, medica- } \\
\text { tion and group therapy. Activites were attended } 5 \text { days per week for } 4 \text { to } 5 \text { hours per day with the rest of } \\
\text { the day spent working in the prison; duration } 12 \text { months. (I) aftercare included mental health counselling, } \\
\text { medication and psychiatric services and basic skills. Activites were attended } 3 \text { to } 7 \text { days per week for } 3 \text { to } 5 \\
\text { hours per day; duration } 6 \text { months. (C) program included intensive psychiatric services with medication, } \\
\text { weekly individual therapy and counselling and specialized groups of cognitive behavioural work, anger } \\
\text { management, therapy and education, domestic violence, parenting and weekly drug/alcohol therpay with } \\
\text { a } 72 \text {-hour course on substance abuse education and relapse prevention; duration } 12 \text { months }\end{array}$ \\
\hline
\end{tabular}

Interventions for drug-using offenders in the courts, secure establishments and the community. (Review) 
Sacks 2004 (Continued)

\begin{tabular}{|c|c|c|}
\hline Outcomes & \multicolumn{2}{|c|}{$\begin{array}{l}\text { Criminal activity regarding a new offence (official records) during the last } 12 \text { months at } 12 \text { months follow- } \\
\text { up } \\
\text { Incarceration for a new offence (official records) during the last } 12 \text { months at } 12 \text { months follow-up }\end{array}$} \\
\hline \multicolumn{3}{|l|}{ Notes } \\
\hline \multicolumn{3}{|l|}{ Risk of bias } \\
\hline Item & Authors' judgement & Description \\
\hline Allocation concealment? & Unclear & B - Unclear \\
\hline
\end{tabular}

Wexler 1999

\begin{tabular}{|c|c|}
\hline Methods & $\begin{array}{l}\text { Allocation: random assignment } \\
\text { Randomisation method: unclear } \\
\text { Similar on drug use: yes } \\
\text { Similar on criminal activity: yes } \\
\text { Blinding methodology: unknown } \\
\text { Loss to follow-up: adequate }\end{array}$ \\
\hline Participants & $\begin{array}{l}715 \text { adults } \\
\text { Mean age } 30.9 \text { (s.d. } 7.4 \text { ) } \\
100 \% \text { male } \\
37.8 \% \text { white } \\
100 \% \text { drug-using } \\
\text { Alcohol use not reported } \\
100 \% \text { psychiatric history } \\
\text { Eligibility criteria: offenders with a drug problem who were between } 9 \text { and } 14 \text { months from parole. } \\
\text { Offenders convicted of arson or sexual crimes to minors were not eligible }\end{array}$ \\
\hline
\end{tabular}

Interventions Secure establishment-based therapeutic community vs. no treatment.

(I) Amity TC \& voluntary residential aftercare $(n=x)$ vs. (C) waiting-list control $(n=x)$.

(I) therapeutic community included a 2 to 3 -month orientation phase, a 5 to 6 -month treatment stage, and a 1 to 3-month re-entry phase; total duration 12 months. (I) included need assessment, education, group work, counselling and prison industry jobs. (I) aftercare duration up to 12 months. (C) duration not applicable

Incarceration (official records) during the last 12 months at 12 months follow-up
Incarceration (official records) during the last 24 months at 24 months follow-up
Incarceration (official records) during the last 36 months at 36 months follow-up
Incarceration (official records) during the last 60 months at 60 months follow-up
Drug use (self-report) during the last 60 months at 60 months follow-up

Notes

Risk of bias

Interventions for drug-using offenders in the courts, secure establishments and the community. (Review) 
Wexler 1999 (Continued)

\begin{tabular}{lll}
\hline Item & Authors' judgement & Description \\
\hline Allocation concealment? & Unclear & B - Unclear \\
\hline
\end{tabular}

Characteristics of excluded studies [ordered by study ID]

\begin{tabular}{|c|c|}
\hline Study & Reason for exclusion \\
\hline Anglin 1999 & $\begin{array}{l}\text { The study did not report relevant drug and/or crime outcome measures at both the pre and post intervention } \\
\text { periods }\end{array}$ \\
\hline Dembo 2000 & $\begin{array}{l}\text { The study did not report relevant drug and/or crime outcome measures at both the pre and post intervention } \\
\text { periods. } \\
\text { The follow-up periods reported for the different groups were not equivalent }\end{array}$ \\
\hline Di Nitto 2002 & The follow-up periods reported for the different groups were not equivalent \\
\hline Dugan 1998 & $\begin{array}{l}\text { The study did not report relevant drug and/or crime outcome measures at both the pre and post intervention } \\
\text { periods }\end{array}$ \\
\hline Grohman 2002 & $\begin{array}{l}\text { The study did not report relevant drug and/or crime outcome measures at both the pre and post intervention } \\
\text { periods }\end{array}$ \\
\hline Harrell 2001 & $\begin{array}{l}\text { The study did not report relevant drug and/or crime outcome measures at both the pre and post intervention } \\
\text { periods }\end{array}$ \\
\hline Henggeler 1991 & $\begin{array}{l}\text { The study did not report relevant drug and/or crime outcome measures at both the pre and post intervention } \\
\text { periods }\end{array}$ \\
\hline Henggeler 2002 & $\begin{array}{l}\text { The study did not report relevant drug and/or crime outcome measures at both the pre and post intervention } \\
\text { periods }\end{array}$ \\
\hline Messina 2000 & $\begin{array}{l}\text { The population of the study was not } 100 \% \text { drug using offenders that were specifically referred by the criminal } \\
\text { justice system to the intervention. } \\
\text { The study did not report relevant drug and/or crime outcome measures at both the pre and post intervention } \\
\text { periods }\end{array}$ \\
\hline Nemes 1998 & $\begin{array}{l}\text { The population of the study was not } 100 \% \text { drug using offenders that were specifically referred by the criminal } \\
\text { justice system to the intervention. } \\
\text { The study did not report relevant drug and/or crime outcome measures at both the pre and post intervention } \\
\text { periods }\end{array}$ \\
\hline Nemes 1999 & $\begin{array}{l}\text { The population of the study was not } 100 \% \text { drug using offenders that were specifically referred by the criminal } \\
\text { justice system to the intervention. } \\
\text { The study did not report relevant drug and/or crime outcome measures at both the pre and post intervention }\end{array}$ \\
\hline
\end{tabular}

Interventions for drug-using offenders in the courts, secure establishments and the community. (Review) 
(Continued)

periods

Stevens 1998 The study did not include an appropriate comparison group.

The population of the study was not $100 \%$ drug using offenders that were specifically referred by the criminal justice system to the intervention 
DATA AND ANALYSES

Comparison 1. RCT Courts (Britt studies $3 \& 4$ ): pre-trial release $\&$ drugs testing $\&$ sanctions vs. routine pretrial release.

Outcome or subgroup title

No. of No. of studies participants

Statistical method

Effect size

\begin{tabular}{lllll}
\hline 1 Arrest at 90 days. & 2 & 1124 & Odds Ratio (M-H, Random, 95\% CI) & 1.33 [1.04, 1.70] \\
\hline
\end{tabular}

Comparison 2. RCT Secure Establishments (Sacks \& Wexler): TC \& aftercare vs. mental health program/waitinglist control.

\begin{tabular}{|c|c|c|c|c|}
\hline Outcome or subgroup title & $\begin{array}{l}\text { No. of } \\
\text { studies }\end{array}$ & $\begin{array}{c}\text { No. of } \\
\text { participants }\end{array}$ & Statistical method & Effect size \\
\hline 1 Incarceration at 1 year. & 2 & 854 & Odds Ratio (M-H, Random, 95\% CI) & $0.37[0.16,0.87]$ \\
\hline $\begin{array}{l}2 \text { Incarceration at I year: sensitivity } \\
\text { analysis. }\end{array}$ & 2 & 951 & Odds Ratio (M-H, Random, 95\% CI) & $0.66[0.38,1.15]$ \\
\hline
\end{tabular}

Comparison 3. RCT Community (Petersilia studies 1-4): intensive supervision vs. routine parole/probation.

\begin{tabular}{lccccc} 
Outcome or subgroup title & $\begin{array}{c}\text { No. of } \\
\text { studies }\end{array}$ & $\begin{array}{c}\text { No. of } \\
\text { participants }\end{array}$ & Statistical method & Effect size \\
\hline 1 Recidivism at 1 year. & 4 & 399 & Odds Ratio (M-H, Random, 95\% CI) & $1.98[1.01,3.87]$ \\
2 Arrest at 1 year. & 4 & 399 & Odds Ratio (M-H, Random, 95\% CI) & $1.49[0.88,2.51]$ \\
3 Drug arrest at 1 year. & 4 & 399 & Odds Ratio (M-H, Random, 95\% CI) & $1.10[0.50,2.39]$ \\
4 Conviction at 1 year. & 4 & 399 & Odds Ratio (M-H, Random, 95\% CI) & $0.93[0.55,1.58]$ \\
5 Incarceration at 1 year. & 4 & 399 & Odds Ratio (M-H, Random, 95\% CI) & $0.88[0.50,1.54]$ \\
\hline
\end{tabular}

Comparison 4. RCT Community (Petersilia studies 5-7): int. supervision \& increased surveillance vs. int. supervision.

\begin{tabular}{lccll} 
Outcome or subgroup title & $\begin{array}{c}\text { No. of } \\
\text { studies }\end{array}$ & $\begin{array}{c}\text { No. of } \\
\text { participants }\end{array}$ & Statistical method & Effect size \\
\hline 1 Recidivism at 1 year. & 3 & 150 & Odds Ratio (M-H, Random, 95\% CI) & $2.09[0.86,5.07]$ \\
2 Arrest at 1 year. & 3 & 150 & Odds Ratio (M-H, Random, 95\% CI) & $1.22[0.51,2.88]$ \\
3 Drug arrest at 1 year. & 3 & 150 & Odds Ratio (M-H, Random, 95\% CI) & $1.29[0.35,4.85]$ \\
4 Conviction at 1 year. & 3 & 150 & Odds Ratio (M-H, Random, 95\% CI) & $1.14[0.22,5.91]$ \\
5 Incarceration at 1 year. & 3 & 150 & Odds Ratio (M-H, Random, 95\% CI) & $1.30[0.39,4.30]$ \\
\hline
\end{tabular}

Interventions for drug-using offenders in the courts, secure establishments and the community. (Review) 
Analysis I.I. Comparison I RCT Courts (Britt studies 3 \& 4): pre-trial release \& drugs testing \& sanctions vs. routine pre-trial release., Outcome I Arrest at 90 days..

\begin{tabular}{|c|c|c|c|c|c|}
\hline \multicolumn{6}{|c|}{ Comparison: I RCT Courts (Britt studies $3 \%$ 4): pre-trial release \% drugs testing \% sanctions vs. routine pre-trial release. } \\
\hline \multicolumn{6}{|c|}{ Outcome: I Arrest at 90 days. } \\
\hline Study or subgroup & Testing\%sanctions & Routine release & $\begin{array}{r}\text { Odds Ratio } \\
\text { M- } \\
\text { H,Random,95\% } \\
\mathrm{Cl}\end{array}$ & Weight & $\begin{array}{c}\text { Odds Ratio } \\
\text { M- } \\
\text { H,Random,95\% } \\
\text { Cl } \\
\end{array}$ \\
\hline Britt 1992 c & $30 / 118$ & $28 / 116$ & $\rightarrow$ & $16.9 \%$ & $1.07[0.59,1.94]$ \\
\hline Britt 1992 d & 193/425 & $174 / 465$ & + & $83.1 \%$ & $1.39[1.06,1.82]$ \\
\hline Total $(95 \% \mathrm{CI})$ & 543 & 581 & - & $100.0 \%$ & $1.33[1.04,1.70]$ \\
\hline \multicolumn{6}{|c|}{ Total events: 223 (Testing\%sanctions), 202 (Routine release) } \\
\hline \multicolumn{6}{|c|}{ Heterogeneity: $\operatorname{Tau}^{2}=0.0 ; \mathrm{Chi}^{2}=0.62, \mathrm{df}=1(P=0.43) ; 1^{2}=0.0 \%$} \\
\hline \multicolumn{6}{|c|}{ Test for overall effect: $Z=2.30(P=0.022)$} \\
\hline
\end{tabular}

Analysis 2.1. Comparison 2 RCT Secure Establishments (Sacks \& Wexler): TC \& aftercare vs. mental health program/waiting-list control., Outcome I Incarceration at I year..

Review: Interventions for drug-using offenders in the courts, secure establishments and the community.

Comparison: 2 RCT Secure Establishments (Sacks \% Wexler): TC \% aftercare vs. mental health program/waiting-list control.

Outcome: I Incarceration at I year.

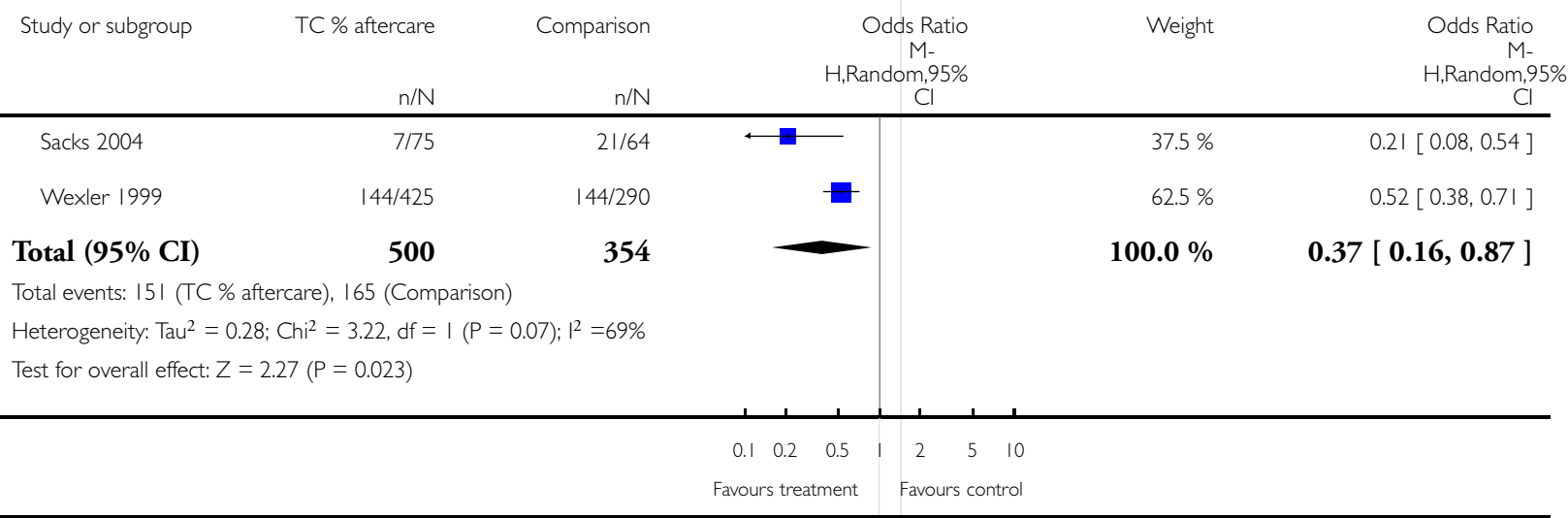

Interventions for drug-using offenders in the courts, secure establishments and the community. (Review)

Copyright () 2008 The Cochrane Collaboration. Published by John Wiley \& Sons, Ltd. 
Analysis 2.2. Comparison 2 RCT Secure Establishments (Sacks \& Wexler): TC \& aftercare vs. mental health program/waiting-list control., Outcome 2 Incarceration at I year: sensitivity analysis..

Review: Interventions for drug-using offenders in the courts, secure establishments and the community.

Comparison: 2 RCT Secure Establishments (Sacks \% Wexler): TC \% aftercare vs. mental health program/waiting-list control.

Outcome: 2 Incarceration at I year: sensitivity analysis.

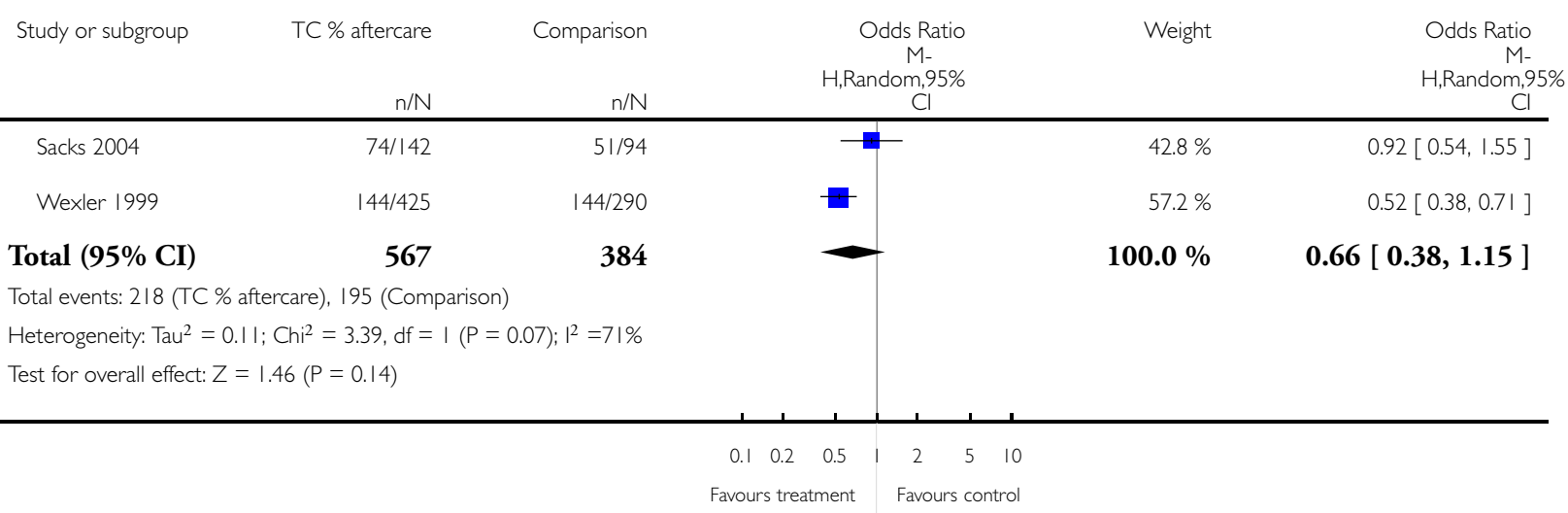


Analysis 3.I. Comparison 3 RCT Community (Petersilia studies I-4): intensive supervision vs. routine parole/probation., Outcome I Recidivism at I year..

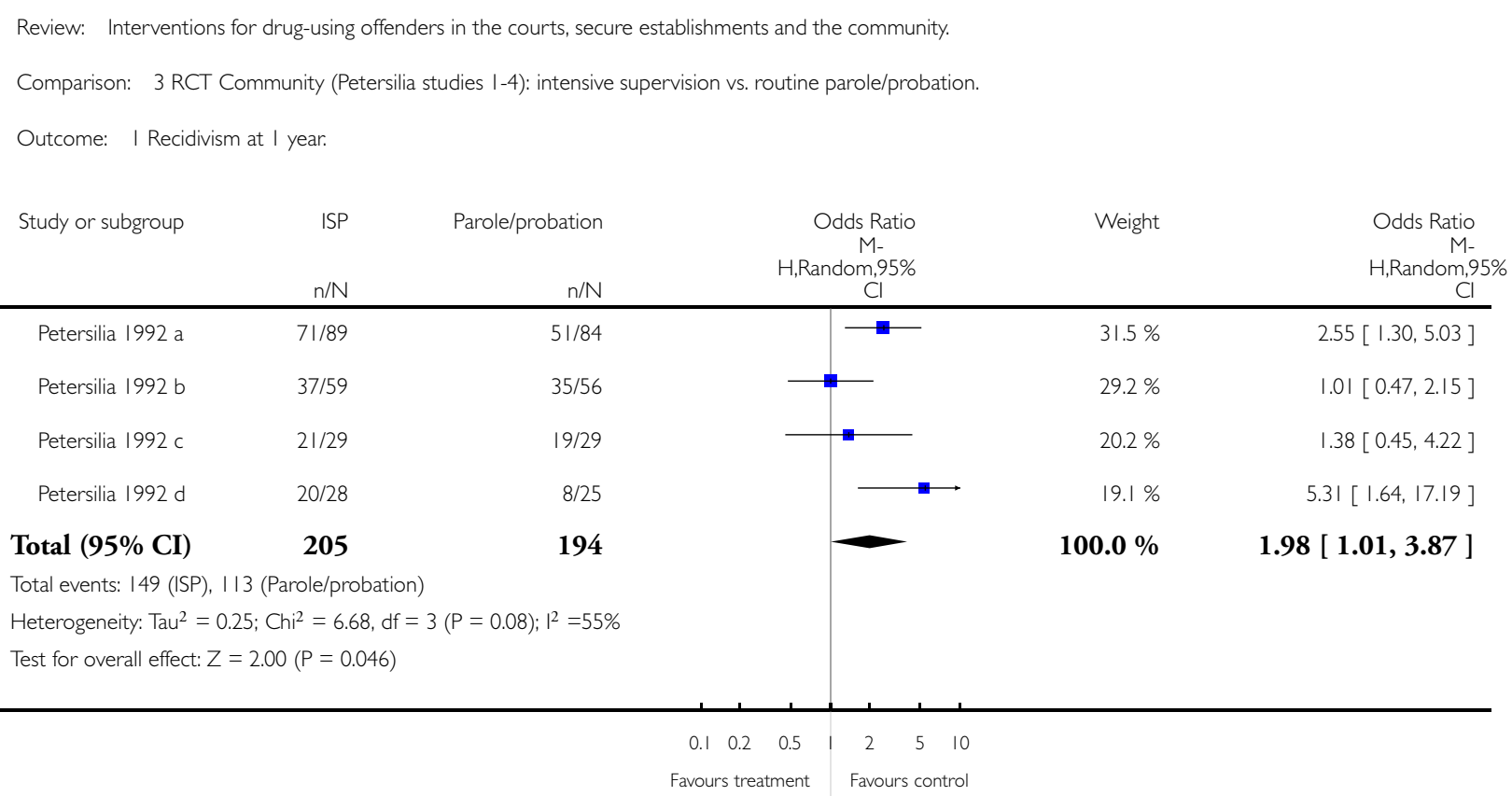


Analysis 3.2. Comparison 3 RCT Community (Petersilia studies I-4): intensive supervision vs. routine parole/probation., Outcome 2 Arrest at I year..

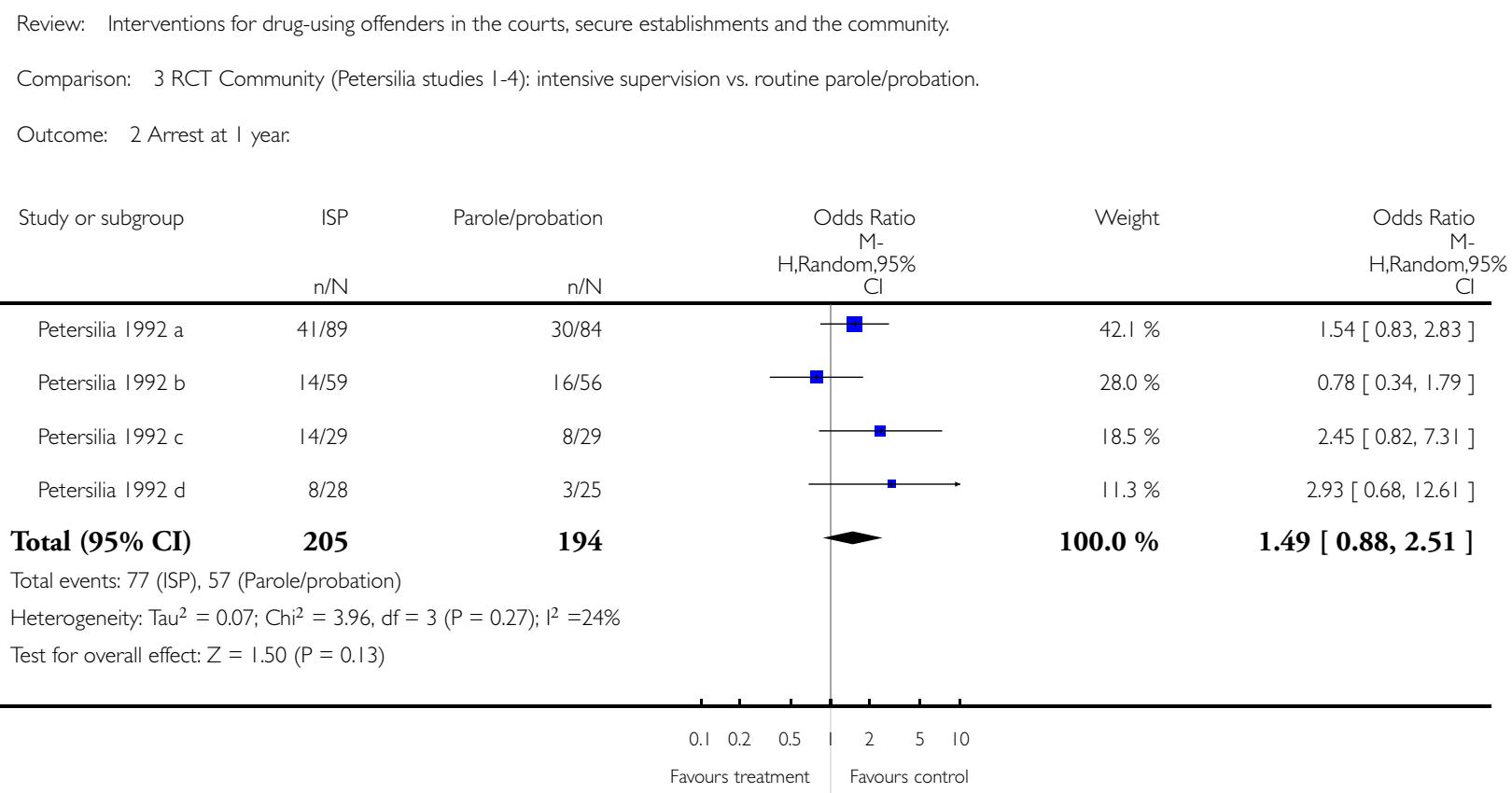


Analysis 3.3. Comparison 3 RCT Community (Petersilia studies I-4): intensive supervision vs. routine parole/probation., Outcome 3 Drug arrest at I year..

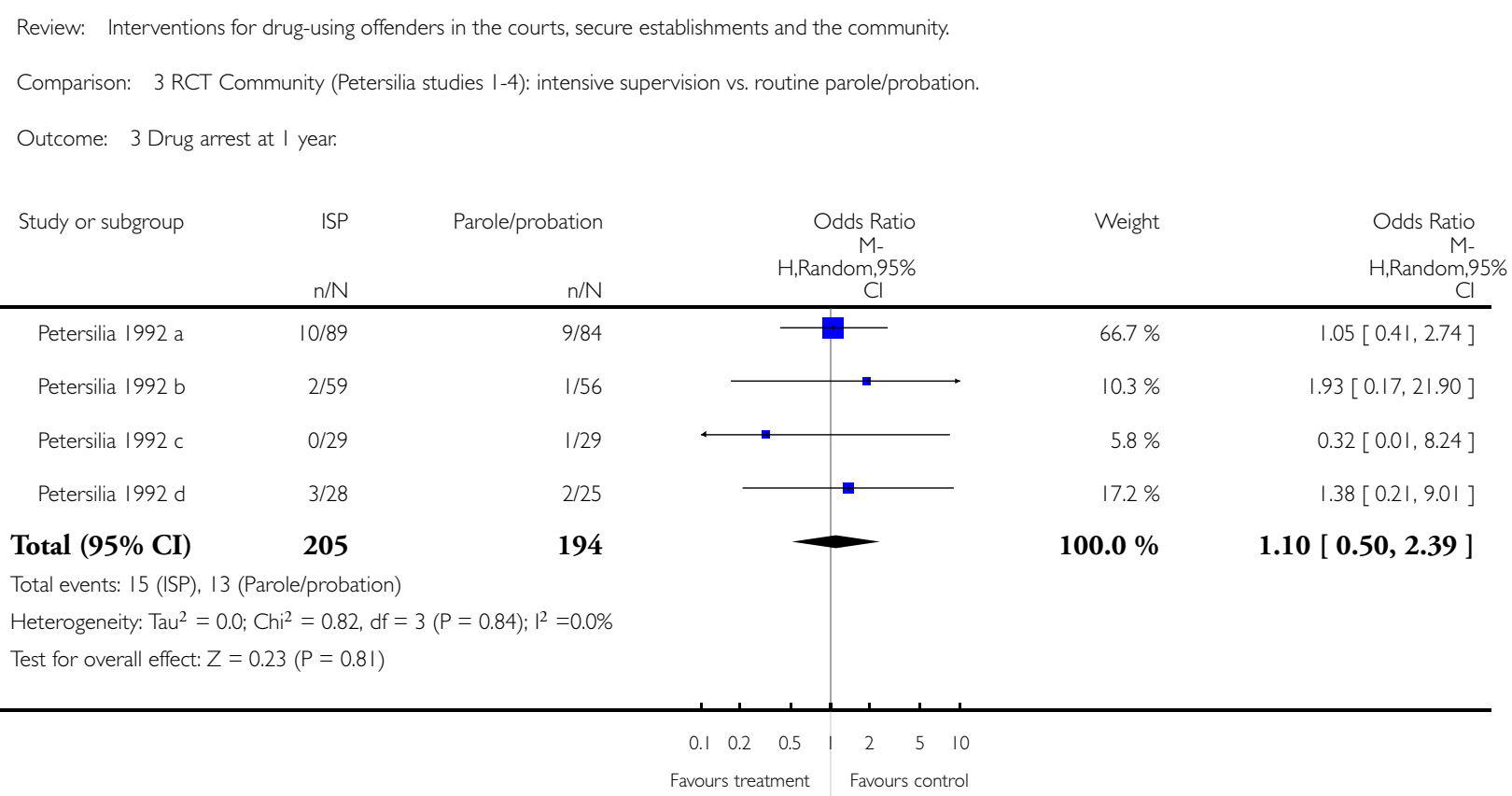


Analysis 3.4. Comparison 3 RCT Community (Petersilia studies I-4): intensive supervision vs. routine parole/probation., Outcome 4 Conviction at I year..

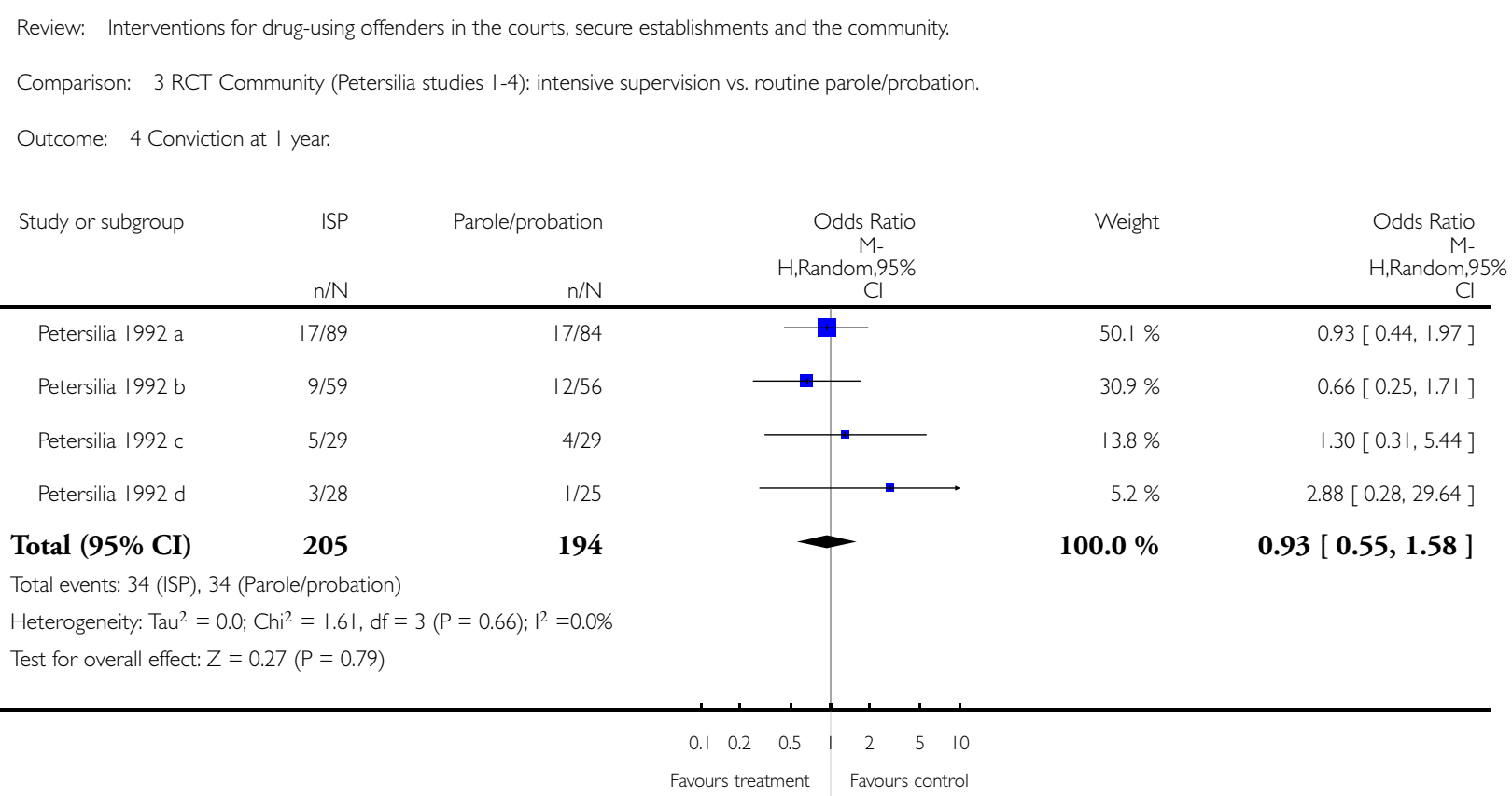


Analysis 3.5. Comparison 3 RCT Community (Petersilia studies I-4): intensive supervision vs. routine parole/probation., Outcome 5 Incarceration at I year..

Review: Interventions for drug-using offenders in the courts, secure establishments and the community.

Comparison: 3 RCT Community (Petersilia studies 1-4): intensive supervision vs. routine parole/probation.

Outcome: 5 Incarceration at I year.

Study or subgroup $\quad$ ISP Parole/probation Odds Ratio Patio

H,Random $95 \% \quad$ H,Random $95 \%$

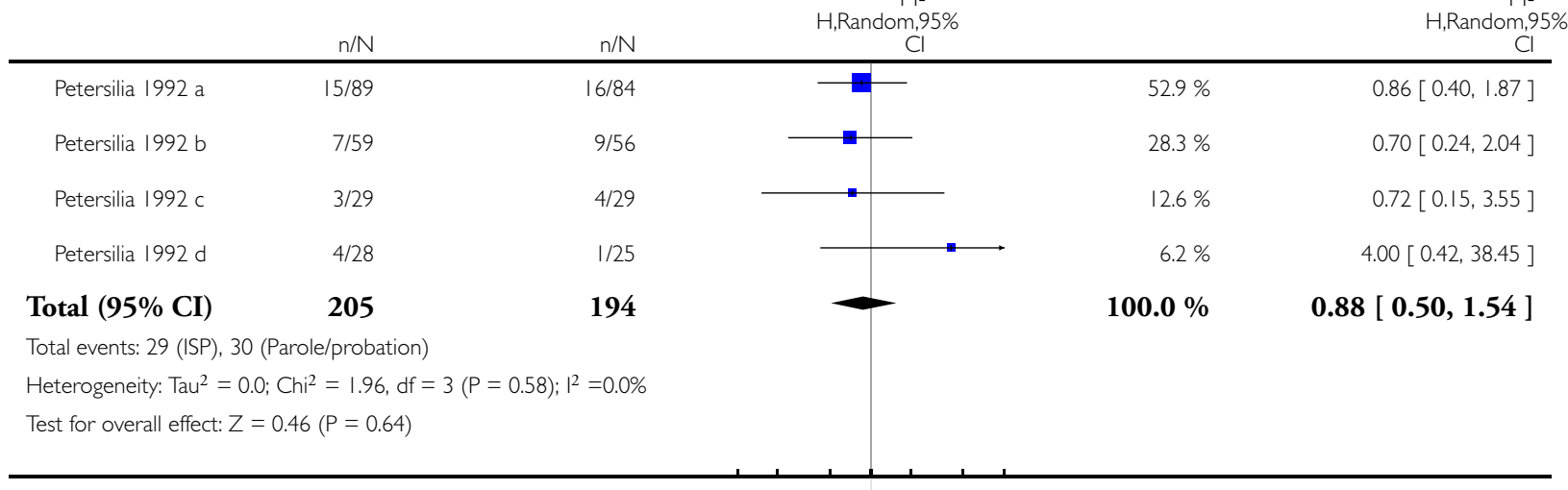

$\begin{array}{lllllll}0.1 & 0.2 & 0.5 & 1 & 2 & 5 & 10\end{array}$

Favours treatment Favours control 
Analysis 4.I. Comparison 4 RCT Community (Petersilia studies 5-7): int. supervision \& increased surveillance vs. int. supervision., Outcome I Recidivism at I year..

\begin{tabular}{|c|c|c|c|c|}
\hline \multicolumn{4}{|c|}{ Comparison: 4 RCT Community (Petersilia studies 5-7): int. supervision \% increased surveillance vs. int. supervision. } & \multirow[b]{3}{*}{$\begin{array}{c}\text { Odds Ratio } \\
\text { M- } \\
\text { H,Random,95\% } \\
\text { Cl }\end{array}$} \\
\hline \multicolumn{4}{|c|}{ Outcome: | Recidivism at I year. } & \\
\hline Study or subgroup & ISP \% surveillance & $\begin{array}{l}\mathrm{ISP} \\
\mathrm{n} / \mathrm{N}\end{array}$ & $\begin{array}{c}\text { Odds Ratio } \\
\text { M- } \\
\text { H,Random,95\% } \\
\mathrm{Cl} \\
\end{array}$ & \\
\hline Petersilia 1992 e & $20 / 26$ & $12 / 24$ & 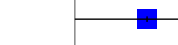 & $3.33[0.99,11.22]$ \\
\hline Petersilia $1992 \mathrm{f}$ & $26 / 26$ & $24 / 24$ & & $0.0[0.0,0.0]$ \\
\hline Petersilia $1992 \mathrm{~g}$ & 9/24 & $8 / 26$ & $\mathbf{m}$ & $1.35[0.42,4.36]$ \\
\hline Total $(95 \% \mathrm{CI})$ & 76 & 74 & - & $2.09[0.86,5.07]$ \\
\hline \multicolumn{4}{|c|}{ Total events: 55 (ISP \% surveillance), 44 (ISP) } & \\
\hline \multicolumn{4}{|c|}{ Heterogeneity: $\mathrm{Tau}^{2}=0.04 ; \mathrm{Chi}^{2}=1.10, \mathrm{df}=1(P=0.29) ; 1^{2}=9 \%$} & \\
\hline \multicolumn{3}{|c|}{ Test for overall effect: $Z=1.63(P=0.10)$} & & \\
\hline
\end{tabular}




\section{Analysis 4.2. Comparison 4 RCT Community (Petersilia studies 5-7): int. supervision \& increased}

surveillance vs. int. supervision., Outcome 2 Arrest at I year..

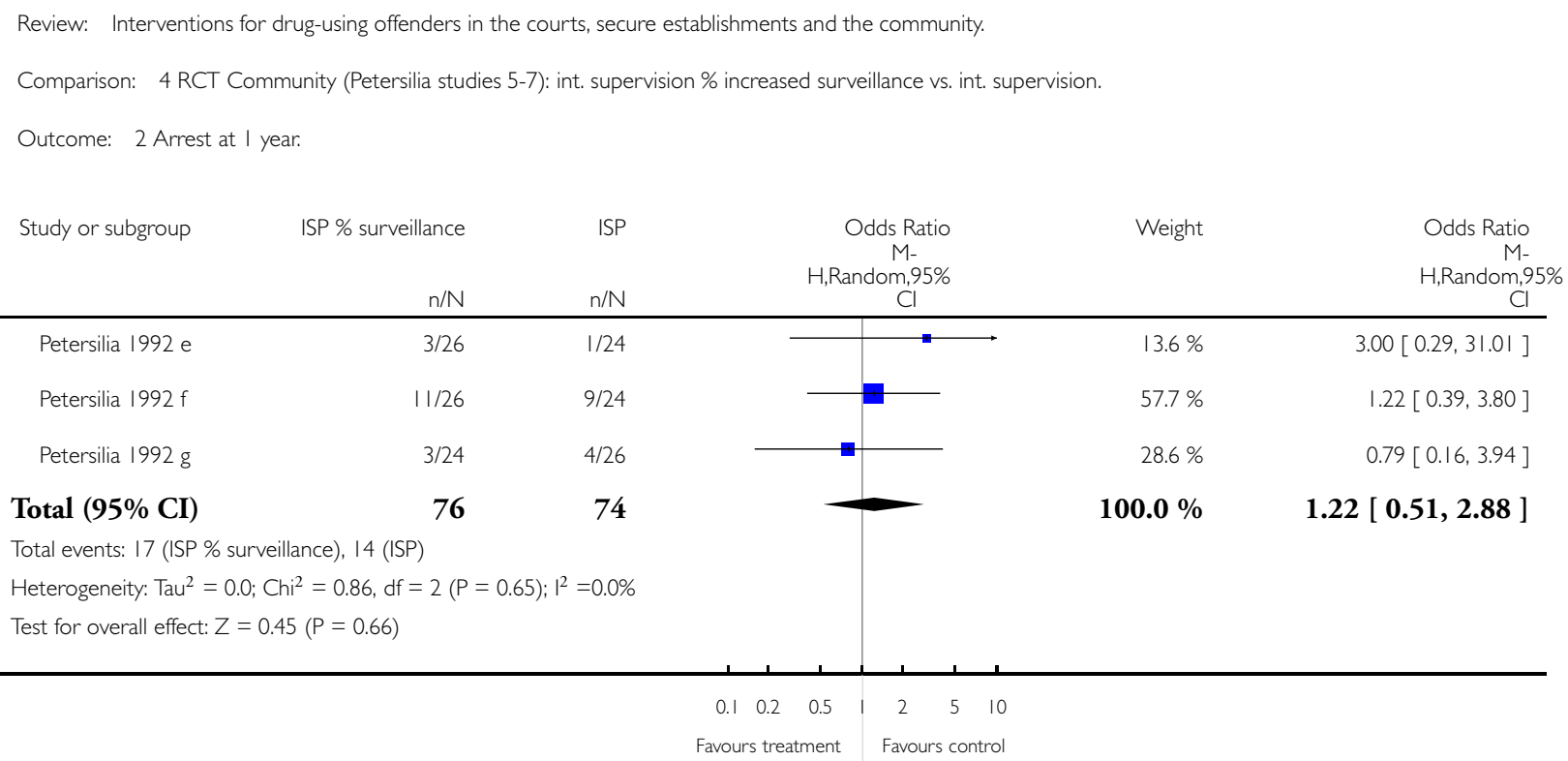


Analysis 4.3. Comparison 4 RCT Community (Petersilia studies 5-7): int. supervision \& increased surveillance vs. int. supervision., Outcome 3 Drug arrest at I year.

Review: Interventions for drug-using offenders in the courts, secure establishments and the community.

Comparison: 4 RCT Community (Petersilia studies 5-7): int. supervision \% increased surveillance vs. int. supervision.

Outcome: 3 Drug arrest at I year.

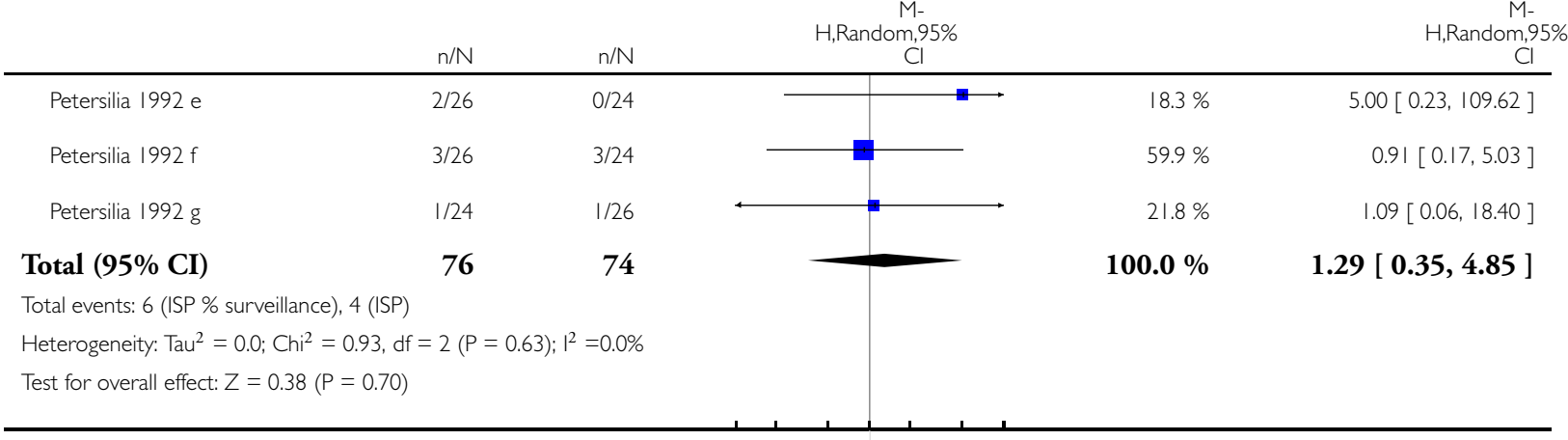

$\begin{array}{llllllll}0.1 & 0.2 & 0.5 & 1 & 2 & 5 & 10\end{array}$

Favours treatment Favours control 
Analysis 4.4. Comparison 4 RCT Community (Petersilia studies 5-7): int. supervision \& increased surveillance vs. int. supervision., Outcome 4 Conviction at I year..

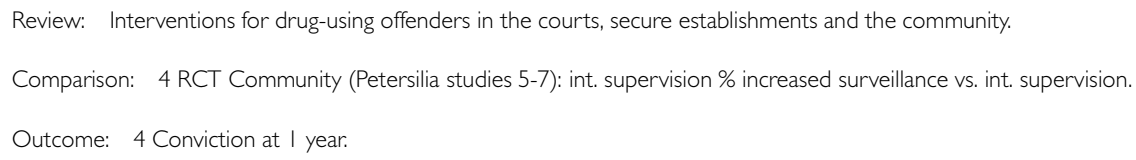

Petersilia 1992 e $\quad$ 2/26 $\quad 0 / 24$

$\begin{array}{lll}\text { Petersilia } 1992 \mathrm{f} & 5 / 26 & 6 / 24\end{array}$

$\begin{array}{lll}\text { Petersilia } 1992 \mathrm{~g} & 0 / 24 & 0 / 26\end{array}$

Total $(95 \%$ CI $)$

Total events: 7 (ISP \% surveillance), 6 (ISP)

Heterogeneity: $\operatorname{Tau}^{2}=0.46 ; \mathrm{Chi}^{2}=1.31, \mathrm{df}=\mathrm{I}(\mathrm{P}=0.25) ; \mathrm{I}^{2}=24 \%$

Test for overall effect: $Z=0.16(P=0.88)$

26

74

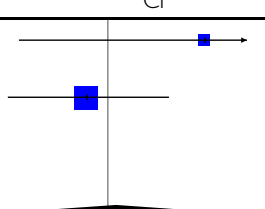
$5.00[0.23,109.62]$

$0.71[0.19,2.74]$

$0.0[0.0,0.0]$

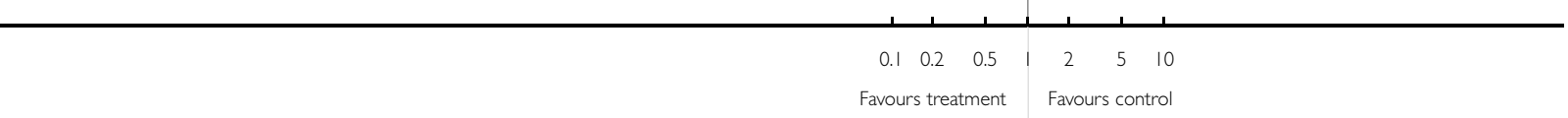


Analysis 4.5. Comparison 4 RCT Community (Petersilia studies 5-7): int. supervision \& increased surveillance vs. int. supervision., Outcome 5 Incarceration at I year..

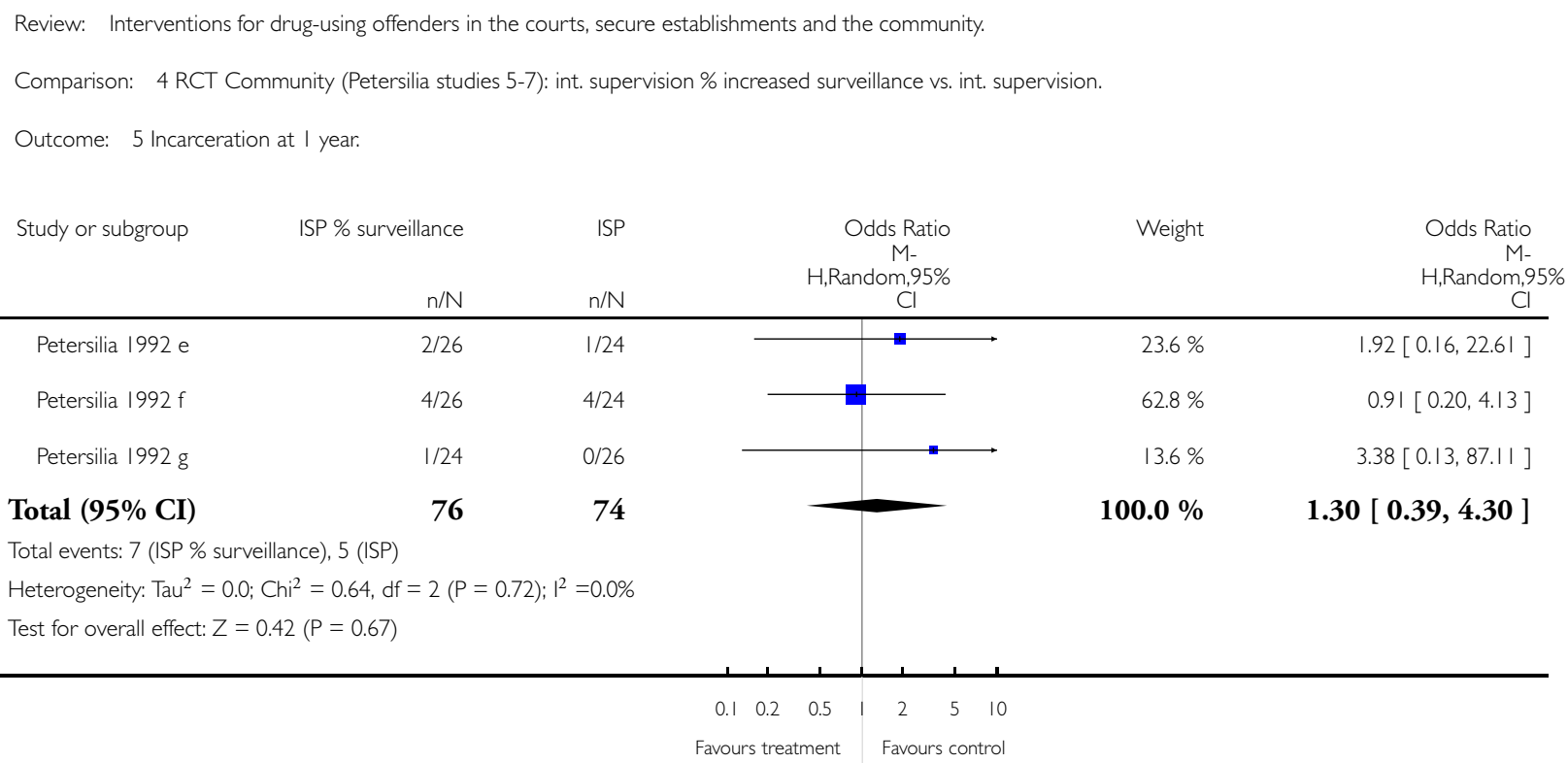

\section{ADDITIONAL TABLES}

Table 1. MEDLINE

\section{MEDLINE search}

1. exp "Substance-Related-Disorders"/

2. ((drug or substance) adj (abuse* or addict* or dependen* ${ }^{*}$ or misuse*)).ti,ab

3. (drug* adj (treat* or intervention* or program*)

4. substance near (treat* or intervention* or program*)

5.(detox* or methadone) in ti,ab

6. narcotic* near (treat* or intervention* or program*)

7. 1 or 2 or 3 or 4 or 5 or 6

8. prison*. ti,ab

9. exp "Prisoners"/

Interventions for drug-using offenders in the courts, secure establishments and the community. (Review)

Copyright () 2008 The Cochrane Collaboration. Published by John Wiley \& Sons, Ltd. 
Table 1. MEDLINE (Continued)

10. offender* or criminal* or inmate* or convict* or probation* or remand or felon*).ti,ab

11. exp "Prisons"।

12. 8 or 9 or 10 or 11

13. 7 and 12

Table 2. EMBASE

\section{Embase search}

1. (detox $\$$ or methadone or antagonist prescri $\$) . t i, a b$.

2. detoxification/ or drug detoxification/ or drug withdrawal/ or drug dependence treatment/ or methadone/ or methadone treatment/ or diamorphine/ or naltrexone/

3. (diamorphine or naltrexone or therapeutic communit\$).ti,ab

4. morality/

5. (motivational interview $\$$ or motivational enhancement).ti,ab

6. (counselling or counseling).ti,ab.

7. exp counseling/

8. (psychotherap\$ or cognitive behavioral or cognitive behavioural).ti,ab

9. exp psychotherapy/

10. (moral adj3 training).ti,ab.

11. (cognitive restructuring or assertiveness training).ti,ab

12. reinforcement/ or self monitoring/ or self control/

13. (relaxation training or rational emotive or family relationship therap\$).ti,ab

14. social learning/ or withdrawal syndrome/ or coping behavior/

15. (community reinforcement or self monitoring or self control or self management or interpersonal skills).ti,ab

16. (goal\$ adj3 setting).ti,ab.

17. (social skills adj3 training).ti,ab. 
Table 2. EMBASE (Continued)

18. anger/ or lifestyle/

19. (basic skills adj3 training).ti,ab.

20. (relapse adj3 prevent\$).ti,ab.

21. (craving adj3 (minimi\$ or reduc\$)).ti,ab.

22. (trigger or triggers or coping skills or anger management or group work).ti,ab

23. (lifestyle adj3 modifi).ti,ab.

24. (high intensity training or resettlement or throughcare or aftercare or after care).ti,ab

25. aftercare/ or halfway house/

26. (brief solution or brief intervention\$ or minnesota program $\$$ or 12 step\$ or twelve step\$).ti,ab

27. (needle exchange or nes or syringe exchange or dual diagnosis or narcotics anonymous).ti,ab

28. self help/ or support group/

29. (self-help or selfhelp or self help or outreach or bail support or arrest referral\$).ti,ab

30. exp urinalysis/ or rehabilitation/ or rehabilitation center/

31. (diversion or dtto or dttos or drug treatment or testing order\$ or carat or carats).ti,ab

32. (combined orders or drug-free or drug free).ti,ab.

33. (peer support or evaluation\$ or urinalysis or drug testing or drug test or drug tests).ti,ab

34. ((rehab or rehabilitation or residential or discrete) adj2 (service\$ or program\$)).ti,ab

35. (asro or addressing substance $\$$ or pasro or prisons addressing or acupuncture or shock or boot camp or boot camps).ti,ab

36. (work ethic camp\$ or drug education or tasc or treatment accountability).ti,ab

37. exp acupuncture/

38. or/1-36

39. (remand or prison or prisoner or prisoners or offender $\$$ or criminal $\$$ or probation or court or courts).ti,ab

40. (secure establishment $\$$ or secure facilit\$).ti,ab. 
Table 2. EMBASE (Continued)

41. (reoffend $\$$ or reincarcerat\$ or recidivi\$ or ex-offender\$ or jail or jails or goal or goals).ti,ab

42. (incarcerat $\$$ or convict or convicts or convicted or felon or felons or conviction\$ or revocation or inmate $\$$ or high security).ti,ab

43. criminal justice/ or custody/ or detention/ or prison/ or prisoner/ or offender/ or probation/ or court/ or recidivism/ or crime/ or criminal behavior/ or punishment/

44. or/39-43

45. 38 and 44

46. (substance abuse $\$$ or substance misuse $\$$ or substance use\$).ti,ab

47. (drug dependanc $\$$ or drug abuse $\$$ or drug use $\$$ or drug misuse $\$$ or drug addict $\$$ ).ti, ab

48. (narcotics adj3 (addict\$ or use $\$$ or misuse $\$$ or abuse $\$)$ ).ti, ab

49. (chemical dependanc $\$$ or opiates or heroin or crack or cocaine or amphetamines or addiction or dependance disorder or drug involved).ti,ab

50. substance abuse/ or drug abuse/ or analgesic agent abuse/ or drug abuse pattern/ or drug misuse/ or intravenous drug abuse/ or multiple drug abuse/

51. addiction/ or drug dependence/ or narcotic dependence/ or exp narcotic agent/ or narcotic analgesic agent/

52. opiate addiction/ or heroin dependence/ or morphine addiction/

53. cocaine/ or amphetamine derivative/ or psychotropic agent/

54. or/46-53

55.45 and 54

56. limit 55 to $y r=1980-2004$

Table 3. PsycInfo

\section{PsycInfo}

1. (detoxification in de) or (drug withdrawal in de)

2. (drug usage screening in de) or (methadone maintenance) in de

3. explode "Narcotic-Antagonists" in DE

\section{1 or 2 or 3}

Interventions for drug-using offenders in the courts, secure establishments and the community. (Review)

Copyright @ 2008 The Cochrane Collaboration. Published by John Wiley \& Sons, Ltd. 
Table 3. PsycInfo (Continued)

5. (counseling in de) or (explode "psychotherapeutic-counseling" in de)

6. (explode "cognitive-therapy" in de) or (explode "psychotherapeutic-techniques" in de)

7. (cognitive restructuring in de) or (assertiveness training in de)

8. explode "relaxation-therapy" in de

9. (rational emotive therapy in de) or (rational-emotive therapy in de)

10. (explode "self monitoring" in de) or (explode self-monitoring) in de

11. (goal setting in de) or (self control in de) or (explode "self-management" in de)

12. (social skills in de) or (relapse prevention in de) or (craving in de) or (coping behavior in de)

13. (anger control in de) or (explode "group-psychotherapy" in de) or (brief psychotherapy in de)

14. (explode "behavior-modification" in de) or (posttreatment followup in de) or (aftercare in de)

15. (halfway houses in de) or (twelve step programs in de)

16. (dual diagnoses in de) or (explode "self help techniques" in de) or (outreach programs in de) or (court referrals in de)

17. (peer pressure in de) or (urinalysis in de)

18. (drug rehabilitation in de) or (residential care institutions in de) or (acupuncture in de) or (drug education in de)

19. (detox* or methadone or antagonist prescri* or diamorphine or naltrexone or therapeutic communit ${ }^{*}$ ) in ti,ab

20. (motivational interview* or motivational enhancemen* or counseling or psychotherapy or psychotherapies) in ti,ab

21. (cognitive behav* or cognitive therapy or cognitive therapies or moral training or cognitive restructuring) in ti,ab

22. (assertiveness training or relaxation training or relaxation therapy or relaxation therapies) in ti,ab

23. (rational emotive therap* or rational emotive behav* therap* or family relationship therap* or community reinforcement) in ti,ab

24. (self-monitor* or self monitor* or goal setting or self control or self-control or self management or self-management) in ti,ab

25. (interpersonal skills training or social skills training or basic skills training) in ti,ab

26. (relapse with prevent ${ }^{*}$ ) in ti,ab

27. (craving near reduc*) in ti,ab

Interventions for drug-using offenders in the courts, secure establishments and the community. (Review) 
Table 3. PsycInfo (Continued)

28. craving with (reduc* in ti,ab)

29. (trigger* or coping skills or anger management or group work or lifestyle modif* or high intensity training or resettlement) in ti, $\mathrm{ab}$

30. (throughcare or aftercare or after care or brief solution* or brief intervention*) in ti,ab

31. (minnesota or 12 step* $^{*}$ or twelve step* or needle exchange or nes or syringe exchange or dual diagnosis) in ti,ab

32. (narcotics anonymous or self-help or self help or outreach or bail support or arrest referral*) in ti,ab

33. (diversion or dtto* or testing order* or carat* or counseling assessment referral or combined order or combined orders or drug free wing* or drug free environment $\left.{ }^{*}\right)$ in ti,ab

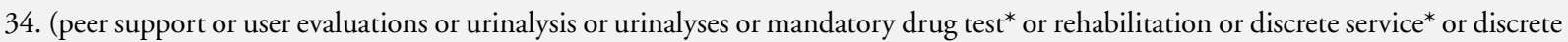
program $\left.^{*}\right)$ in ti,ab

35. (residential program* or residential scheme* or asro or addressing substance* or pasro or prisons addressing substance) in ti,ab

36. (acupuncture or shock or boot camp* or work ethic or drug education or tasc or treatment accountability) in ti,ab

37. or/4-36

38. (secure facilities or convict* or revocation or inmate* or high security) in ti,ab

39. (prisoners in de) or (explode "correctional-institutions" in de)

40. (perpetrators in de) or (explode criminals in de)

41. (probation in de) or (parole in de) or (incarceration in de) or (recidivism in de) or (criminal conviction in de) or (crime in de)

42. (remand or prison* ${ }^{*}$ offender* or criminal* or probation or court or courts or secure establishment* or reoffend* or reincarcerat* or recidivi* or ex-offender* or jail or jails or incarcerat $\left.{ }^{*}\right)$ in ti,ab

43. (drug abuse in de) or (explode "inhalant-abuse" in de) or (explode "drug-dependency" in de)

44. (polydrug abuse in de) or (drug abuse in de) or (intravenous drug usage in de)

45. (narcotic drugs in de) or (heroin in de) or (cocaine in de) or (explode amphetamine in de)

46. (substance abuse* or substance misuse* or substance user*) in ti,ab

47. (drug dependen* or drug abuse* or drug misuse* or drug addict* or drug use) in ti,ab

48. (narcotic abuse* or narcotic misuse* or chemical dependen* or opiate misuse* or opiate abuse*) in ti,ab

49. (heroin use* or heroin addict* or heroin misuse* or heroin abuse*) in ti,ab 
Table 3. PsycInfo (Continued)

50. (crack use* or crack addict* or crack misuse* or crack abuse*) in ti,ab

51. (cocaine use* or cocaine addict* or cocaine misuse* or cocaine abuse*) in ti,ab

52. (amphetamine* use* or amphetamine* addict* or amphetamine* misuse* or amphetamine* abuse*) in ti,ab

53. (dependence disorder or drug involved or dug-involved) in ti,ab

54. \#38 or \#39 or \#40 or \#41 or \#42

$55 . \# 4$ or \#43 or \#44 or \#45 or \#46 or \#47 or \#48 or \#49 or \#50 or \#51 or \#52 or \#53

56. \#37 and \#54 and \#55

Table 4. SPECTRA

\section{SPECTRA search}

1. $\{$ remand or $\{$ prison $\}$ or $\{$ offender $\}$ or $\{$ criminal $\}$ or $\{$ probation $\}$ or $\{$ court $\}$ or $\{$ tribunal $\}$ or $\{$ secure establishment $\}$ or $\{$ secure facilit $\}$ or \{reoffend $\}$ or $\{$ reincarcerat $\}$ or $\{$ recidivi $\}$ or $\{$ ex-offender $\}$ or $\{$ jail $\}$ or $\{$ incarcerat $\}$ or $\{$ convict $\}$ or $\{$ felon $\}$ or $\{$ reconvict $\}$ or $\{$ high security $\}$ or $\{$ law enforcement $\}$

$\{$ remand or $\{$ prison $\}$ or $\{$ offender $\}$ or $\{$ criminal $\}$ or $\{$ probation $\}$ or $\{$ court $\}$ or $\{$ tribunal $\}$ or $\{$ secure establishment $\}$ or $\{$ secure facilit $\}$ or \{reoffend\} or $\{$ reincarcerat $\}$ or $\{$ recidivi $\}$ or $\{$ ex-offender $\}$ or $\{$ jail $\}$ or $\{$ incarcerat $\}$ or $\{$ convict $\}$ or $\{$ felon $\}$ or $\{$ reconvict $\}$ or $\{$ high security $\}$ or $\{$ law enforcement $\}$

2. $\{$ substance $\}$ or $\{$ dependenc $\}$ or $\{$ drug abuse $\}$ or $\{$ drug use $\}$ or $\{$ drug misuse $\}$ or \{addict $\}$

All indexed fields: $\{$ remand or $\{$ prison\} or $\{$ offender $\}$ or $\{$ criminal $\}$ or $\{$ probation $\}$ or $\{$ court $\}$ or $\{$ tribunal $\}$ or $\{$ secure establishment $\}$ or \{secure facilit $\}$ or $\{$ reoffend $\}$ or $\{$ reincarcerat $\}$ or $\{$ recidivi $\}$ or $\{$ ex-offender $\}$ or $\{$ jail $\}$ or $\{$ incarcerat $\}$ or $\{$ convict $\}$ or $\{$ felon $\}$ or $\{$ reconvict $\}$ or $\{$ high security\} or $\{$ law enforcement $\}$

OR

All unindexed fields: \{remand\} or \{prison\} or $\{$ offender $\}$ or $\{$ criminal $\}$ or $\{$ probation $\}$ or $\{$ court $\}$ or $\{$ tribunal $\}$ or $\{$ secure establishment $\}$ or $\{$ secure facilit $\}$ or $\{$ reoffend $\}$ or $\{$ reincarcerat $\}$ or $\{$ recidivi $\}$ or $\{$ ex-offender $\}$ or $\{$ jail $\}$ or $\{$ incarcerat $\}$ or $\{$ convict $\}$ or $\{$ felon $\}$ or $\{$ reconvict $\}$ or $\{$ high security\} or $\{$ law enforcement $\}$

AND

All unindexed fields: \{substance $\}$ or $\{$ dependenc $\}$ or $\{$ drug abuse $\}$ or $\{$ drug use $\}$ or $\{$ drug misuse $\}$ or $\{$ addict $\}$ or $\{$ narcotics $\}$ or $\{$ opiates\} or $\{$ heroin $\}$ or $\{$ crack $\}$ or $\{$ cocaine $\}$ or $\{$ amphetamines $\}$ or $\{$ drug involved $\}$ or $\{$ substance-related $\}$ or $\{$ amphetamine-related $\}$ or $\{$ cocainerelated or $\{$ marijuana $\}$ or $\{$ opioid\} or $\{$ street drug $\}$ or $\{$ designer drug\}

3. narcotics

4. opiates

5. heroin

6. $\{$ crack $\}$

7. cocaine

Interventions for drug-using offenders in the courts, secure establishments and the community. (Review)

Copyright $\odot 2008$ The Cochrane Collaboration. Published by John Wiley \& Sons, Ltd. 
Table 4. SPECTRA (Continued)

8. amphetamines

9. drug involved

10. substance-related

11. amphetamine-related

12. cocaine-related

13. marijuana

14. opioid

15. street drug

16. designer drug

17. 2 or 3 or 4 or 5 or 6 or 7 or 8 or 9 or 10 or 11 or 12 or 13 or 14 or 15 or 16

18. 1 AND 17

Table 5. PASCAL, SciSearch, Social SciSearch, Wilson Applied Science and Technology Abstr

PASCAL search

1. (DETOX? OR METHADONE OR ANTAGONIST()PRESCRI?)/TI,AB

2. METHADONE/DE OR NALTREXONE/DE

3. (DIAMORPHINE OR NALTREXONE)/TI,AB

4. THERAPEUTIC()COMMUNITY/DE OR THERAPEUTIC()COMMUNIT?)/TI,AB

5. (MOTIVATIONAL()INTERVIEW? OR MOTIVATIONAL()ENHANCEMENT)/TI,AB

6. (COUNSELLING OR COUNSELING)/TI,AB

7. COUNSELING/DE

8. (PSYCHOTHERAP? OR COGNITIVE()BEHAVIORAL OR COGNITIVE()BEHAVIOURAL)/TI,AB

9. PSYCHOTHERAPY!/DE

10. (MORAL(3W)TRAINING)/TI,AB

11. (COGNITIVE()RESTRUCTURING OR ASSERTIVENESS()TRAINING)/TI,AB

Interventions for drug-using offenders in the courts, secure establishments and the community. (Review)

Copyright @ 2008 The Cochrane Collaboration. Published by John Wiley \& Sons, Ltd. 
Table 5. PASCAL, SciSearch, Social SciSearch, Wilson Applied Science and Technology Abstr (Continued)

12. ASSERTIVENESS/DE OR RELAXATION()TECHNIQUES/DE

13. (RELAXATION()TRAINING OR RATIONAL()EMOTIVE OR FAMILY()RELATIONSHIP()THERAP?)/TI,AB

14. FAMILY()RELATIONS/DE

15. (COMMUNITY()REINFORCEMENT OR SELF()MONITORING OR SELF()CONTROL OR SELF()MANAGEMENT OR INTERPERSONAL()SKILLS)/TI,AB

16. (GOAL?(3W)SETTING)/TI,AB

17. (SOCIAL(3W)TRAINING)/TI,AB

18. SOCIAL RESPONSIBILITY/DE

19. (BASIC()SKILLS(3W)TRAINING)/TI,AB

20. (RELAPSE(3W)PREVENT?)/TI,AB

21. (CRAVING(3W)(MINIMI? OR REDUC?))/TI,AB

22. (TRIGGER OR TRIGGERS OR COPING()SKILLS OR ANGER()MANAGEMENT OR GROUP()WORK)/TI,AB

23. (LIFESTYLE(3W)MODIFI?)/TI,AB

24. (HIGH()INTENSITY()TRAINING OR RESETTLEMENT OR THROUGHCARE OR AFTERCARE OR AFTER()CARE) /TI,AB

25. ADAPTATION,-PSYCHOLOGICAL!/DE OR ANGER/DE OR LIFE()STYLE/DE OR AFTER()CARE/DE OR HALFWAY ()HOUSES/DE

26. (BRIEF()SOLUTION OR BRIEF()INTERVENTION? OR MINNESOTA()PROGRAM? OR 12()STEP? OR TWELVE() STEP?)/TI,AB

27. (NEEDLE()EXCHANGE OR NES OR SYRINGE()EXCHANGE OR DUAL()DIAGNOSIS OR NARCOTICS()ANONYMOUS)/TI,AB

28. NEEDLE-EXCHANGE()PROGRAMS/DE

29. (SELF-HELP OR SELFHELP OR SELF()HELP OR OUTREACH OR BAIL()SUPPORT OR ARREST()REFERRAL?)/TI, $\mathrm{AB}$

30. SELF-HELP()GROUPS/DE OR URINALYSIS/DE OR SUBSTANCE()ABUSE()DETECTION/DE

31. (DIVERSION OR DTTO OR DTTOS OR DRUG()TREATMENT OR TESTING()ORDER? ? OR CARAT OR CARATS) /TI,AB

32. (COMBINED()ORDERS OR DRUG-FREE OR DRUG()FREE)/TI,AB 
Table 5. PASCAL, SciSearch, Social SciSearch, Wilson Applied Science and Technology Abstr (Continued)

33. (PEER()SUPPORT OR EVALUATION? ? OR URINALYSIS OR DRUG()TESTING OR DRUG()TEST? ?)/TI,AB

34. ((REHAB OR REHABILITATION OR RESIDENTIAL OR DISCRETE)(2W)(SERVICE? ? OR PROGRAM?))/TI,AB

35. (ASRO OR ADDRESSING()SUBSTANCE? OR PASRO OR PRISONS()ADDRESSING OR ACUPUNCTURE OR SHOCK OR BOOT()CAMP OR BOOT()CAMPS)/TI,AB

36. (WORK()ETHIC()CAMP? ? OR DRUG()EDUCATION OR TASC OR TREATMENT()ACCOUNTABILITY)/TI,AB

37. ACUPUNCTURE-THERAPY!/DE OR ACUPUNCTURE/DE OR HEALTH()EDUCATION/DE OR SUBSTANCE() ABUSE()TREATMENT()CENTERS/DE

38. S1:S3

39. S4:S37

40. S38 AND S39

40. (REMAND OR PRISON OR PRISONER OR PRISONERS OR OFFENDER? ? OR CRIMINAL? ? OR PROBATION OR COURT OR COURTS)/TI,AB

41. (SECURE()ESTABLISHMENT? ? OR SECURE()FACILIT?)/TI,AB

42. (REOFFEND? OR REINCARCERAT? OR RECIDIVI? OR EX()OFFENDER? ? OR JAIL OR JAILS)/TI,AB

43. (INCARCERAT? OR CONVICT OR CONVICTS OR CONVICTED OR FELON? ? OR CONVICTION? ? OR REVOCATION OR INMATE? ? OR HIGH()SECURITY)/TI,AB

44. PRISONERS/DE OR LAW()ENFORCEMENT/DE OR JURISPRUDENCE/DE

45. S40:S44

46. S40 AND S45

47. (SUBSTANCE()ABUSE? OR SUBSTANCE()MISUSE? OR SUBSTANCE()USE?)/TI,AB

48. (DRUG()DEPENDANC? OR DRUG()ABUSE? OR DRUG()USE? OR DRUG()MISUSE? OR DRUG()ADDICT?)/TI,AB

49. (NARCOTICS(3W)(ADDICT? OR USE? OR MISUSE? OR ABUSE?))/TI,AB

50. (CHEMICAL()DEPENDANC? OR OPIATES OR HEROIN OR CRACK OR COCAINE OR AMPHETAMINES OR ADDICTION OR DEPENDENCE()DISORDER OR DRUG()INVOLVED)/TI,AB

51. SUBSTANCE-RELATED()DISORDERS/DE OR AMPHETAMINE-RELATED()DISORDERS/DE OR COCAINE-RELATED()DISORDERS/DE OR MARIJUANA ()ABUSE/DE

52. OPIOID-RELATED-DISORDERS!/DE OR PHENCYCLIDINE()ABUSE/DE OR SUBSTANCE()ABUSE()INTRAVENOUS/DE 
Table 5. PASCAL, SciSearch, Social SciSearch, Wilson Applied Science and Technology Abstr (Continued)

53. STREET()DRUGS/DE OR DESIGNER()DRUGS/DE OR NARCOTICS/DE

54. COCAINE!/DE OR AMPHETAMINES!/DE OR ANALGESICS()OPIOID/DE

55. S47:S54

56. S46 AND S55

57. (DETOXIFICATION OR METHADONE OR ANTAGONIST-PRESCRIBING)/DE FROM 144,34,434,7,99,65,35,6

58. (DIAMORPHINE OR NALTREXONE)/DE FROM 144,34,434,7,99,65,35,6

59. THERAPEUTIC-COMMUNITY)/DE FROM 144,34,434,7,99,65,35,6

60. (MOTIVATIONAL-INTERVIEW OR MOTIVATIONAL-ENHANCEMENT)/DE FROM 144,34,434,7,99,65,35,6

61. (COUNSELLING OR COUNSELING)/DE FROM 144,34,434,7,99,65,35,6

62. (PSYCHOTHERAPY! OR COGNITIVE-BEHAVIORAL OR COGNITIVE-BEHAVIOURAL)/DE FROM 144,34,434,7, $99,65,35,6$

63. (MORAL-TRAINING)/DE FROM 144,34,434,7,99,65,35,6

64. (COGNITIVE-RESTRUCTURING OR ASSERTIVENESS-TRAINING)/DE FROM 144,34,434,7,99,65,35,6

65. (RELAXATION-TRAINING OR RATIONAL-EMOTIVE OR FAMILY-RELATIONSHIP-THERAPY)/DE FROM 144,34, $434,7,99,65,35,6$

66. FAMILY-RELATIONS/DE

67. (COMMUNITY-REINFORCEMENT OR SELF-MONITORING OR SELF-CONTROL OR SELF-MANAGEMENT OR INTERPERSONAL-SKILLS)/DE FROM 44,34,434,7,99,65,35,6

68. (GOAL-SETTING)/DE FROM 144,34,434,7,99,65,35,6

69. (SOCIAL-SKILLS-TRAINING)/DE FROM 144,34,434,7,99,65,35,6

70. SOCIAL-RESPONSIBILITY/DE

71. (BASIC-SKILLS-TRAINING)/DE FROM 144,34,434,7,99,65,35,6

72. (RELAPSE-PREVENTION)/DE FROM 144,34,434,7,99,65,35,6

73. CRAVING/DE FROM 144,34,434,7,99,65,35,6

74. (TRIGGER OR COPING-SKILLS OR ANGER-MANAGEMENT OR GROUP-WORK)/DE FROM 144,34,434,7,99,65, 35,6

75. (LIFESTYLE-MODIFICATION)/DE FROM 144,34,434,7,99,65,35,6 
Table 5. PASCAL, SciSearch, Social SciSearch, Wilson Applied Science and Technology Abstr (Continued)

76. (HIGH-INTENSITY-TRAINING OR RESETTLEMENT OR THROUGHCARE OR AFTERCARE OR AFTER-CARE)/ DE FROM 144,34,434,7,99,65,35,6

77. (BRIEF-SOLUTION OR BRIEF-INTERVENTIONS OR MINNESOTA-PROGRAM OR 12-STEP-PROGRAM OR TWELVE-STEP-PROGRAM)/DE FROM 144,34,434,7,99,65,35,6

77. (NEEDLE-EXCHANGE OR SYRINGE-EXCHANGE OR DUAL-DIAGNOSIS OR NARCOTICS-ANONYMOUS)/DE FROM 144,34,434,7,99,65,35,6

79. (SELF-HELP OR OUTREACH OR BAIL-SUPPORT OR ARREST-REFERRAL)/DE FROM 144,34,434,7,99,65,35,6

80. (DRUG-TREATMENT OR TESTING-ORDERS OR CARAT)/DE FROM 144,34,434,7,99,65,35,6

81. (COMBINED-ORDERS OR DRUG-FREE)/DE FROM 144,34,434,7,99,65,35,6

82. (PEER-SUPPORT OR EVALUATION OR URINALYSIS OR DRUG-TESTING OR DRUG-TESTS)/DE FROM 144,34, $434,7,99,65,35,6$

83. (REHABILITATION OR RESIDENTIAL OR DISCRETE-SERVICES)/DE FROM 144,34,434,7,99,65,35,6

84. (ASRO OR PASRO ACUPUNCTURE OR BOOT-CAMP)/DE FROM 144,34,434,7,99,65,35,6

85. (WORK-ETHIC-CAMP OR DRUG-EDUCATION OR TASC OR TREATMENT-ACCOUNTABILITY)/DE FROM 144, $34,434,7,99,65,35,6$

86. (REMAND OR PRISON OR PRISONER OR PRISONERS OR OFFENDER OR OFFENDERS OR CRIMINAL OR CRIMINALS OR PROBATION OR COURT OR COURTS)/DE FROM 144,34,434,7,99,65,35,6

87. (SECURE-ESTABLISHMENTS OR SECURE-FACILITY)/DE FROM 144,34,434,7,99,65,35,6

88. (REOFFENDERS OR REINCARCERATION OR RECIDIVISM OR EX-OFFENDERS OR JAILS)/DE FROM 144,34, $434,7,99,65,35,6$

89. (INCARCERATION OR CONVICT OR CONVICTS OR FELON OR FELONS OR CONVICTIONS OR REVOCATION OR INMATE OR INMATES OR HIGH-SECURITY)/DE FROM 144,34,434,7,99,65,35,6

90. (SUBSTANCE-ABUSE OR SUBSTANCE-MISUSE OR SUBSTANCE-USE)/DE FROM 144,34,434,7,99,65,35,6

91. (DRUG-DEPENDANCE OR DRUG-DEPENDENCY OR DRUG-ABUSE OR DRUG-MISUSE OR DRUG-ADDICT OR DRUG-ADDICTION)/DE FROM 144,34,434,7,99,65,35,6

92. (CHEMICAL-DEPENDANCY OR OPIATE-DEPENDENCY OR HEROIN-DEPENDENCY OR CRACK-DEPENDENCY OR COCAINE-DEPENDENCY OR AMPHETAMINES OR ADDICTION OR DEPENDENCE-DISORDER OR DRUG-INVOLVED)/DE FROM 144,34,434,7,99,65,35,6

93. S40 OR S57:S85

94. S45 OR S86:S89

Interventions for drug-using offenders in the courts, secure establishments and the community. (Review)

Copyright $\odot 2008$ The Cochrane Collaboration. Published by John Wiley \& Sons, Ltd. 
Table 5. PASCAL, SciSearch, Social SciSearch, Wilson Applied Science and Technology Abstr (Continued)

95. S55 OR S90:S92

96. S93 AND S94 AND S95

97. S96/1980-2004

Table 6. The CENTRAL Register of Controlled Trials

CENTRAL search

1. prison* $^{*}$

2. offender*

3. $\left(\right.$ criminal $^{*}$ or probation or court $\left.{ }^{*}\right)$

4. (secure next establishment*)

5. reoffend*

6. reincarcerat*

7. recidiv*

8. exoffend*

9. (jail or jails or incarcerat*)

10. (secure next facilit*)

10(secure next facilit*)

11. (convict* or revocation or inmate* or (high next security))

12. PRISONERS

13. LAW ENFORCEMENT

14. JURISPRUDENCE

15. CRIME

16. \#1 or \#2 or \#3 or \#4 or \#5 or \#6 or \#7 or \#8 or \#9 or \#10 or \#11 or \#12 or \#13 or \#14 or \#15

17. SUBSTANCE-RELATED DISORDERS

18. ((substance or drug*) next (abuse* or misuse* or dependen* ${ }^{*}$ or use* or addict* $\left.^{*}\right)$ ) 
Table 6. The CENTRAL Register of Controlled Trials (Continued)

19. (narcotics or chemical or opiate) next (dependen* or addict* or abuse* or misuse*))

20. ((heroin) next (addict* or dependen* or misuse* or abuse*))

21. ((crack) next (addict* or dependen* or misuse* ${ }^{*}$ or abuse* or use*))

22. ((cocaine next addict $\left.{ }^{*}\right)$ or (cocaine next dependenc $\left.{ }^{*}\right)$ or $\left(\right.$ cocaine next misuse $\left.{ }^{*}\right)$ or $\left(\right.$ cocaine next abuse $\left.{ }^{*}\right)$ or $\left(\right.$ cocaine next use $\left.\left.^{*}\right)\right)$

23. ((amphetamine $\left.{ }^{*}\right)$ next (addict* or dependen* or misuse* or abuse* or use*))

24. (addicts or (dependence next disorder) or (drug next involved))

25. (street next drugs)

26. STREET DRUGS

27. DESIGNER DRUGS

28. NARCOTICS

29. COCAINE

30. AMPHETAMINES

31. ANALGESICS ADDICTIVE

32. ANALGESICS OPIOID

33. PSYCHOTROPIC DRUGS

34. opioid* or opiat*

$35 . \# 17$ or $\# 18$ or $\# 19$ or \#20 or \#21 or \#22 or \#23 or \#24 or \#25 or \#26 or \#27 or \#28 or \#29 or \#30 or \#31 or \#32 or \#33 or \#34

35. (\#16 and \#35)

Table 7. SIGLE

\section{SIGLE}

1. ((reoffend* ${ }^{*}$ or reincarcerat* ${ }^{*}$ or recidivi* or ex-offend* ${ }^{*}$ or jail or jails or incarcerat* ${ }^{*}$ or secure facilit* ${ }^{*}$ or convict* or revocation or inmate*) in ti,ab)

2. ((remand or prison* or offender* or criminal* or probation or court or courts or secure establishment*) in ti,ab

3. ((drug dependenc* or drug addict* or narcotics abuse* or narcotics use* or narcotics misuse* or narcotics addict*) in ti,ab 
Table 7. SIGLE (Continued)

4. ((drug abuse* or drug misuse* or drug use* $)$ in ti,ab

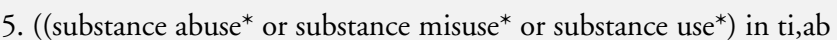

6. ((detox* or methadone maintenance or methadone prescri* or antagonist prescri* or dimorphine or naltrexone) in ti,ab

7. ((dependence disorder or drug involved) in ti,ab

8. ((amphetamine* abuse* or amphetamine* misuse* or amphetamine* use* or amphetamine* addict*) in ti,ab

9. ((cocaine abuse* or cocaine misuse* or cocaine use* or cocaine addict*) in ti,ab

10. ((crack abuse* or crack misuse* or crack use* or crack addict*) in ti,ab

11. ((heroin abuse* or heroin misuse* or heroin use* or heroin addict $\left.^{*}\right)$ in ti,ab

12. ((chemical dependenc* or opiate abuse* or opiate misuse* or opiate use* or opiate addict*) in ti,ab

13. \#1 or \#2

14. \#3 or \#4 or \#5 or \#6 or \#7 or \#8 or \#9 or \#10 or \#11 or \#12

15. \#13 and \#14

Table 8. Sociological Abstracts

\section{Sociological Abstrac}

1. remand in de

2. detention in de

3. prisoners in de

4. prisons in de

5. offenders in de

6. parole in de

7. probation in de

8. correctional system in de

9. courts in de

10. imprisonment in de

Copyright (C) 2008 The Cochrane Collaboration. Published by John Wiley \& Sons, Ltd. 


\section{Table 8. Sociological Abstracts (Continued)}

11. criminal justice in de

12. criminal proceedings in de

13. recidivism in de

14. jail in de

15. institutionalization (persons) in de

16. conviction/convictions in de

17. (remand or prison* ${ }^{*}$ offender* ${ }^{*}$ criminal $^{*}$ or probation or court or courts or secure establishment ${ }^{*}$ ) in ti,ab

18. (reoffend* or reincarcerat* or recidivi* ${ }^{*}$ or ex-offend* or jail or jails or incarcerat* ${ }^{*}$ or secure facilit* or convict* or revocation or inmate $\left.^{*}\right)$ in ti,ab

19. \#1 or $\# 2$ or $\# 3$ or $\# 4$ or $\# 5$ or $\# 6$ or $\# 7$ or $\# 8$ or $\# 9$ or $\# 10$ or $\# 11$ or $\# 12$ or \#13 or \#14 or \#15 or \#16 or \#17 or \#18 or \#19

20. substance abuse in de

21. explode "Drug-Abuse" in DE

22. "Drug-Injection" in DE

23. explode "Narcotic-Drugs" in DE

24. "Cocaine-" in DE

25. "Addiction-" in DE

26. explode "Psychedelic-Drugs" in DE

27. (substance abuse* or substance misuse* or substance use*) in ti,ab

28. (drug abuse* or drug misuse* or drug use*) in ti,ab

29. (drug dependenc* or drug addict* or narcotics abuse* or narcotics use* or narcotics misuse* or narcotics addict*) in ti,ab

30. (chemical dependenc* or opiate abuse* or opiate misuse* or opiate use* or opiate addict*) in ti,ab

31. (heroin abuse* or heroin misuse* or heroin use* or heroin addict*) in ti,ab

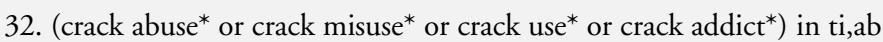

33. (cocaine abuse* or cocaine misuse* or cocaine use* or cocaine addict*) in ti,ab

34. (amphetamine* abuse* or amphetamine* misuse* or amphetamine* use* or amphetamine* addict*) in ti,ab 


\section{Table 8. Sociological Abstracts (Continued)}

35. (dependence disorder or drug involved) in ti,ab

36. \#22 or \#23 or \#24 or \#25 or \#26 or \#27 or \#28 or \#29 or \#30 or \#31 or \#32 or \#33 or \#34 or \#35

37. \#19 and \#36

38. "Detoxification-" in DE

39. "Methadone-Maintenance" in DE

40. "Counseling-" in DE

41. "Psychotherapy-" in DE

42. "Assertiveness-" in DE

43. (detoxification in de) or (methadone maintenance in de) or (treatment programs in de)

44. (counseling in de) or (psychotherapy in de) or (assertiveness in de) or (group therapy in de) or (goals in de) or (self control in de)

45. (interpersonal communication in de) or (social interaction in de) or (social competence in de) or (coping in de)

46. (social behavior in de) or (group work in de) or (lifestyle in de)

47. (after care in de) or (support networks in de) or (self help in de) or (self help groups in de) or (outreach programmes in de)

48. (outreach programs in de) or (referral in de) or (delinquency prevention in de) or (diversion/diversions in de)

49. (peer groups in de) or (peer influence in de) or (drug use screening in de) or (rehabilitation in de) or (work experience in de)

50. (detox* or methadone maintenance or methadone prescri* or antagonist prescri* or dimorphine or naltrexone) in ti,ab

51. (therapeutic communit* or motivational interview* or motivational enhance* or counseling or counselling or psychotherapy or cognitive behavi*) in ti,ab

52. (moral training or cognitive restructuring or assertiveness training or relaxation training) in ti,ab

53. (rational-emotive or rational emotive or family relationship therap* or community reinforcement or self monitoring or goal setting or self control training) in ti,ab

54. (self management or interpersonal skills or social skills or basic skills or relapse prevent* or prevent* relapse or craving reduc* or reduc* craving) in ti,ab

55. (trigger* or coping skills or anger management or group work or lifestyle modif* or high intensity training or resettlement or throughcare) in ti,ab 


\section{Table 8. Sociological Abstracts (Continued)}

56. (aftercare or after care or brief solution or brief intervention* or 12 step* $^{*}$ or twelve step* or minnesota program* or needle exchange or nes) in ti,ab

57. (syringe exchange or dual diagnosis or narcotics anonymous or self help or selfhelp or outreach or bail support) in ti,ab

58. (arrest referral* or diversion or dtto or dttos or drug treatment or carat or carats or counseling assessment or combined orders) in ti,ab

59. (drug-free or drug free or peer support or evaluation* or urinalysis or drug testing or drug use screen* or rehabilitation or discrete service* or discrete program*) in ti,ab

60. (residential program* or residential scheme* or residential service*) in ti,ab

61. (asro or addressing substance or pasro or prisons addressing or acupuncture or shock or boot camp*) in ti,ab

62. (work ethic or drug education or tasc or treatment accountability) in ti,ab

63. \#38 or \#39 \#or \#40 or \#41 or \#42 or \#43 or \#44 or \#45 or \#46 or \#47 or \#48 or \#49 or \#50 or \#51 or \#52 or \#53 or \#54 or \# 55 or $\# 56$ or $\# 57$ or $\# 58$ or $\# 59$ or $\# 60$ or \#61 or \#62

64. \#37 and \#63

Table 9. ASSIA

\section{ASSIA search}

1. remand

2. prison or prisoner or prisoners

3. offender*

4. criminal*

5. probation

6. court or courts

7. tribunal or tribunals

8. secure establishment*

9. secure facilit*

10. reoffend ${ }^{*}$

11. reincarcerat ${ }^{*}$ 
Table 9. ASSIA (Continued)

12. recidivi* $^{*}$

13. ex-offender*

14. jail or jails

15. incarcerat*

16. convict or convicts

17. convicted

18. felon or felons

19. conviction*

20. reconviction*

21. high security

22. law enforcement

23. Substance abuse* or substance misuse* or substance use*

24. drug dependanc* or drug abuse* or drug use*

25. drug misuse* or drug addict*

26. narcotics addict* narcotics use* narcotics misuse* narcotics abuse*

27. chemical dependanc*

28. opiates

29. heroin

30. crack

31. cocaine

32. amphetamines

33. cocaine

34. addiction

35. dependence disorder*

36. drug involved

Interventions for drug-using offenders in the courts, secure establishments and the community. (Review)

Copyright () 2008 The Cochrane Collaboration. Published by John Wiley \& Sons, Ltd. 
Table 9. ASSIA (Continued)

37. Substance-related disorders

38. amphetamine-related disorders

39. cocaine-related disorders

40. marijuana abuse

41. opioid-related disorders

42. street drugs

43. designer drugs

44. 1 or 2 or 3 or 4 or 5 or 6 or 7 or 8 or 9 or 10 or 11 or 12 or 13 or 14 or 15 or 16 or 17 or 18 or 19 or 20 or 21 or 22

45.23 or 24 or 25 or 26 or 27 or 28 or 29 or 30 or 31 or 32 or 33 or 34 or 35 or 36 or 37 or 38 or 39 or 40 or 41 or 42 or 43

46. 44 and 45

Table 10. HMIC

HMIC

1. remand in de

2. detention in de

3. prisoners in de

4. prisons in de

5. offenders in de

6. parole in de

7. probation in de

8. correctional system in de

9. courts in de

10. imprisonment in de

11. criminal justice in de

12. criminal proceedings in de

Copyright (? 2008 The Cochrane Collaboration. Published by John Wiley \& Sons, Ltd. 
Table 10. HMIC (Continued)

13. recidivism in de

14. jail in de

15. institutionalization (persons) in de

16. conviction/convictions in de

17. (remand or prison* or offender* or criminal* or probation or court or courts or secure establishment*) in ti,ab

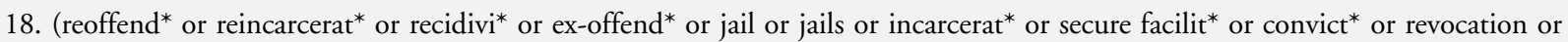
inmate* in ti,ab

$19 . \# 1$ or $\# 2$ or $\# 3$ or $\# 4$ or $\# 5$ or $\# 6$ or $\# 7$ or $\# 8$ or $\# 9$ or $\# 10$ or $\# 11$ or $\# 12$ or $\# 13$ or $\# 14$ or $\# 15$ or $\# 16$ or \#17 or \#18

20. substance abuse in de

21. explode "Drug-Abuse" in DE

22. "Drug-Injection” in DE

23. explode "Narcotic-Drugs" in DE

24. "Cocaine-" in DE

25. "Addiction-" in DE

26. explode "Psychedelic-Drugs" in DE

27. (substance abuse* or substance misuse* or substance use*) in ti,ab

28. (drug abuse* or drug misuse* or drug use*) in ti,ab

29. (drug dependenc* or drug addict* or narcotics abuse* or narcotics use* or narcotics misuse* or narcotics addict*) in ti,ab

30. (chemical dependenc* or opiate abuse* or opiate misuse* or opiate use* or opiate addict*) in ti,ab

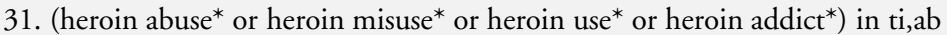

32. (crack abuse* or crack misuse* or crack use* or crack addict*) in ti,ab

33. (cocaine abuse* or cocaine misuse* or cocaine use* or cocaine addict ${ }^{*}$ ) in ti,ab

34. (amphetamine* abuse* or amphetamine* misuse* or amphetamine* use* or amphetamine* addict*) in ti,ab

35. (dependence disorder or drug involved) in ti,ab

$36 . \# 20$ or \#21 or \#22 or \#23 or \#24 or \#25 or \#26 or \#27 or \#28 or \#29 or \#30 or \#31 or \#32 or \#33 or \#34 or \#35

Interventions for drug-using offenders in the courts, secure establishments and the community. (Review)

Copyright @ 2008 The Cochrane Collaboration. Published by John Wiley \& Sons, Ltd. 
Table 10. HMIC (Continued)

37. \#19 and \#36

Table 11. National Research Register

NRR search

1. REMAND

2. PRISON*

3. OFFENDER*

4. ((CRIMINAL* or PROBATION) or COURT) or COURTS)

5. (SECURE next ESTABLISHMENT*)

6. REOFFEND*

7. REINCARCERAT*

8. RECIDIV*

9. EXOFFEND*

10. ((JAIL or JAILS) or INCARCERAT*)

11. (SECURE next FACILIT*)

12. (((CONVICT* or REVOCATION) or INMATE*) OR (HIGH next SECURITY))

13. PRISONERS:ME

14. LAW-ENFORCEMENT:ME

15. JURISPRUDENCE:ME

16. CRIME:ME

17. $\# 1$ or $\# 2$ or $\# 3$ or $\# 4$ or $\# 5$ or $\# 6$ or $\# 7$ or $\# 8$ or $\# 9$ or $\# 10$

18. \#11 or \#12 or \#13 or \#14 or \#15 or \#16

19. $\# 17$ or \#18

20. ((SUBSTANCE next ABUSE*) or (SUBSTANCE next MISUSE*)) OR (DRUG NEXT DEPENDENC*)) OR (DRUG NEXT ABUSE*)) OR (DRUG NEXT MISUSE*)) OR (DRUG NEXT USE*)) OR (DRUG NEXT ADDICTION)) 
Table 11. National Research Register (Continued)

21. ((NARCOTICS or (CHEMICAL next DEPENDENC*)) OR (OPIATE NEXT ADDICT*)) OR (OPIATE NEXT DEPENDENC*)) OR (OPIATE NEXT ABUSE*)) OR (OPIATE NEXT MISUSE*))

22. ((HEROIN next ADDICT*) or (HEROIN next DEPENDENC*)) OR (HEROIN NEXT MISUSE*)) OR (HEROIN NEXT $\left.\left.\mathrm{ABUSE}^{*}\right)\right)$

23. ((CRACK next ADDICT*) or (CRACK next DEPENDENC*)) OR (CRACK NEXT MISUSE*)) OR (CRACK NEXT ABUSE*)) OR (CRACK NEXT USE*))

24. ((COCAINE next ADDICT*) or (COCAINE next DEPENDENC*)) OR (COCAINE NEXT MISUSE*)) OR (COCAINE NEXT ABUSE*)) OR (COCAINE NEXT USE*))

25. ((AMPHETAMINE* next ADDICT*) or (AMPHETAMINE* next DEPENDENC*)) OR (AMPHETAMINE* NEXT MISUSE*)) OR (AMPHETAMINE* NEXT ABUSE*)) OR (AMPHETAMINE* NEXT USE*))

26. ((ADDICTS or (DEPENDENCE next DISORDER)) OR (DRUG NEXT INVOLVED))

27. (SUBSTANCE-RELATED and DISORDERS:ME)

28. SUBSTANCE-RELATED-DISORDERS:ME

29. AMPHETAMINE-ABUSE:ME

30. COCAINE-ABUSE:ME

31. MARIJUANA-ABUSE:ME

32. OPIOID-RELATED-DISORDERS:ME

33. PHENCYCLIDINE-ABUSE:ME

34. SUBSTANCE-ABUSE-INTRAVENOUS:ME

35. SUBSTANCE-WITHDRAWAL-SYNDROME:ME

36. (STREET next DRUGS)

38. STREET-DRUGS:ME

39. DESIGNER-DRUGS:ME

40. NARCOTICS:ME

41. (COCAINE:ME or AMPHETAMINES:ME)

42. ANALGESICS-ADDICTIVE:ME

43. ANALGESICS-OPIOID:ME 
Table 11. National Research Register (Continued)

\section{PSYCHOTROPIC-DRUGS:ME}

$45 . \# 20$ or $\# 21$ or $\# 22$ or $\# 23$ or \#24 or \#25 or \#26 or \#27 or \#28 or \#29 or \#30 or \#31 or \#32 or \#33 or \#34 or \#35 or \#36 or \#37 or \#38 or \#39 or \#40 or \#41 or \#42 or \#43 or \#44

46. 19 and 45

Table 12. PAIS

\section{PAIS}

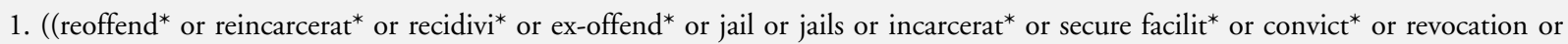
inmate ${ }^{*}$ in ti,ab)

2. ((remand or prison* or offender* or criminal* or probation or court or courts or secure establishment*) in ti,ab)

3. ((drug dependenc* or drug addict* or narcotics abuse* or narcotics use* or narcotics misuse* or narcotics addict*) in ti,ab)

4. ((drug abuse* or drug misuse* or drug use* ${ }^{*}$ in ti,ab) or ((substance abuse* or substance misuse* or substance use* ${ }^{*}$ in ti,ab)

5. ((detox ${ }^{*}$ or methadone maintenance or methadone prescri* or antagonist prescri* or dimorphine or naltrexone) in ti,ab)

6. ((dependence disorder or drug involved) in ti,ab)

7. ((amphetamine* abuse* or amphetamine* misuse* or amphetamine* use* or amphetamine* addict*) in ti,ab)

8. ((cocaine abuse* or cocaine misuse* or cocaine use* or cocaine addict $\left.^{*}\right)$ in ti,ab)

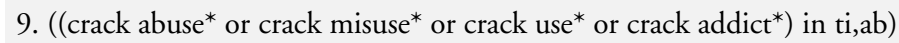

10. ((heroin abuse* or heroin misuse* or heroin use* or heroin addict*) in ti,ab)

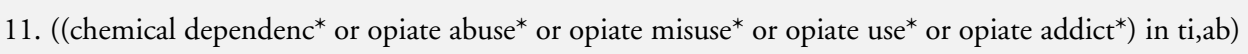

12. ((moral training or cognitive restructuring or assertiveness training or relaxation training) in ti,ab)

13. ((therapeutic communit* or motivational interview* or motivational enhance* or counseling or counselling or psychotherapy or cognitive behavi*) in ti,ab)

14. ((work ethic or drug education or tasc or treatment accountability) in ti,ab)

15. ((asro or addressing substance or pasro or prisons addressing or acupuncture or shock or boot camp*) in ti,ab)

16. ((arrest referral* or diversion or dtto or dttos or drug treatment or carat or carats or counseling assessment or combined orders) in $\mathrm{ti}, \mathrm{ab})$

17. ((residential program* or residential scheme* or residential service*) in ti,ab)

Interventions for drug-using offenders in the courts, secure establishments and the community. (Review)

Copyright () 2008 The Cochrane Collaboration. Published by John Wiley \& Sons, Ltd. 


\section{Table 12. PAIS (Continued)}

18. ((syringe exchange or dual diagnosis or narcotics anonymous or self help or selfhelp or outreach or bail support) in ti,ab)

19. ((drug-free or drug free or peer support or evaluation* or urinalysis or drug testing or drug use screen* or rehabilitation or discrete

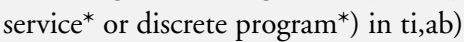

20. ((aftercare or after care or brief solution or brief intervention* or 12 step* $^{*}$ or twelve step* or minnesota program* or needle exchange or nes) in ti,ab)

21. ((trigger* or coping skills or anger management or group work or lifestyle modif* or high intensity training or resettlement or throughcare) in ti,ab)

22. ((self management or interpersonal skills or social skills or basic skills or relapse prevent* or prevent* relapse or craving reduc* or reduc* craving) in ti,ab)

24. ((rational-emotive or rational emotive or family relationship therap* or community reinforcement or self monitoring or goal setting or self control training) in ti,ab)

25. \#1 or \#2

26. $\# 3$ or $\# 4$ or $\# 5$ or $\# 6$ or $\# 7$ or $\# 8$ or 9 or $\# 10$ or $\# 11$

27. \#12 or \#13 or \#14 or \#15 or \#16 or \#17 or \#18 or \#19 or \#20 or \#21 or \#22 or \#23 or \#24

28. 25 and \#26 and \#27

Table 13. Criminal Justice Abstracts

\section{CJA search}

1. (substance abuse* or substance misuse* or substance use or substance users) in ti,ab,de

2. substance related in ti,ab,de

3. drug related in ti,ab,de

4. (drug dependenc* or drug abuse* or drug misuse* or drug use or drug users or drug addiction) in ti,ab,de

5. (narcotics use or narcotics users or narcotics abuse* or narcotics misuse* or chemical dependenc*) in ti,ab,de

6. (opiates or heroin or crack or cocaine or amphetamines or addict or addicts or addicted or dependence disorder* or drug involved) in ti,ab,de

7. (designer drugs or street drugs or polydrug misuse* or polydrug abuse*) in ti,ab,de

8. $\# 1$ or $\# 2$ or $\# 3$ or $\# 4$ or $\# 5$ or $\# 6$ or $\# 7$

9. ((antagonist near prescri*) or diamorphine or naltrexone) in ti,ab,de 


\section{Table 13. Criminal Justice Abstracts (Continued)}

10(therapeutic communit* or (motivational near interview*)) in ti,ab,de

11. (motivational near enhancement) in ti,ab,de

12. (counselling or counseling) in ti,ab,de

13. (psychotherap* or cognitive behav* or behav* therap* or (moral near training)) in ti,ab,de

14. (cognitive restructuring or (assertiveness near train*) or relaxation training) in ti,ab,de

15. (rational emotive or family relationship therap*) in ti,ab,de

16. (community reinforcement or self monitoring or goal setting or goalsetting) in ti,ab,de

17. (self control near training) in ti,ab, de

18. (self management) in ti,ab,de

19. (interpersonal skills near training) in ti,ab,de

20. ((social skills or basic skills) near training) in ti,ab,de

21. ((relapse near prevent $\left.{ }^{*}\right)$ or $\left(\right.$ craving near reduc $\left.\left.{ }^{*}\right)\right)$ in ti,ab,de

22. (trigger* or coping skills or anger management or group work or (lifestyle near modif*)) in ti,ab,de

23. (high intensity training or resettlement or throughcare or aftercare or after care) in ti,ab,de

24. (brief solution* ${ }^{*}$ or brief intervention*) in ti,ab,de

25. (minnesota in ti,ab) in ti,ab,de

26. (12 step* or twelve step*) in ti,ab,de

27. (needle exchange or nes or syringe exchange) in ti,ab,de

28. (dual diagnosis or narcotics anonymous or self help or selfhelp or outreach) in ti,ab,de

29. (bail support or bail program* or arrest referral* or diversion or dtto* or drug treatment) in ti,ab,de

30. (carat or counselling assessment or counseling assessment) in ti,ab,de

31. (combined order* or drug free wing* or drug free environment* or peer support) in ti,ab,de

32. (user evaluations or urinalys* or urinanalys* or drug test* or rehab* or discrete service*) in ti,ab,de 
Table 13. Criminal Justice Abstracts (Continued)

33. (discrete program* or residential program* or residential scheme*) in ti,ab,de

34. (asro or addressing substance*) in ti,ab,de

35. (pasro or prisons addressing) in ti,ab,de

36. (acupuncture or shock or boot camp or boot camps or work ethic camp*) in ti,ab,de

37. (drug education or tasc or treatment accountability) in ti,ab,de

38. (detoxification or detox or methadone maintenance or (methadone near prescri*)) in ti,ab,de

39 . $\# 9$ or $\# 10$ or $\# 11$ or $\# 12$ or $\# 13$ or $\# 14$ or $\# 15$ or \#16 or \#17 or \#18 or \#19 or \#20 or \#21 or \#22 or \#23 or \#24 or \#25 or \#26 or \#27 or \#28 or \#29

40. \#30 or \#31 or \#32 or \#33 or \#34 or \#35 or \#36 or \#37 or \#38 or \#39

41. \#39 or \#40

42. \#8 and \#41

9. \#42 and (PY > “1979")

\section{WHAT'S NEW}

Last assessed as up-to-date: 18 May 2006.

\begin{tabular}{|c|c|c|}
\hline Date & Event & Description \\
\hline 25 March 2008 & Amended & Converted to new review format. \\
\hline
\end{tabular}

\section{H I S T O R Y}

Protocol first published: Issue 2, 2005

Review first published: Issue 3, 2006 


\begin{tabular}{lll}
\hline Date & Event & Description \\
\hline 19 May 2006 & New citation required and conclusions have changed & Substantive amendment \\
\hline
\end{tabular}

\section{CONTRIBUTIONSOFAUTHORS}

Two independent reviewers inspected the search hits by reading the titles and abstracts. Each potentially relevant study located in the search was obtained as a full article and independently assessed for inclusion by two reviewers. In the case of discordance, a third independent reviewer arbitrated. Where it was not possible to evaluate the study because of language problems or missing information the studies were classified as 'translation/information required to determine decision' until a translation or further details was provided.

\section{DECLARATIONSOF INTEREST}

None

\section{SOURCES OF SUPPORT}

\section{Internal sources}

- No sources of support supplied

\section{External sources}

- Department of Health, UK.

\section{INDEX TERMS}

\section{Medical Subject Headings (MeSH)}

*Law Enforcement; ${ }^{*}$ Therapeutic Community; Aftercare; Crime [ ${ }^{*}$ prevention $\&$ control]; Substance-Related Disorders [* rehabilitation]

\section{MeSH check words}

Humans 